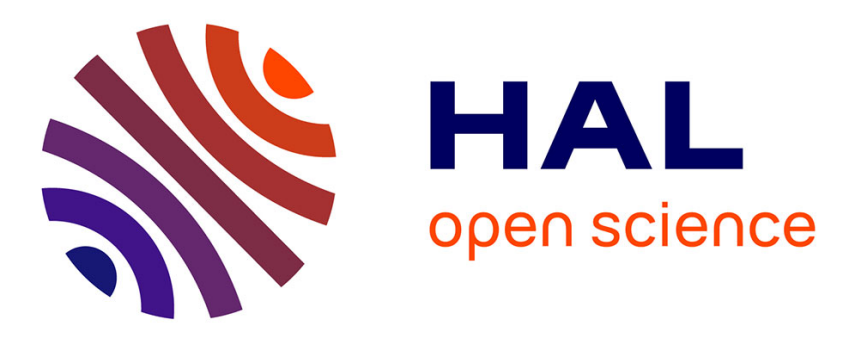

\title{
Phosphorylation of bio-based compounds: the state of the art
}

Nicolas Illy, Maxence Fache, Raphaël Ménard, Claire Negrell, Sylvain Caillol, Ghislain David

\section{> To cite this version:}

Nicolas Illy, Maxence Fache, Raphaël Ménard, Claire Negrell, Sylvain Caillol, et al.. Phosphorylation of bio-based compounds: the state of the art. Polymer Chemistry, 2015, 6 (35), pp.6257-6291. 10.1039/c5py00812c . hal-01186950

\section{HAL Id: hal-01186950 https://hal.science/hal-01186950}

Submitted on 28 Sep 2015

HAL is a multi-disciplinary open access archive for the deposit and dissemination of scientific research documents, whether they are published or not. The documents may come from teaching and research institutions in France or abroad, or from public or private research centers.
L'archive ouverte pluridisciplinaire $\mathbf{H A L}$, est destinée au dépôt et à la diffusion de documents scientifiques de niveau recherche, publiés ou non, émanant des établissements d'enseignement et de recherche français ou étrangers, des laboratoires publics ou privés. 


\section{Phosphorylation of bio-based compounds: state of the art}

Nicolas Illy, ${ }^{a, b, *}$ Maxence Fache, ${ }^{c}$ Raphaël Ménard, ${ }^{c}$ Claire Negrell, ${ }^{c}$ Sylvain Caillol, ${ }^{c}$ and Ghislain David ${ }^{c}$

Over the last few years more and more papers have been devoted to phosphorus-containing polymers, mainly due to their fire resistance, excellent chelating and metal-adhesion properties. Nevertheless, sustainability, reduction of environmental impacts and green chemistry are increasingly guiding the development of the next generation of materials. The use of biobased polymer matrices might allow the reduction of environmental impacts by using renewable carbon and by achieving more easily biodegradable or reusable materials. The aim of this review is to present both fundamental and applied research of phosphorylation of renewable resources, through reactions on natural occurring functions, and their use in biobased polymer chemistry and applications. In the first part, different strategies for the introduction of phosphorus-containing functions on organic backbones are described. In the following sections, the main families of chemicals based on renewable resources are covered: namely polysaccharides (cellulose, chitosan, starch, dextran...), biophenols (lignins, biobased phenolic compounds, cardanol...), triglycerides (oils, glycerol) and hydroxy acid compounds. 


\section{Introduction}

The use of phosphorus in technical applications is primarily intended for use in polymeric materials to improve the electronic conduction, fire-retardancy, lubrication, adhesion properties and anti-corrosion. In these applications, phosphorus advantageously replaces hazardous substances historically used in these applications, such as chromium VI derivatives for anti-corrosion or halogen compounds for fire-retardancy. Replacing these substances is a social and industrial challenge; indeed chromium VI derivatives or halogen compounds used in these applications are generally carcinogenic, mutagenic and reprotoxic (CMR) substances that regulations tend to ban (European Regulation EC/2000/60)). Recently developed halogen-free phosphorus-containing polymers can be employed for a wide range of technological applications, such as for example scaffolds in regenerative medicine applications or for drug delivery. ${ }^{1}$

Compared to the use of phosphorylated additives, the use of polymeric backbones reduces toxic bioaccumulation and minimizes losses due to diffusion and washing process. In addition, reuse and recycling become possible. Nevertheless, the replacement of petro-based chemicals and materials is currently challenging both research and industry. ${ }^{2}$ Sustainability, reduction of environmental impacts and green chemistry are increasingly guiding the development of the next generation of materials. The use of bio-based polymer matrices will allow the reduction of environmental impacts by using renewable carbon and by achieving more easily biodegradable or reusable materials. It will also permit the valorization of numerous by-products and wastes of different activities. ${ }^{3}$ In addition, the functionalization with phosphorus-containing-moieties modifies the properties of bio-based compounds, such as water-solubility, which enables an easier processing and makes them more competitive with petro-based derivatives.

To our knowledge, even if literature reports some reviews on phosphorus monomers and polymers ${ }^{1,4-12}$ there is no review on the use of phosphorus in biobased polymers. The aim of this review is to present both fundamental and applied research of phosphorylation of renewable resources, through reactions on natural occurring functions, and their use in biobased polymer chemistry and applications. Numerous strategies have been developed to introduce phosphorus-containing moieties. Nevertheless, these strategies have to be adjusted to bio-based compounds which significantly differ from regular chemicals. Biopolymers contain a low diversity of functional groups with often a high degree of oxidation: mainly hydroxy and phenolic hydroxy groups or unsaturated groups; more rarely amino groups (chitosan), carboxylic acid or aldehyde groups (lignin). On the other hand, on the same macromolecule, these moieties are often abundant and have similar reactivities which may be problematic in terms of functionalization degree and regioselectivity. In the first part, the more frequent strategies for the introduction of phosphorus-containing functions on bio-based backbones are described. The following parts provide precise and complete information on the phosphorylation of a specific family of biopolymers (i.e. polysaccharides, biophenols, triglycerides and hydroxy acid compounds). The end of each part is devoted to the properties of the phosphorylated compounds and their potential applications. 


\section{Common routes to functional phosphoric acids or esters on bio-based products.}

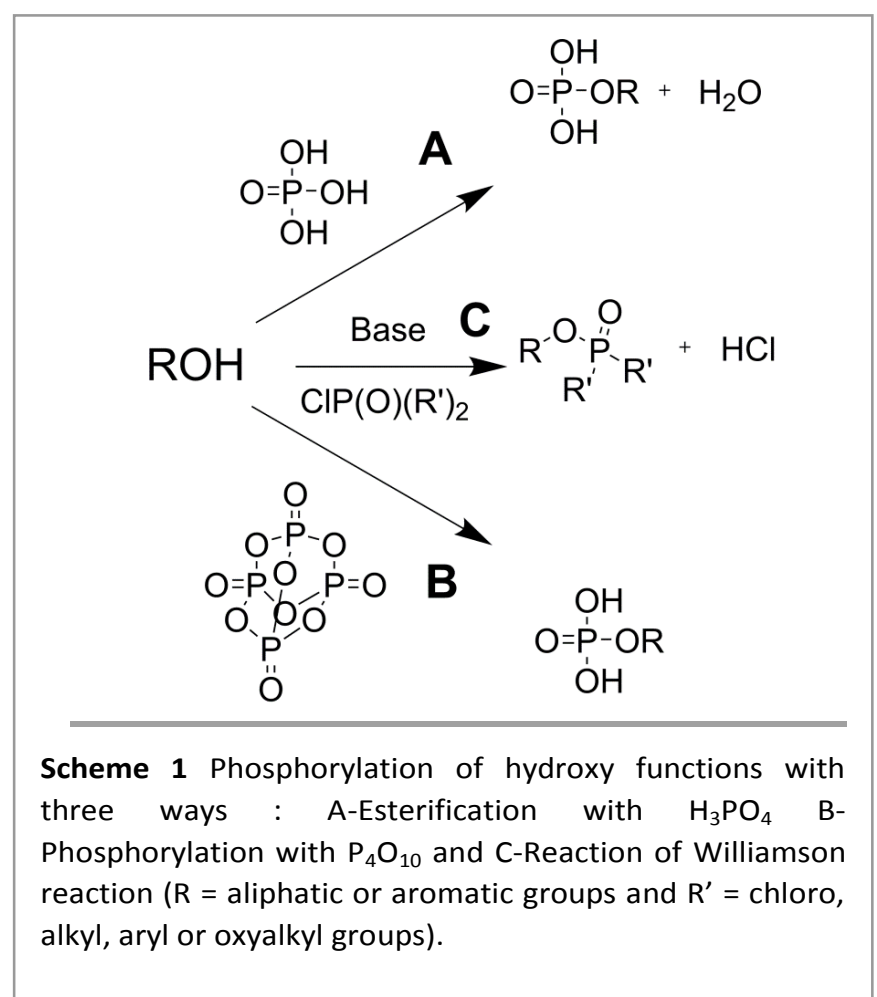

Different strategies for the introduction of phosphoric function on organic bio-based backbones are described hereafter. From a synthetic chemistry point of view, a wide range of methodologies for the incorporation of phosphorus have been discovered and reported as early as in $1898 .{ }^{13}$ Since many advances have been made, this will allow for the introduction of phosphorus directly into different organic molecules. In this review, we will focus on the methods adapted to functions present on the renewable molecules. These available functions are hydroxy and amine groups in polysaccharides, carboxylic, hydroxy, aldehyde groups in biophenols or double bonds in triglycerides, principally.

\subsection{Phosphorylation of R-OH}

On bio-based products, two types of hydroxy groups are available: the aliphatic $\mathrm{OH}$ such as in the cellulose and aromatic $\mathrm{OH}$ such as in the biophenols (lignin derivates). The different synthesis described after are adapted to the two types of hydroxy functions. The easiest method to introduce phosphorus-containing function on hydroxy groups was by esterification reactions with $\mathrm{H}_{3} \mathrm{PO}_{3}$ or $\mathrm{H}_{3} \mathrm{PO}_{4}$ : the phosphorus can be covalently attached to the renewable molecule chain via a reaction of hydroxy groups to give: phosphate groups $\mathrm{R}-\mathrm{O}-\mathrm{P}(\mathrm{O})(\mathrm{OH})_{2}$, phosphite groups $\mathrm{R}-\mathrm{O}-\mathrm{P}(\mathrm{OH})_{2}$ or phosphonic acid group $\mathrm{R}-\mathrm{P}(\mathrm{O})(\mathrm{OH})_{2} \ldots \mathrm{H}_{3} \mathrm{PO}_{3}$ and these derivatives containing mobile hydrogen atoms directly attached to phosphor are in tautomeric equilibrium and allow to obtain phosphonated compounds.

From the perspective of green chemistry, the direct catalytic condensation of equimolar amounts of phosphoric acid $\left(\mathrm{H}_{3} \mathrm{PO}_{4}\right)$ and alcohols is attractive for the synthesis of phosphoric acid monoesters (Scheme $\left.1 \mathrm{~A}\right)$. The classical method is the dehydrative condensation promoted by a catalyst under reflux condition in polar solvents. ${ }^{14}$ A derivative method uses (poly)phosphoric acid salts to introduce charged phosphonic function via $\mathrm{OH}$ containing organic compounds. ${ }^{15}$ The phosphorylation reactions of $\mathrm{OH}$-containing organic molecules with phosphorus pentoxide $\left(\mathrm{P}_{4} \mathrm{O}_{10}\right)$ with its common name derived from its empirical formula $\mathrm{P}_{2} \mathrm{O}_{5}$ is another classical method. It is also an esterification reaction and this reagent works as an anhydride of phosphoric acid (Scheme 1B). The mechanism ${ }^{16}$ of this reaction includes the 4 steps with a large excess of alcohol (4 equivalents) to have the better efficiency of $\mathrm{P}_{4} \mathrm{O}_{10}$. The combined use of $\mathrm{P}_{2} \mathrm{O}_{5}$ and $\mathrm{H}_{3} \mathrm{PO}_{4}$, allows obtaining highly phosphorylated sugar derivatives. ${ }^{17}$

Phosphorus oxychloride, dialkyl chlorophosphonates or diphenylphosphinic chloride are the most employed phosphorylating agents for $\mathrm{OH}$-containing organic compounds, this reaction is a derivate of Williamson reaction (Scheme 1C). The use of $\mathrm{POCl}_{3}$ was first proposed in 1857. The reaction of alcohols with $\mathrm{POCl}_{3}$ in the presence of 
water and pyridine as a base provides phosphate monoesters along with pyridine hydrochloride as a by-product. ${ }^{18}$ Since $\mathrm{POCl}_{3}$ is very reactive, phosphate diesters and triesters could be produced with an adapted stoichiometry. The use of phosphorochloridates provides an organic soluble phosphate triesters.

Generally, these phosphorylations with trivalent or pentavalent phosphorus reagents proceed only on reactive hydroxy group and allowed to obtain P-O bond. The use of trivalent phosphorus reagent like phosphorochloridites, is possible despite the sensitivity of moisture. When the reaction occurs on a hydroxy in $\alpha$-position of a double bond with trivalent phosphorus reagent, it leads to a rearrangement to form a $\mathrm{P}-\mathrm{C}$ bond giving a pentavalent phosphorus function fix to the organic molecules. ${ }^{19}$

The phosphorylation of substituted phenols with dialkyl chlorophosphonate was occurred with magnesia or alumina catalyst without solvent and give better reactive results when the aromatic part of phenol carry electronwithdrawing groups. ${ }^{20}$ Dialkyl chlorophosphate was efficient on many alcohols in the presence of DABCO as both a catalyst and a proton scavenger giving phosphate product with good yields. ${ }^{21}$

\subsection{Phosphorylation on double bonds}

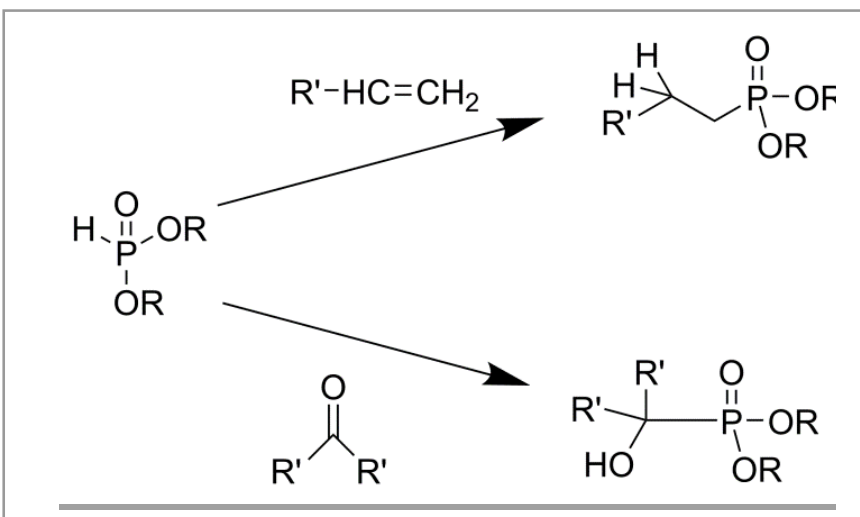

Scheme 2 Pudovik reaction.

The Pudovik reaction is the addition of organophosphorus compounds containing labile $\mathrm{P}-\mathrm{H}$ bond with unsaturated systems and it can progress via radical or ionic mechanism, depending upon the structure of the unsaturated substrates, the phosphorus reagents and the experimental conditions. ${ }^{22}$ Addition of $\mathrm{H}$-phosphonates to carbonyl compound, such as aldehyde function, in basic media, is a powerful and widely applied strategy for the construction of P-C bonds. Dialkyl phosphites added to carbonyl compounds upon deprotonation, is a straightforward tool for providing efficient access to chiral $\alpha$-hydroxy phosphonates and their corresponding phosphonic acids. ${ }^{23}$ Group transfer is not necessary in this case, as neutralization of the tetrahedral intermediate occurs via proton transfer. (Scheme 2) A catalytic, enantioselective variant of the Pudovik reaction has recently been developed. ${ }^{24}$

The same reaction was used for the preparation of dialkyl 2-(alkoxycarbonyl)ethyl phosphonates which involves the conjugate addition of a dialkyl phosphite to a $C=C$ double bond of $\alpha, \beta$-unsaturated carboxylates in the presence of base. ${ }^{25}$

Derivative of the Pudovik reaction, the radical addition of $\mathrm{H}$-phosphonate to unsaturated hydrocarbons, especially on $\mathrm{C}=\mathrm{C}$ represents another useful synthetic route for the phosphorylation of compounds, and can produce following different methodologies. The reaction is initiated by the formation of a phosphonic radical from dialkyl H-phosphonate during photolysis, irradiation, or most frequently in the presence of a catalyst or a radical initiator. ${ }^{26}$ The initial step of the free radical reaction is the initiator or thermal-induced generation of phosphonyl radical. Then rupture of the double bond from alkenes by the phosphonyl radical affords the product with a new $\mathrm{P}-\mathrm{C}$ bond and another radical enable to continue the phosphorylation.

Radical activation is mainly favorable to addition between unsaturated systems having a nucleophilic character with phosphine or phosphite. In the presence of AIBN in homogeneous medium, the radical reaction is stereospecific and successfully applied to a large panel of alkenes (except electron-deficient alkenes) to produce valuable optically pure phosphinates. ${ }^{27}$ Photoactivation is the most efficient method but the reaction time is long and entails often an isomerization of phosphorus product. When the addition occurs on $\mathrm{C}=\mathrm{C}$ bond bearing electron-withdrawing substituent, the anionic activation could be favorable. ${ }^{28}$ 
Hydrophosphonylation consists to addition of $\mathrm{H}$-phosphonate to alkenes using metal-based catalyst. This atom-economic process was accessible to $\mathrm{C}=\mathrm{C}$ double bond bearing on aromatic groups. The reaction runs at high temperature, under solvent or solvent-free with a low percentage of catalyst such as $\mathrm{Mn}(\mathrm{OAc})_{2}{ }^{29}$ palladium complex $^{30} \ldots$

The phospha-michael reaction is also one of important reaction for $\mathrm{P}-\mathrm{C}$ bond formation which consists in the 1,4-addition of nucleophiles derived from the $\mathrm{HPO}_{3} \mathrm{R}_{2}$ general structure, to alkenes (Scheme 3$) .{ }^{31}$ The reaction proceeds smoothly under mild conditions and shows tolerance to variety of functional electrophilic groups ( $R^{\prime}$ ) close to the double bond. Most often, this reaction is carried out at room temperature using a base, such as sodium hydroxide ${ }^{32}$ or tetramethylguanidine ${ }^{33}$ but micro-wave activation can be alternative. ${ }^{34}$ The introduction of specific catalysts can be performed a stereoselectivity: whereas the catalyst (secondary amine) reacts with the carbonyl group to form iminium ion thereby favoring the attack at one face of the substrate, and finally a simple hydrolysis regenerates the carbonyl group as well as the catalyst. ${ }^{35}$

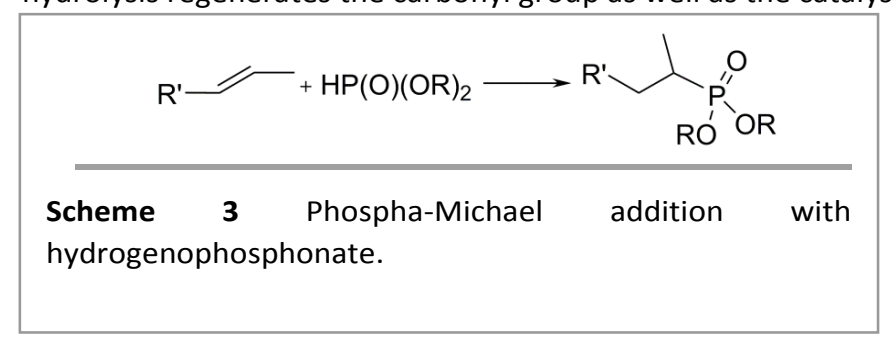

\subsection{Phosphorylation of amine functions}

For amine function, two important ways can be proposed. The Atherton-Todd reaction is a classic reaction in organophosphorus chemistry. ${ }^{36}$ Originally, Atherton and Todd reported the reaction as a very effective single-step route to yield phosphoramidates from diphenyl and dialkyl phosphonates (Scheme 4).

The Atherton-Todd reaction is a one-pot reaction. The reaction of carbon tetrachloride, an amine (in excess) and an organophosphorus compound containing a $\mathrm{P}-\mathrm{H}$ bond (many $\mathrm{P}-\mathrm{H}$ reactive compounds are commercially available) results in the in situ formation of a $\mathrm{P}(\mathrm{O}) \mathrm{Cl}$ oxychloride species then the condensation of this intermediary with $\mathrm{N}-\mathrm{H}$ containing substrates. ${ }^{26}$

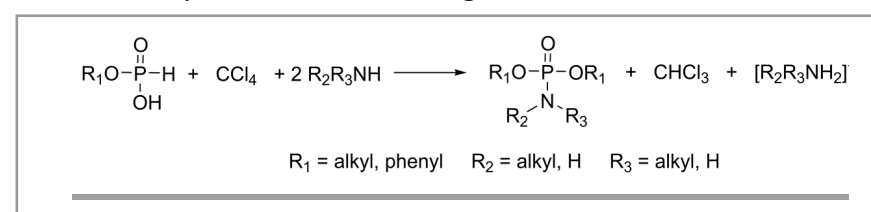

Scheme 4 The reaction reported by Atherton and Todd.

Another method to the phosphorylation of amine functions to obtain $\alpha$-aminophosphonic acids, is the one described by Kabachnik and Medved. ${ }^{37}$ The Kabachnik-Fields reaction is still very useful, especially for the preparation of dialkyl 1-aminoalkanephosphonate. According to this method, $\alpha$-aminophosphonates were obtained reacting ammonia or amine, carbonyl compounds (aldehydes or ketones) and dialkyl H-phosphonate (Scheme 5). Cherkasov and Galkin ${ }^{38}$ suggested that the synthesis shows at least two possible reaction pathways: for a ternary system, the mechanism involving imine intermediate formation (Scheme 5.A) took place when the N$\mathrm{H}$ acidity of amine was high such as aniline. As a contrary, for a system with a cyclohexylamine, for example, the 'hydroxyl phosphonate' mechanism is operative due to the low N-H acidity (Scheme 5.B) followed by substitution of the hydroxy group by the amine.

This reaction was extended to $>\mathrm{P}(\mathrm{O}) \mathrm{H}$ species, comprising cyclic phosphites, acyclic and cyclic $\mathrm{H}$-phosphinates, as well as secondary phosphines oxides. In most cases, the synthesis took place in solvent media but new studies proposed the synthesis under solvent-free microwave conditions without catalyst. ${ }^{39}$ The double Kabachnik-Fields reaction (Scheme 5.C) was extended for primary amines when 2 equivalents of phosphorus-containing and 2 equivalents of aldehyde-containing reagents were used. The substitution of the second $\mathrm{N}-\mathrm{H}$ hydrogen atom is considerably lower than the first one.

Moedritzer and $\operatorname{Irani}^{40}$ have suggested the same reaction with phosphorus acid to obtain aminomethylenephosphonic acid. It was shown that very low $\mathrm{pH}$ is required for the formaldehyde/amine/ $\mathrm{H}_{3} \mathrm{PO}_{4}$ reaction to be efficient.

Unlike direct functionalization, coupling reactions using simple suitably functionalized phosphorus-containing reagents $\left(\mathrm{Z}-\left(\mathrm{CH}_{2}\right)_{n}-\mathrm{P}\right)$ offer a diversity of chemical additions and a potential control of the distance between the bio-based products and the phosphorus function by varying the $\mathrm{Z}$ function as well as the length of the $\left(\mathrm{CH}_{2}\right)_{\mathrm{n}}$ spacer. 
The different ways to introduce phosphoryl functions on bio-based products allow obtaining various bonds i.e. C-P, C-O-P or C-N-P. Depending on the applications, the stability of the newly formed bond must be taken into account. Furthermore, the presence of heteroatom between the $C$ and $P$ may bring some instability at high temperature and in wet conditions.

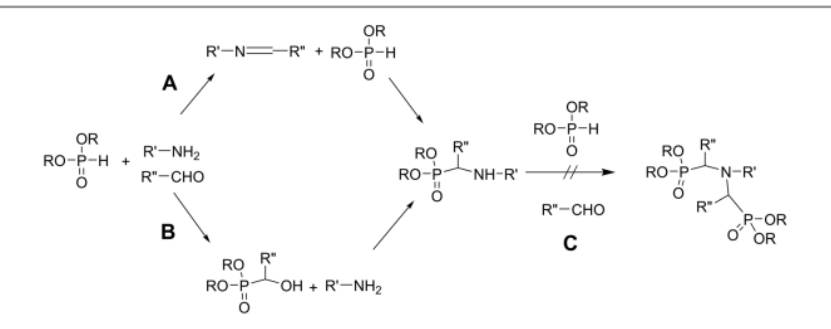

Scheme 5 (A) The "imine" mechanism or (B) the " $\alpha$ hydroxyphosphonate" mechanism proposed for a Kabachnik-Fields reaction and (C) the "double" KabachnikFields reaction.

\section{Phosphorylation of polysaccharides}

Polysaccharides are natural polymers abundantly fund in Nature as structural building blocks. ${ }^{41}$ They are renewable, biodegradable, biocompatible, $\mathrm{CO}_{2}$ neutral and therefore very promising in term of sustainable chemistry. They are widely used in numerous fields such as materials science, biomedical fields, food or textile industry. Specific groups can also be introduced to achieve original polysaccharide derivatives with different physico-chemical properties and improved performances for selected applications. ${ }^{42}$

Carbohydrates represents about $75 \%$ of the plant biomass mainly in the form of cellulose, starch and sucrose. ${ }^{43}$ Cellulose is present in the cell walls of all plants and is therefore the most abundant biopolymer on earth with an estimated output of 1011 tons per year. ${ }^{44}$ Cellulose can be obtained either by natural synthesis procedures including plant photosynthesis, or by bacterial synthesis. The major commercial sources of cellulose are plant fibers such as cotton (> 90\% of cellulose) and wood pulp (about 40-50 percent cellulose). Unicellular plankton and algae also contain cellulose and might potentially be the largest resource for cellulose production. The main plant sources for starch are readily available and inexpensive raw materials such as maize, rice, wheat, potatoes, cassava and bananas. ${ }^{45}$ Commercial chitin and chitosan are principally extracted from crustacean wastes, especially shrimp shells, and from exoskeleton of cephalopods (squid bones). ${ }^{46}$ However nowadays, the alternative production of chitosan from fungal mycelia is a growing field. ${ }^{47}$ Other polysaccharides are mainly produced by the action of bacteria on carbohydrate substrates: for example xanthan is produced by the xanthomonas bacterium. ${ }^{48}$ Sucrose is converted to dextran by some lactic acid bacteria. Hyaluronan is produced via microbial fermentation through the use of large scale fermenters. ${ }^{49}$ Commercially available curdlan is mainly produced by mutant strains of bacteria. agrobacterium species from sucrose with high fermentation yield. ${ }^{50,51}$ The used sucrose comes from cheap byproducts of the sugar industry such as sugar beet or sugar cane molasses. ${ }^{52}$

This part covers methods for the chemical phosphorylation of polysaccharides. The chemical phosphorylation of polysaccharides is particularly challenging. Indeed polysaccharides are often insoluble in water or in common organic solvents. Therefore, the choice of an appropriate solvent for the reaction is a key issue. Various more or less exotic solvent systems were developed to overcome this problem and to make polysaccharides accessible for tailored modification. ${ }^{53}$ The phosphorylation of polysaccharide has been performed under homogeneous conditions or heterogeneous conditions with or without swelling step. Related to these reaction conditions, the achieved polysaccharide functionalization might be partial or uniform and must be accurately described. Therefore, the extent of derivatization reactions is given in terms of the degree of substitution. The Degree of Substitution (DS) of a polysaccharide is defined as the average number of substituted functional groups per monosaccharide unit. For instance, many polysaccharides, such as cellulose, starch or curdlan, have three hydroxy groups available for substitution. Thus, the maximum theoretical DS value is three. In addition, polysaccharides are susceptible to decompose at high temperature. In particular, there is a significant risk of polysaccharide depolymerization in acidic conditions. After the functionalization, it is important to check if no degradation of the polymer backbone has occurred. 
Table 1 Polysaccharides phosphorylation using phosphoric acid in excess.

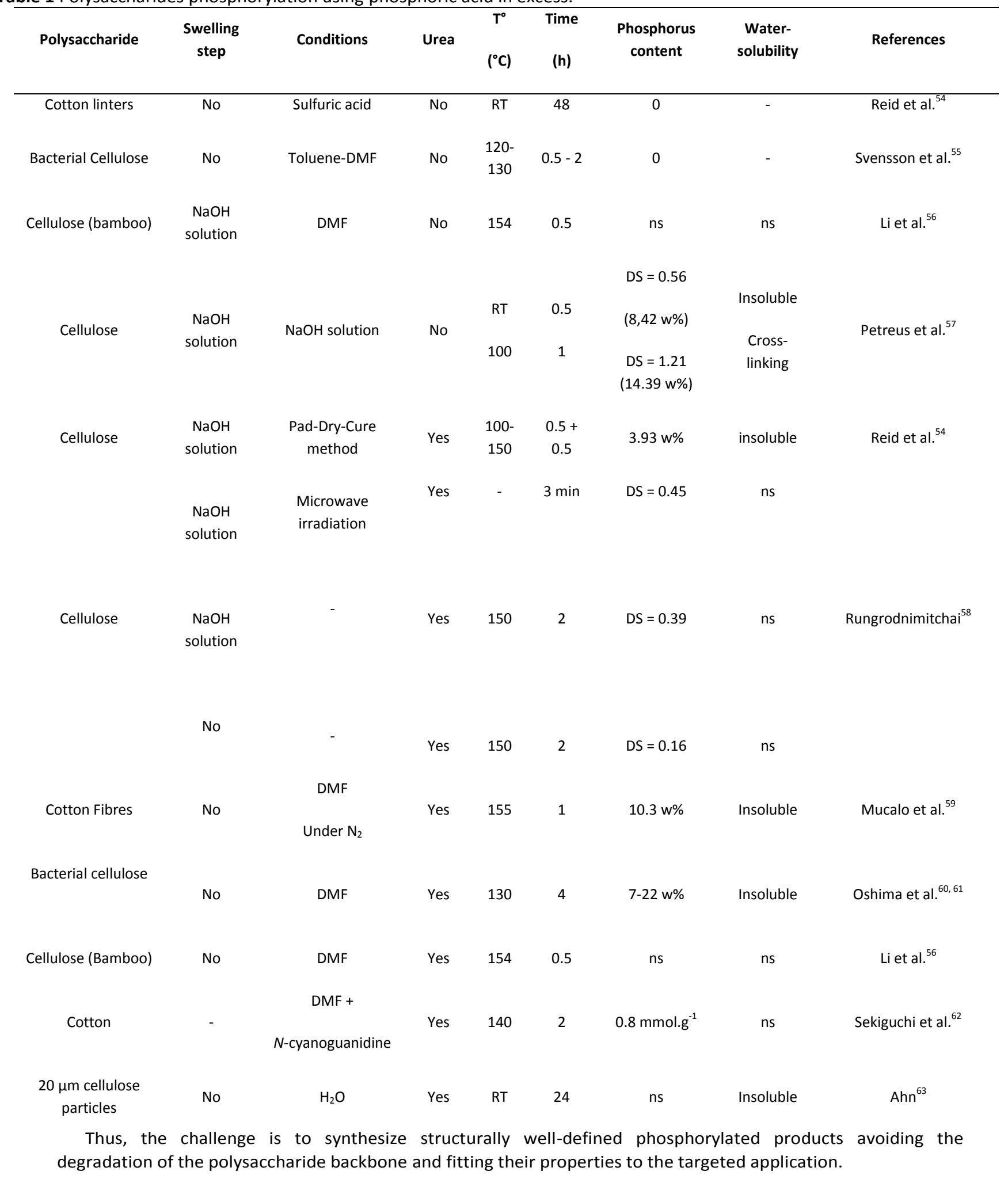




\subsection{Hydroxy groups functionalization}

Numerous polysaccharides only contain repeating units with hydroxy groups as the only functional groups. For example, the very abundant cellulose and starch possess one primary and two secondary hydroxy groups per repeating unit. In this case, the primary hydroxy groups are most of the time more nucleophilic than the secondary alcohols, which may lead to a partial or a full regioselectivity. ${ }^{42}$

\subsubsection{Polysaccharide phosphorylation with $\mathrm{H}_{3} \mathrm{PO}_{4}$ and its salts}

Since more than 60 years, orthophosphoric acid $\left(\mathrm{H}_{3} \mathrm{PO}_{4}\right)^{54}$ or salts of orthophosphoric acid $\left(\mathrm{NaH}_{2} \mathrm{PO}_{4}, \mathrm{KH}_{2} \mathrm{PO}_{4}\right.$, $\left.\mathrm{Na}_{2} \mathrm{HPO}_{4}, \mathrm{~K}_{2} \mathrm{HPO}_{4}, \mathrm{Na}_{3} \mathrm{PO}_{4}, \mathrm{NaPO}_{3}\right)^{15,75,76}$ have been widely employed to introduce phosphate groups onto polysaccharides by esterification. Table 1 shows different reaction conditions reported with phosphoric acid in the literature.

Some authors have pre-treated cellulose with $\mathrm{NaOH}$ aqueous solution. ${ }^{56,57}$ They claimed that the $\mathrm{NaOH}$ treatment breaks the van der Waals and hydrogen bonds between cellulose molecules, which causes more hydroxy groups to become exposed to $\mathrm{H}_{3} \mathrm{PO}_{4}$ in the second step of the process. After the $\mathrm{NaOH}$ pre-treatment, Li et al. have rinsed the fibers and then reacted them with phosphoric acid in DMF at $154{ }^{\circ} \mathrm{C} .{ }^{56}$ In the work of Petreus et al. ${ }^{57}$, microcrystalline cellulose was dissolved in aqueous $\mathrm{NaOH}$, treated with a phosphoric acid aqueous solution for half an hour and then heated at $100{ }^{\circ} \mathrm{C}$ for one hour. The phosphorylated products were insoluble in several solvents, including water and alkaline solutions and showed DS of 1.19.

Frequently, urea was added to a polar solvent in order to favor the phosphorylation reaction (Scheme 6). Chitosan and chitin, ${ }^{64-68}$ cotton fibres, ${ }^{59}$ bamboo, ${ }^{56}$ or bacterial cellulose ${ }^{60}$ were phosphorylated in a mixture of DMF, urea and phosphoric acid at $120-155^{\circ} \mathrm{C}$ (Table 1). The phosphorylation of water-insoluble curdlan was carried out in DMSO and led to water-soluble products with low DS. ${ }^{69,70}$ Some authors worked under "greener" conditions by replacing organic solvents by water for the phosphorylation of cellulose ${ }^{63}$ and starch. $^{73}$ Polysaccharides were also reacted with phosphoric and urea without any solvent. ${ }^{72}$ Very recently, Rungrodnimitchai showed that the phosphonation of cellulose with $\mathrm{H}_{3} \mathrm{PO}_{4}$ and urea was more efficient after a pretreatment by $\mathrm{NaOH}$ solution and under microwave irradiation. ${ }^{58}$

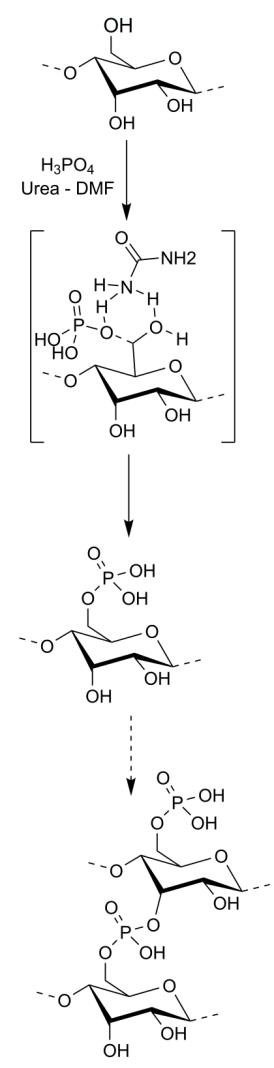

Scheme 6 Proposed mechanism by Nehls et al. ${ }^{74}$ for the cellulose phosphorylation with $\mathrm{H}_{3} \mathrm{PO}_{4}$ in presence of urea. The substitution preferentially occurs in the C-6-position and is potentially followed by cross-linking. 
It is worth to note that concerning the previous reactions, only quite low degrees of phosphorylation were obtained (less than 1.2). Granja et al. ${ }^{17}$ prepared highly phosphorylated products by reacting cellulose with the mixture $\mathrm{H}_{3} \mathrm{PO}_{4}-\mathrm{P}_{2} \mathrm{O}_{5}$ in hexanol $-\mathrm{Et}_{3} \mathrm{PO}_{4}$ as solvent at room temperature according to a modified 1956 patent. ${ }^{77}$ $\mathrm{P}_{2} \mathrm{O}_{5}$ aimed at eliminating water from the reaction mixture and thus was introduced in excess. Monophosphates groups were exclusively obtained regardless to the achieved degree of substitution. 2.9 was the highest achieved degree of substitution, which almost corresponds to cellulose triphosphate. This sample swelled considerably in water, forming a translucent gel.

Phosphated chitosan and chitin derivatives were prepared by Jayakumar et al. in hexanol ${ }^{78,79}$ or in butanol by Amaral et al. ${ }^{80}$ High substitution degrees up to 1.9 were obtained with chitin, which increased the solubility properties in aqueous media and in organic solvents. ${ }^{79}$ Nevertheless, a drastic reduction (more than $80 \%$ ) of the molecular weight has been noticed. Phosphated chitosans with a DS up to 1.7 were obtained also resulting in an increase of the derivatives solubility in aqueous solutions. ${ }^{78}$ Very recently and in contradiction with Amaral et al. ${ }^{80}$, Wang and $\mathrm{Liu}^{68}$ claimed that only amino groups were phosphorylated under the presence of $\mathrm{H}_{3} \mathrm{PO}_{4}-\mathrm{Et}_{3} \mathrm{PO}_{4}$ $\mathrm{P}_{2} \mathrm{O}_{5}$ - butanol and that hydroxy groups remained unmodified.

Another process for the phosphorylation of polysaccharides is the pad-dry-cure method. This process is often used in the textile industry. After impregnation with the phosphorylating reagents, the fabric is dried (and-or pressed) and the chemical reaction is allowed by heating in a curing step. In 1949 , Reid et al. ${ }^{54,88}$ synthesized phosphorylated cellulose derivatives according to a previously described method by Coppick et al. ${ }^{89}$ : cellulose was soaked in an aqueous solution of phosphoric acid and urea, was then pressed, and successively cured at 100 and $150^{\circ} \mathrm{C}$. The Pad-Dry-Cure process was also used with inorganic phosphate salts, for example for the phosphorylation of cellulose with $\mathrm{NaH}_{2} \mathrm{PO}_{4}$ - urea. ${ }^{90,91}$ Monophosphated starch derivatives were synthesized by reacting dry starch with monosodium dihydrogenphosphate and disodium hydrogenphosphate at $150-180^{\circ} \mathrm{C}$ under air ${ }^{92,93}$ or under vacuum. ${ }^{94-96}$ In most cases, the prepared products were insoluble in water and in organic solvents and have been poorly characterized. Substitution degrees depend on reaction time and temperatures, $\mathrm{pH}$ of the reaction mixture and polysaccharide source (origin) but are quite low, typically between 0 and $0.35 .^{90,94}$ Passaeur et al have shown by ${ }^{31} \mathrm{P} N \mathrm{NMR}$ and Raman spectroscopy that mainly starch monophosphate were formed. ${ }^{97}$ But some authors showed that alkaline $\mathrm{pH}^{98}$ and-or presence of atmospheric oxygen and moisture ${ }^{94}$ may induce cross-linking due to the possible binding of two starch molecules per phosphorus atom. On the contrary, under vacuum mono starch phosphates are preferentially prepared with higher degrees of substitution. ${ }^{94}$ 


\subsubsection{Polysaccharide phosphorylation with $\mathrm{H}_{3} \mathrm{PO}_{3}$}

Table 2 Polysaccharides phosphorylation using phosphorus acid.

\begin{tabular}{|c|c|c|c|c|c|c|c|}
\hline Polysaccharide & $\begin{array}{l}\text { Swelling } \\
\text { step }\end{array}$ & Conditions & $\mathbf{T}^{\circ}$ & Time (h) & Phosphorus content & $\begin{array}{c}\text { Water- } \\
\text { solubility }\end{array}$ & References \\
\hline \multirow[t]{2}{*}{ Cellulose } & $\begin{array}{c}\mathrm{ZnCl} \\
\text { solution }\end{array}$ & Molten urea under $\mathrm{N}_{2}$ & 150 & 8 & $\mathrm{DS}=2.0$ & $?$ & Inagaki et al. ${ }^{81}$ \\
\hline & & Molten urea & & & & & \\
\hline Cellulose & - & under $\mathrm{N}_{2}$ & 150 & $2-5$ & $\mathrm{DS}=0.96-1.06$ & Yes & Suflet et al. ${ }^{82}$ \\
\hline \multirow[t]{2}{*}{$\begin{array}{l}\text { Microcrystalline } \\
\text { cellulose }\end{array}$} & - & $\begin{array}{l}\text { Molten urea } \\
\text { under } \mathrm{N}_{2}\end{array}$ & 150 & $1-9$ & $\mathrm{DS}=0.59-2.0$ & $\begin{array}{l}\text { Yes for DS } \\
\text { around } 1.0\end{array}$ & Petreus et al. ${ }^{83}$ \\
\hline & & & & & $\mathrm{DS}=0.49$ & & \\
\hline \multirow{3}{*}{ Cellulose } & & & RT & 0.5 & (7.94 w\%) & & \\
\hline & - & Aqueous $\mathrm{NaOH}$ & $\mathrm{RT}+100$ & $0.5+1$ & $\mathrm{DS}=0.72$ & Insoluble & Petreus et $a l^{57}$ \\
\hline & & & & & (10.65 w\%) & & \\
\hline \multirow[t]{2}{*}{ Cotton fibres } & No & $\begin{array}{c}\text { Solution of urea in DMF } \\
\text { under } \mathrm{N}_{2}\end{array}$ & $130-145$ & 0.5 & - & - & Mucalo et al. ${ }^{84}$ \\
\hline & & Solvent free microwave & 85 & 6 & $\mathrm{DS}=0.6$ & Yes & \\
\hline
\end{tabular}

Phosphate and phosphoramide groups have excellent chelating properties but they are not very stable towards hydrolysis. In general, phosphonate groups are much less sensitive towards hydrolysis than phosphates ${ }^{99}$. Therefore, even if they are slightly less efficient as chelating agent, it could be of great interest to introduce phosphonate or phosphonic acid groups onto polysaccharides.

The phosphorylation of polysaccharides with phosphorus acid $\left(\mathrm{H}_{3} \mathrm{PO}_{3}\right)$ leads to the incorporation of $\mathrm{H}$ phosphonate groups into the material. As with phosphoric acid, many phosphorylation reactions with phosphorus acid were carried out in the presence of urea. But most of the time, the reactions were performed without any solvent in molten urea. In the process described by Inagaki et al. ${ }^{81}$, Cellulose was first swollen in $70 \%$ aqueous solution of zinc chloride. Then after washing, cellulose was reacted with phosphorus acid in molten urea at $150^{\circ} \mathrm{C}$. After 8 hours of reaction a degree of substitution of 2.0 was achieved and monoesters were predominantly obtained with phosphorus residues in phosphonic acid form. The incorporated $\mathrm{H}$-phosphonate groups are very reactive and can be further functionalized (Scheme 7). ${ }^{81,100,101}$

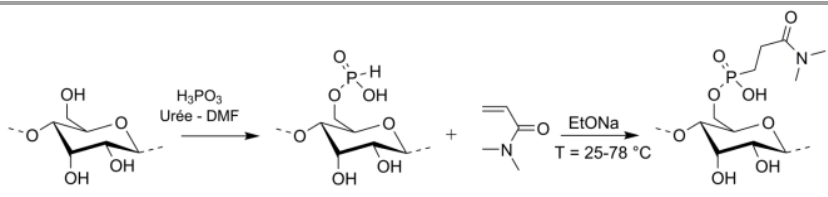

Scheme 7 Phosphorylation of cellulose with phosphorus acid and further functionalization with dimethylacetamide according to Inagaki et al. ${ }^{101}$

The use of zinc chloride is problematic because of its corrosivity and its environmental toxicity. Nevertheless, the swelling step is unnecessary: Suflet et al. performed the phosphorylation of three different polysaccharides (cellulose, dextran and curdlan) with $\mathrm{H}_{3} \mathrm{PO}_{3}$ without any swelling step. ${ }^{82,86,87}$ After 5 hours of reaction, fully watersoluble $\mathrm{H}$-phosphonate bearing cellulose, curdlan or dextran derivatives were obtained with DS up to $1.0,1.0$ and 
1.9, respectively. Degrees of substitution ranging from 0.59 to 2.0 can be achieved by adjusting the reaction time. ${ }^{83}$

Gospodinova et al. ${ }^{85}$ have described a rapid solvent-free microwave phosphorylation of cellulose with urea and phosphorus acid. For this rapid procedure no swelling in an appropriate solvent is required. Phosphorus acid monosubstituted esters of cellulose with degrees of substitution ranging from 0.2 to 2.8 were obtained. Those degrees of substitution are higher than those obtained with conventional heating processes at the same temperature. $^{85}$

Other phosphonic acid derivatives have also been employed as phosphorylating reagents. Blanchard ${ }^{102}$ performed the phosphorylation of cellulose using a conventional pad-dry-cure method with aqueous solution of phosphonic acid derivatives (Figure 1.B-E) in the presence and in absence of urea and dicyandiamide at elevated temperatures. It must be emphasized that the phosphorylation occurred only in presence of urea.

Few reports described the successful phosphorylation with phosphorus acid in absence of urea. Petreus et al. ${ }^{57}$ dissolved cellulose in aqueous $\mathrm{NaOH}$ and reacted the mixture with $\mathrm{H}_{3} \mathrm{PO}_{3}$ or with amido ethyl phosphite oligomers (Figure 1.A) yielding compounds with DS ranging from 0.4 to 0.7 .

A<smiles>CP(NCCO)OCCNP(C)(C)=O</smiles><smiles>[B]P(=O)(O)C(C)(O)P(=O)(O)O</smiles>

C<smiles>O=P(O)(O)c1ccccc1</smiles><smiles>[2H]</smiles><smiles>O=C(O)CCP(=O)(O)O</smiles>

E<smiles>O=C(O)CN(CC(=O)O)CP(=O)(O)O</smiles>

Fig. 1 A: amido ethyl phosphite oligomers; B: 1hydroxyethylidene-1,1-diphosphonic acid; C: phenyl phosphonic acid; D: 2-carboxyethyl phosphonic acid; E: N(phosphonomethyl) iminodiacetic acid.

\subsubsection{Polysaccharide phosphorylation with polyphosphorus compounds}

Native polysaccharides were phosphorylated with polyphosphoric acid or polyphosphates (Table 3). Several patents have been registered on the phosphorylation of starch with different inorganic polyphosphate salts: tetrasodium pyrophosphate $\left(\mathrm{Na}_{4} \mathrm{P}_{2} \mathrm{O}_{7}\right),{ }^{15,}{ }^{75}, 76$ pyrophosphate diester $\left(\mathrm{Na}_{2} \mathrm{R}_{2} \mathrm{P}_{2} \mathrm{O}_{7}\right),{ }^{103}$ sodium tripolyphosphate $\left(\mathrm{Na}_{5} \mathrm{P}_{3} \mathrm{O}_{10}\right),{ }^{15,75,76}$, trisodium trimetaphosphate $\left(\mathrm{Na}_{3} \mathrm{P}_{3} \mathrm{O}_{9}\right){ }^{15}$ and-or sodium hexametaphosphate $\left(\mathrm{Na}_{6} \mathrm{P}_{6} \mathrm{O}_{18}\right){ }^{15}, 75,76$

Sodium trimetaphosphate and sodium tripolyphosphate are long time known to be efficient starch crosslinking agents in aqueous suspension. ${ }^{104,105}$ Both compounds have very low toxicities. Depending on the reaction conditions, monostarch phosphates were obtained via substitution reaction or distarch phosphates were obtained via cross-linking. ${ }^{106} \mathrm{Lim}$ and Seib ${ }^{107}$ have studied the influence of the initial $\mathrm{pH}$ on the cross-linking and phosphorus content for the phosphorylation of starch by sodium tripolyphosphate (STPP) and-or sodium trimetaphosphate (STMP) in presence of sodium sulfate. The phosphorylation of cyclodextrin ${ }^{108}$, disaccharides ${ }^{109}$ and cellulose ${ }^{110}$ with sodium trimetaphosphate has been reported (Scheme 8). The phosphorylation of starch with sodium trimetaphosphate was also performed by reactive extrusion allowing higher degrees of substitution. ${ }^{111,112}$

Sekiguchi et al. ${ }^{62}$ showed that the phosphorylation of cellulose in DMF with $\mathrm{H}_{4} \mathrm{P}_{2} \mathrm{O}_{7}$ was more efficient when the reaction was performed in the presence of phosphoric acid and-or cyanoguanidine.

Phosphate derivatives of chitosan may be obtained by interpolymer linkage of chitosan with sodium tripolyphosphate or polyphosphate. Starch has been impregnated with alkali metal tripolyphosphate in water and then after filtration has been heat-reacted to produce phosphate starch esters. ${ }^{113,114}$ 
Table 3 Polysaccharides phosphorylation using polyphosphorus compounds.

\begin{tabular}{|c|c|c|c|c|c|c|}
\hline Polysaccharide & Reactant & Conditions & $T^{\circ}$ & Time (h) & Phosphorus content & References \\
\hline Xanthan & $\mathrm{Na}_{4} \mathrm{P}_{2} \mathrm{O}_{7}$ & Moderate vacuum & 60 & 2 & $4.0 \mathrm{w} \%$ & $\begin{array}{l}\text { Yalpani et } \\
\text { al. }^{115}\end{array}$ \\
\hline \multirow[t]{2}{*}{ Chitin or chitosan } & $\mathrm{Na}_{4} \mathrm{P}_{2} \mathrm{O}_{7}$ & Moderate vacuum & 60 & 3 & $6-7 w \%$ & $\begin{array}{l}\text { Yalpani et } \\
\text { al. }^{115}\end{array}$ \\
\hline & & - & & & $0.323 \mathrm{mmol} . \mathrm{g}^{-1}$ & \\
\hline \multirow{4}{*}{ Cotton } & & Urea & & & $0.822 \mathrm{mmol} . \mathrm{g}^{-1}$ & \\
\hline & $\mathrm{H}_{4} \mathrm{P}_{2} \mathrm{O}_{7}$ & DMF & 140 & 3 & & 62 \\
\hline & & $N$-cyanoguanidine & & & $0.725 \mathrm{mmol} . \mathrm{g}^{-1}$ & \\
\hline & & Urea $+N$-cyanoguanidine & & & $1.067 \mathrm{mmol} . \mathrm{g}^{-1}$ & \\
\hline \multirow{3}{*}{ Cellulose } & $\mathrm{H}_{4} \mathrm{P}_{2} \mathrm{O}_{7}$ & & & & & \\
\hline & and & In presence of urea & $120-160$ & ns & $\mathrm{DS}=0.3-0.6$ & $\begin{array}{l}\text { Luneva et } \\
\text { al. }^{116}\end{array}$ \\
\hline & $\mathrm{H}_{5} \mathrm{P}_{3} \mathrm{O}_{10}$ & & & & & \\
\hline Cellulose paper & $\mathrm{Na}_{3} \mathrm{P}_{3} \mathrm{O}_{9}$ & Aqueous solution & RT-50 & $\begin{array}{c}\text { 2-4 } \\
\text { weeks }\end{array}$ & $0.14-0.63 w \%$ & Inoue et al. ${ }^{110}$ \\
\hline $\begin{array}{l}\text { 2,3-deacetylated } \\
\text { cellulose }\end{array}$ & $\mathrm{H}_{6} \mathrm{P}_{4} \mathrm{O}_{13}$ & Tri- $n$-butylamine in excess; DMF & 120 & 6 & $\mathrm{DS}=0.2-0.8$ & Klemm et al. ${ }^{117}$ \\
\hline \multirow{2}{*}{$\begin{array}{l}\text { Hydroxypropyl } \\
\text { cellulose }\end{array}$} & & Triethylamine & & & & \\
\hline & $\mathrm{H}_{n+2} \mathrm{P}_{n} \mathrm{O}_{3 n+1}$ & DMF & 120 & 6 & $\mathrm{DS}=1.3$ & $\begin{array}{c}\text { Kowalik et } \\
\text { al. }^{118}\end{array}$ \\
\hline $\begin{array}{c}\text { Carboxymethyl } \\
\text { cellulose }\end{array}$ & $\mathrm{Na}_{3} \mathrm{P}_{3} \mathrm{O}_{9}$ & $\mathrm{NaOH}$ solution & RT & 2 & $\mathrm{DS}=0.5$ & Leone et al. ${ }^{119}$ \\
\hline
\end{tabular}

The previous reactions are carried out under heterogeneous conditions. Therefore, the functional group distribution might not be uniform. The use of polysaccharide derivatives often allows a more even distribution along the polymer backbone by working under homogeneous conditions. For instance 2,3-deacetylated cellulose and hydroxypropyl cellulose were dissolved in DMF and then reacted with polyphosphoric acid at $120^{\circ} \mathrm{C}$ in presence of a tertiary amine (Table 3. 4-5, Scheme 9). Barbucci and coll. ${ }^{119}$ synthesized phosphorylated derivatives of carboxymethylcellulose using trisodium trimetaphosphate (STMP) as the phosphate agent. They claimed that
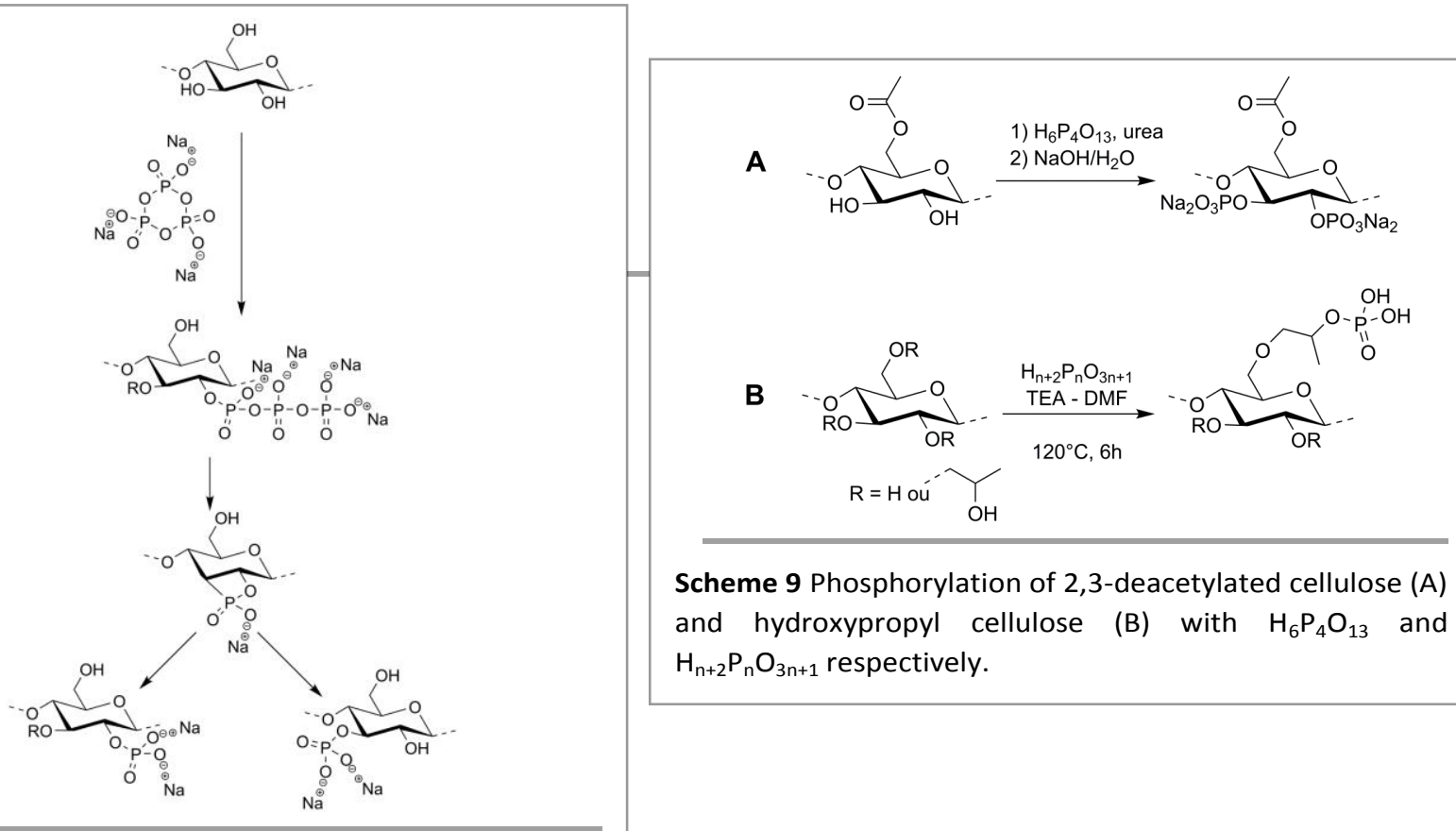

Scheme 9 Phosphorylation of 2,3-deacetylated cellulose (A) and hydroxypropyl cellulose (B) with $\mathrm{H}_{6} \mathrm{P}_{4} \mathrm{O}_{13}$ and $\mathrm{H}_{n+2} \mathrm{P}_{\mathrm{n}} \mathrm{O}_{3 \mathrm{n}+1}$ respectively.

Scheme 8 Polysaccharide phosphorylation with sodium trimetaphosphate, $\mathrm{Na}_{3} \mathrm{P}_{3} \mathrm{O}_{9}$. 
carboxymethyl cellulose with one phosphate group for each disaccharide unit was obtained. ${ }^{120}$

\subsubsection{Polysaccharide phosphorylation with phosphorus pentoxide $\left(P_{4} O_{10}\right)$ and phosphorus pentasulfide $\left(P_{4} S_{10}\right)$}

In 1971, Clermont patented the phosphorylation of cellulose at room temperature with a solution of phosphorus pentoxide in DMF leading to insoluble products in aqueous and organic solvents. ${ }^{121}$ Phosphate groups were grafted onto the surface of cellulose membranes by a reaction in heterogeneous conditions between hydroxy groups and phosphorus pentoxide in DMF at $25^{\circ} \mathrm{C}$ for 48 hours. ${ }^{122}$ Although the obtained degrees of substitution were low (DS $=0.6$ ), high adsorption of serum protein was obtained with phosphated cellulose.

Phosphorylation of the hydroxy functions from chitin and chitosan to yield phosphate groups has been performed by reacting chitosan with phosphorus pentoxide in the presence of methanesulfonic acid. ${ }^{123-125}$ Due to the ionic shielding of the primary amino groups by methanesulfonic acid, only the hydroxy groups are phosphorylated and the phosphorylation preferentially occurs at the C- 6 position. ${ }^{68}$ Dace et al. phosphorylated xylan, fucoidan and carrageenan by using the same methane sulfonic acid - phosphorus pentoxide mixture. ${ }^{126}$ Nevertheless, the use of concentrated methanesulfonic acid drastically reduced the molecular weight of the polymer (reduced viscosity divided by 2 ). ${ }^{124}$

Different polysaccharides (cellulose, starch, $\beta$-cyclodextrin) have also been reacted with phosphorus pentasulfide $\left(\mathrm{P}_{4} \mathrm{~S}_{10}\right)$ in the absence or in the presence of DMF, yielding carbohydrate derivatives containing both sulfur and phosphorus. ${ }^{115}$ The obtained derivatives have been only characterized by elemental analysis and infrared spectroscopy, thus their structures are not fully known. In addition, phosphorus pentasulfide is highly flammable and ignite in presence of moisture. Its reaction with water forms toxic hydrogen sulfide gas and phosphoric acid.

\subsubsection{Polysaccharide phosphorylation with halogenated derivatives}

Phosphorus oxychloride $\left(\mathrm{POCl}_{3}\right)$ and phosphorus pentachloride are long time known to be efficient starch crosslinking agents in alkaline suspension. ${ }^{127}$ Cross-linked starch phosphate diesters were obtained from the reaction of starch with phosphorus oxychloride in pyridine. ${ }^{128}$ The phosphorylation of cotton fibers was also performed with phosphorus oxychloride in pyridine. ${ }^{54}$ Nevertheless, this method has some drawbacks: the chlorination of the polysaccharides occurred as side-reaction and the phosphorus content in the final product is rather low. ${ }^{129}$ In addition, degradation of the polysaccharide backbones and loss of the mechanical properties have been observed. ${ }^{54}$ Despite its toxicity, $\mathrm{POCl}_{3}$ has been used to cross-link food grade starches for a long time. ${ }^{106,130}$ Chitosan alkyl phosphates were also synthesized through the use of chlorophosphates: diethyl chlorophosphate ${ }^{131}$ or 2-chloro-2-oxo-1,2,3-dioxaphospholane. ${ }^{132}$

Phosphonate containing cellulose derivatives were synthesized by Marvel et al. ${ }^{133}$ in a two-steps reaction: first a chloroacetylation and then a Arbuzov reaction with triethylphosphite. The obtained products are flame resistant but their exact structure is not known due to a lack of characterizations.

The phosphorylation of polysaccharides with phosphorus-containing alkyl halides has also been investigated. Phosphate or phosphonic acid bearing celluloses were prepared by reacting cotton in alkaline conditions with sodium 2-chloroethylphosphate and chloromethylphosphonic acid, respectively. ${ }^{134}$ Palma et al. ${ }^{135}$ claimed that the phosphonation of chitosan hydroxy functions was carried out with 2-chloro ethyl phosphonic acid in alkaline conditions. It is interesting to note that despite the nucleophilicity of the primary amine groups, their reaction with alkyl chloride was not detected.

\subsubsection{Polysaccharide phosphorylation with $\boldsymbol{n}$-Propyl phosphonic acid anhydride}

Heinze et al. ${ }^{136}$ reacted cellulose with $n$-propyl phosphonic acid anhydride and different carboxylic acids at $100{ }^{\circ} \mathrm{C}$ in $\mathrm{LiCl} / \mathrm{NMP}$ as solvent for 3 hours. The reaction occurred in homogeneous conditions and $n$-propyl phosphonic acid anhydride acted both as a phosphorylation agent and as an activating agent for the carboxylation reaction, which simultaneously undergone the introduction of acyl and propylphosphonate moieties in the polymer chain (Scheme 10). According to the alkyl chain length of the carboxylic acids, the novel mixed cellulose esters displayed different solubilities. 


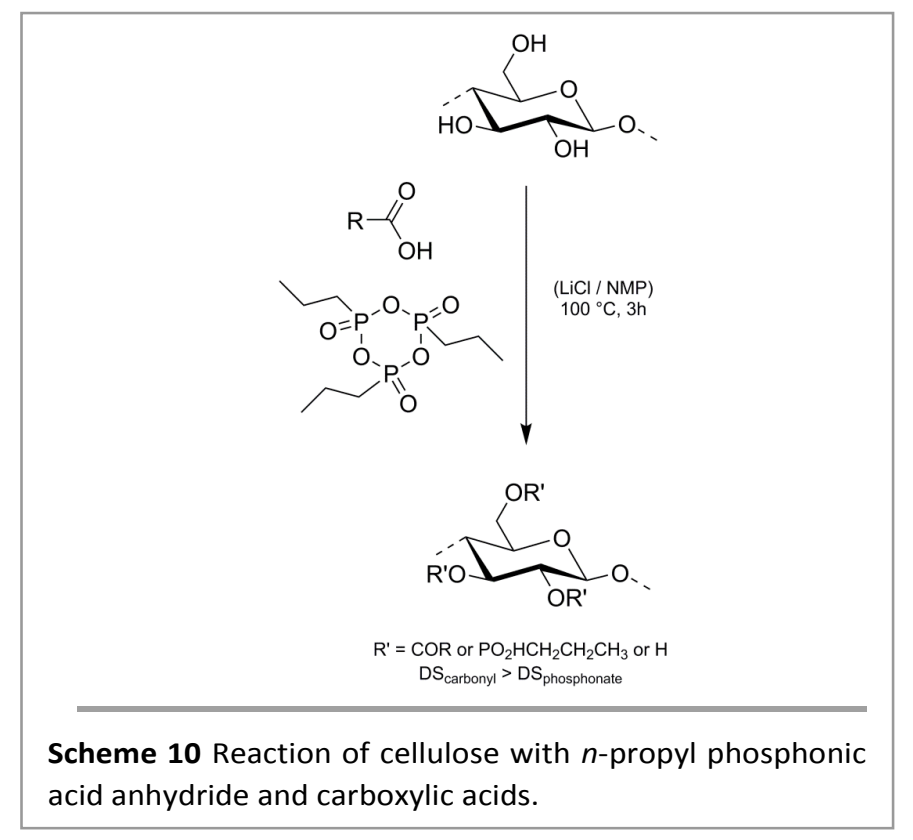

\subsubsection{Polysaccharide phosphorylation in unconventional solvents}

A chemistry concern is to use proper solvents that can replace hazardous and volatile solvents in chemical processes with similar or enhanced efficiency. During the last 15 years, organic salt with low melting points (ionic liquids) have demonstrated their huge potential for the synthesis of various cellulose derivatives. They can dissolve high amount of polysaccharide without pretreatment allowing the derivatization to take place in homogeneous conditions. ${ }^{137}$ In fact, homogeneous conditions are well-known to be suitable in term of efficient control of amount and distribution of substituents along the polymer backbone.

Xie and Shao prepared phosphorylated starch ( $D S=0.03$ to 0.55 ) in 1-butyl-3-methylimidazolium chloride with sodium dihydrogenphosphate or disodium hydrogenphosphate in presence of urea. ${ }^{138}$ Vo et al. ${ }^{139}$ obtained water-soluble cellulose derivatives by dissolving cellulose in 1,3-dimethylimidazolium methyl phosphite above 120 ${ }^{\circ} \mathrm{C}$ (Scheme 11). In this case, the ionic salt has been tuned in order to be both the reaction solvent and the phosphorylating agent. Hydroxy groups reacted with methyl phosphite anions and were converted into $\mathrm{H}$ phosphonate anions concomitantly with the loss of a methanol molecule. The obtained $\mathrm{H}$-phosphonate bearing cellulose is a polyanion for which dimethylimidazolium cations play the role of counter-ions. NMR analyses showed that the functionalization mainly occurred at the C6 position of the anhydroglucopyranose. Nevertheless, the degree of substitution was not limited to 1.0 and a maximum value of 1.3 has been obtained.

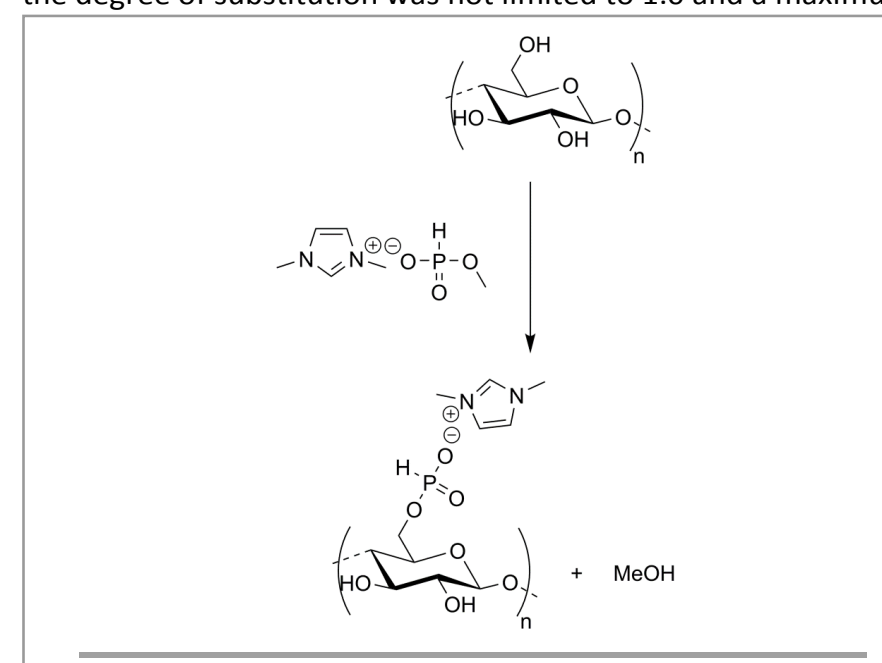

Scheme 11 Phosphorylation of cellulose in 1,3dimethylimidazolium methyl phosphite.

However, the use of ionic liquid present several drawbacks that may hamper the use of ionic liquid in commercialized processes. For instance, imidazolium based ionic liquid are proven to generate side reactions with 
polysaccharides. ${ }^{137}$ In addition even after several washings, cellulose derivatives still contain up to several percent of ionic liquid residues which may be detrimental for different applications especially in biomedical field. ${ }^{137}$

Another alternative to conventional solvents is the use of supercritical fluids. Their high dissolving ability allows achieving the modification of polysaccharides. In particular, supercritical carbon dioxide is easy to generate, cheap, recyclable, non-toxic and non-flammable. The phosphorylation of amylose was conducted in supercritical carbon dioxide with sodium tripolyphosphate for $1.5 \mathrm{~h}$, yielding phosphate ester derivative with a DS equal to $0.25 .{ }^{140}$ Manoi et al. ${ }^{141}$ achieved the cross-linking of starch by supercritical fluid extrusion with sodium trimetaphosphate.

\subsection{Grafting of phosphorus containing polymers on polysaccharides}

The synthesis of grafted polysaccharide is a promising route to combine the advantages of the material properties of native polysaccharides with those of synthetic phosphorus polymers. Grafting strategies enable an increase of the phosphorus weight percent and allow increasing the distances between phosphorus atoms and the main backbone. Daul and Reid used a "grafting onto" strategy: they reacted poly(vinyl phosphoric acid) with cotton cellulose in presence of urea at $130-160{ }^{\circ} \mathrm{C}$ in order to increase the number of free phosphoric acid groups and, at the same time, the ion-exchange capacity of phosphorylated cellulose materials. ${ }^{142,143}$ It has to be noticed that the final product structures are not perfectly known due to uncontrolled cross-linking. Masuko et al. prepared compounds by graft copolymerization of vinyl phosphonate oligomers (Fyrol 76) on to cotton fabric and studied their thermal degradation and flammability. ${ }^{144,} 145$ Unfortunately, the "grafting onto" strategy often leads to low grafting density and requires constraining purifications steps. Another strategy is called "grafting from", involves the growth of polymer grafts directly from the polymer backbone.

\subsubsection{Free radical polymerization}

Free radical polymerization has been used to attach numerous Phosphorus-containing monomer units to different polysaccharides. Predominantly, vinyl monomers were polymerized from polysaccharides after direct activation of the cellulose fibers surface by redox-systems or by high-energy radiations. The grafting is often performed under heterogeneous conditions with the solid polymer and with the monomer in organic solution.

Ishihara et al. ${ }^{146}$ synthesized the poly(2-methacryloyloxyethyl phosphorylcholine) grafted cellulose by a radical graft copolymerization of 2-methacryloyloxyethyl phosphorylcholine (MPC, Figure 2.M1) onto a cellulose membrane directly by using cerium ammonium nitrate, $\left(\mathrm{NH}_{4}\right)_{2} \mathrm{Ce}\left(\mathrm{NO}_{3}\right)_{6}$, as initiator. Phosphorus containing diacrylate monomers (Figure 2.M10) were attached and cross-linked onto cotton fabric using potassium persulfate as thermal initiator. ${ }^{147}$

Cellulose film or cotton fabric have been gamma ray irradiated to initiate the grafting of different phosphoruscontaining methacrylates, such as $\mathrm{MPC}^{148}$ or diethyl (acryloyloxy) ethylthiophosphoramidate (Figure 2.M3). ${ }^{149}$ Nevertheless, grafting under gamma irradiation is often connected with considerable decomposition and crosslinking of the polymer backbone and heavy equipment are required.

Tsafack and Levalois-Grützmacher developed the simultaneous grafting and polymerization of acrylate and methacrylate monomers bearing phosphate, phosphonate and amidophosphate groups (Figure 2.M4-M7) onto cotton surfaces. ${ }^{150}$ Cotton textiles were impregnated with a solution of monomer and photo-initiator in methanol and the polymerization of the monomers was induced by means of an argon plasma. El-Shafei and coll. used an atmospheric-pressure plasma process to graft and polymerize two phosphoramidate acrylate monomers (Figure 2.M8 and M9) onto cotton fabric. ${ }^{151}$

Phosphorylated monomers and cross-linking agents were polymerized on cotton surfaces under UV irradiation. Different mixtures were investigated such as tri(acryloyloxyethyl) phosphate (Figure 2.M11) and triglycidyl isocyanurate acrylate according to Xing et al. ${ }^{152}$ or vinyl phosphonic acid and 1,3,5-Triazine-2,4,6(1H,3H,5H)trion,1,3,5-tri-2- propenyl according to Opwis et al. ${ }^{153}$

Graft polymerization of monomers by free radical polymerization is an effective and accessible method for introducing high amounts of phosphorus moieties in natural polysaccharides. Free radical polymerization widens considerably the choice of monomers, making possible the syntheses of graft polysaccharides with various physico-chemical properties. Nevertheless polysaccharide graft polymerization is inevitably combined with some homopolymerization of the monomer as well as cross-linking of the chains, which can be a serious drawback in terms of purification and characterization (grafting efficiency determination). 


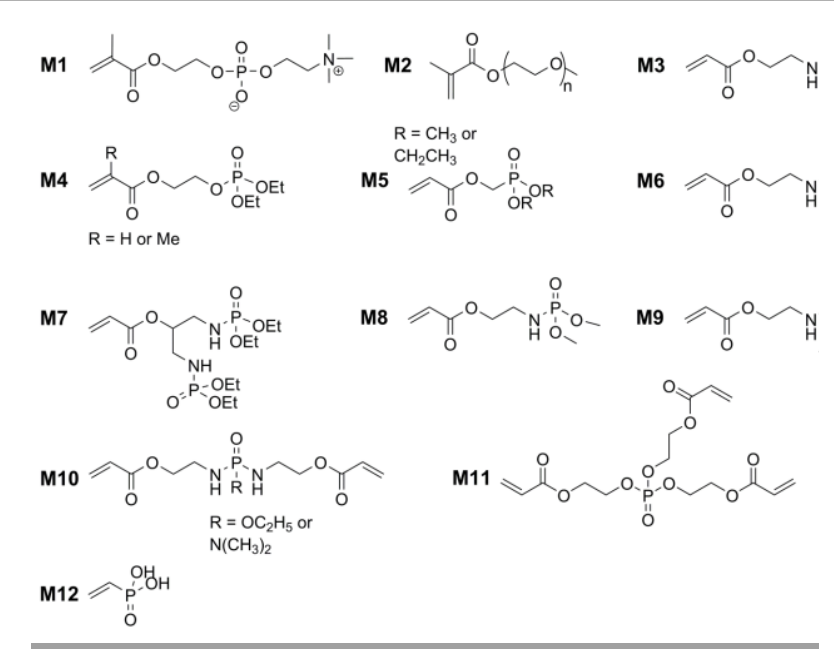

Fig. 2 (Meth)acrylates (M1-M11) and vinylphosphonic acid (M12) graft-polymerized onto polysaccharides.

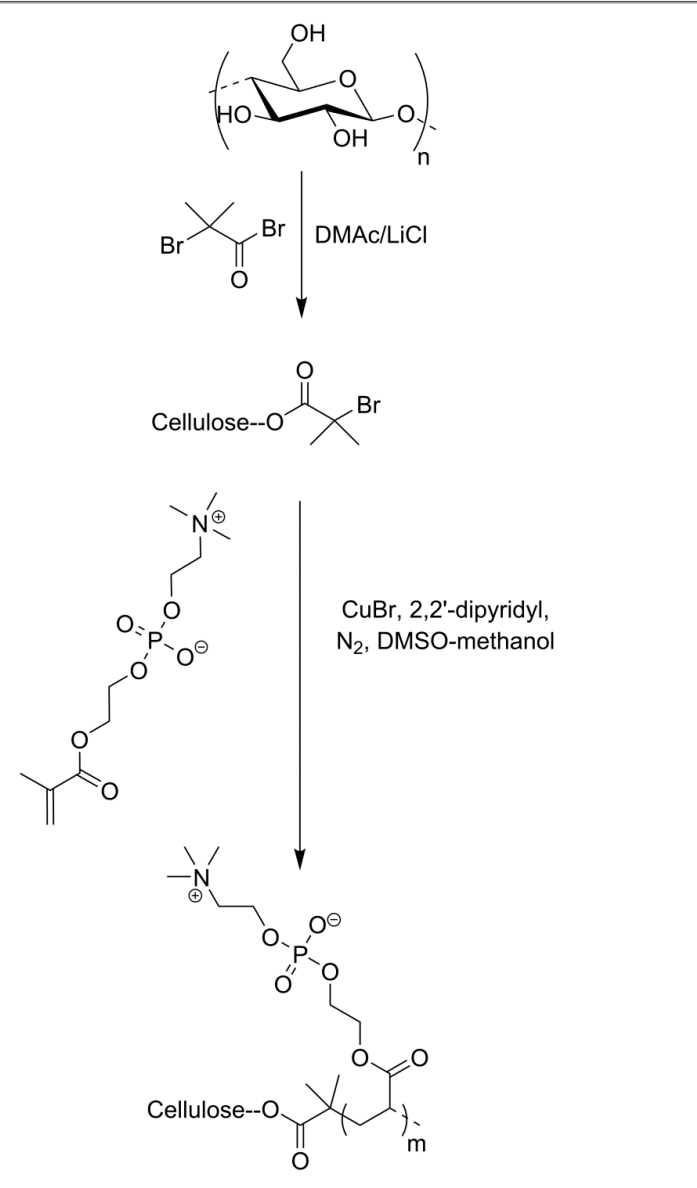

Scheme 12 Graft copolymerization of MPC on cellulose backbone in homogenous solution via ATRP route.

\subsubsection{Controlled radical polymerizations}

Previous methodologies were based on conventional radical polymerization. Thus, it displays some drawbacks like rather high polydispersity indexes and lack of $\mathrm{Mw}$ control. The first report on the controlled ATRP grafting of native cellulose under homogeneous conditions was presented in 2008 by Yan and Ishihara ${ }^{154}$ who grafted 2- 
methacryloyloxyethyl phosphorylcholine from a cellulose-based ATRP macroinitiator prepared by the homogeneous acylation of cotton with 2-bromoisobutyl bromide (Scheme 12).

Verma and Kaur claimed that they have grafted by controlled radical polymerization diethyl (acryloyloxy) ethylthiophosphoroamidate (Figure 2.M3) onto cotton fabric where iniferter groups, i.e. benzyl N,Ndiethyldithiocarbamates, had been previously introduced. ${ }^{155}$ The polymerization took place in toluene under UV irradiation. The obtained graft copolymers were not much characterized but their flame retardant properties significantly increased.

\subsection{Chitosan primary amine phosphorylation}

Chitosan is the fully or partially deacetylated form of chitin, the second most abundant natural polysaccharide derived from the exoskeletons of crustaceans and also cell walls of fungi and insects. With the poly(lysine), chitosan is one of the very few polymers from natural origin which has a primary amino group along its backbone. Chitosan contains one primary hydroxy group at position C-6, one secondary hydroxy group at position C-3 and one primary amino group at position C-2. The difference of reactivity between hydroxy groups and primary amine groups allows to chemo selectively modified the nitrogen position or the hydroxy groups. In this part, we will focus on the functionalization of primary amino groups, which give rise to a large variety of chemical reactions where the nitrogen acts as a nucleophile.

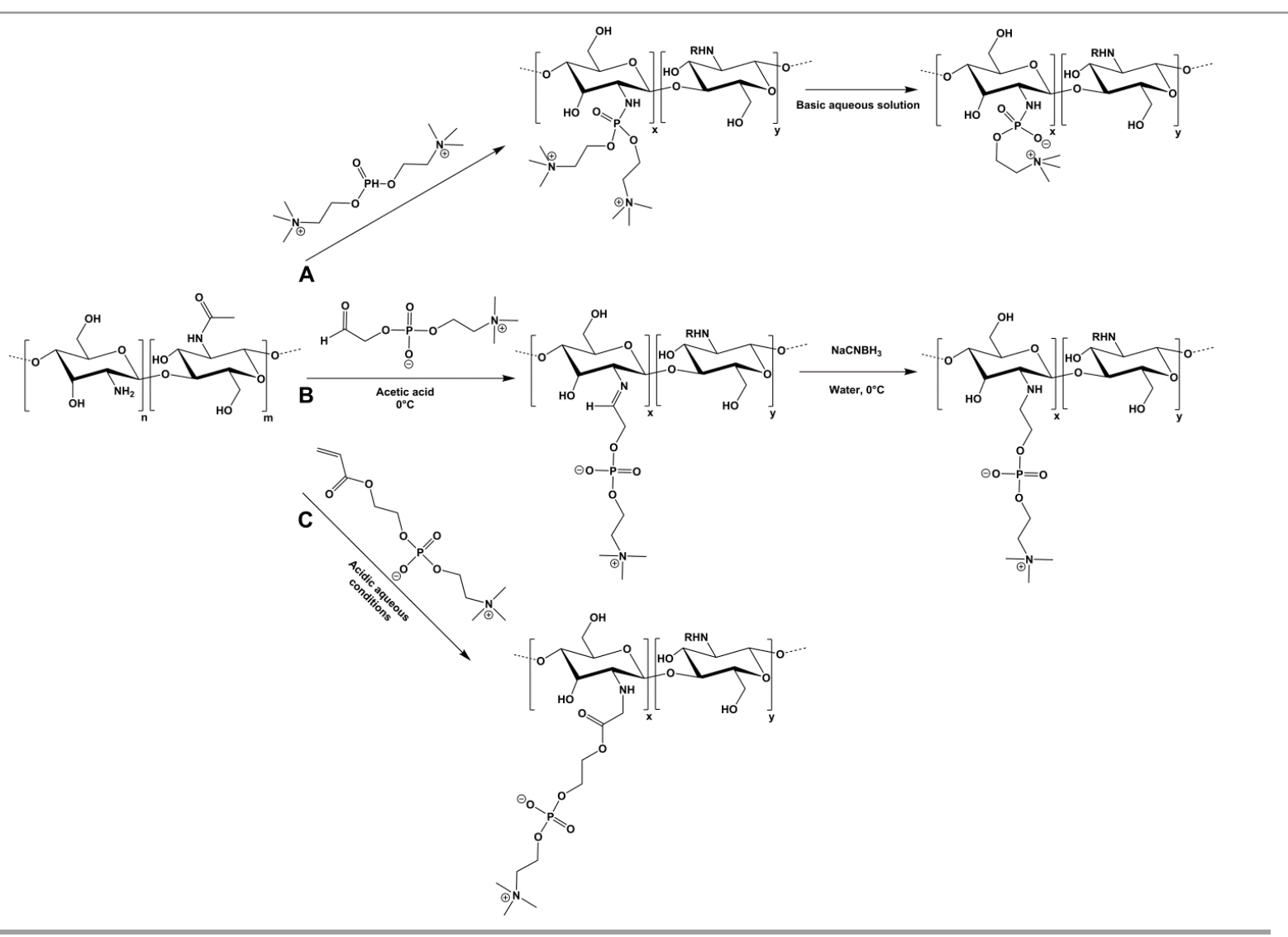

Scheme 13 Introduction of phosphorylcholine group onto chitosan: A. Atherton Todd reaction; B. Reductive amination; C. Michael addition.

\subsubsection{Atherton Todd Reaction: phosphoramidate linkage synthesis}

Phosphate and amidophosphate chitosan derivatives have been synthesized by Atherton Todd reaction (phosphoramide linkage). ${ }^{156,157}$ Atherton-Todd reaction was also used to synthesize, under mild conditions, phosphorylcholine chitosan derivatives with different degrees of substitution (Scheme 13.A). ${ }^{158}$ These derivatives can be hydrolyzed in aqueous basic solution yielding zwitterionic polymers. Less commonly phosphatefunctionalized chitosan derivatives can be synthesized by graft polymerization of mono (2-methacryloyl oxyethyl) 
acid phosphate initiated by ceric ammonium nitrate ${ }^{159}$ or directly via Michael addition with mono-(2acryloyloxyethyl) phosphonate ${ }^{160}$ (Scheme 13.C) or with 2-methacryloyloxyethyl phosphorylcholine. ${ }^{161}$

\subsubsection{Reductive amination}

The reductive amination of the amine group is commonly employed for the chitosan derivatization. ${ }^{42}$ In this method, the amine is first condensed with an aldehyde in a slightly acidic solution to give an imine which is then reduced by a reducing agent to give a secondary amine. This reaction is generally fully chemo selective. For instance, the reductive amination of phosphorylcholine-glyceraldehyde with chitosan primary amines was used to generate phosphorylcholine-substituted chitosan (Scheme 13.B). ${ }^{162}$ Compounds with DS higher than 0.23 were obtained and were water-soluble over the entire $\mathrm{pH}$ range.

\subsubsection{Moedritzer-Irani and Kabachnik-Fields reactions}

The Moedritzer reaction is the most common chitosan phosphonation reaction (Scheme 14.B). Numerous papers reported the introduction of $\alpha$-aminomethylphosphonic acid groups onto chitosan based on this reaction. ${ }^{163-175}$ The regioselectivity of this reaction is however unclear. Heras et al. claimed a regioselective functionalization of the amine groups ${ }^{163}$ in contradiction to Matevosyan et al. who also reported the esterification reaction of the hydroxy groups ${ }^{164}$. More recently, Lebouc and al. showed that a side reaction, i.e. methylation of the amines, occurred, leading to $\mathrm{N}$-methyl and $\mathrm{N}, \mathrm{N}$-dimethyl chitosan. ${ }^{169}$ This reaction could even be predominant under some conditions. Few papers deal with the synthesis of $\alpha$-aminomethylphosphonate according to a Kabachnik-Fields reaction. ${ }^{164,176}$

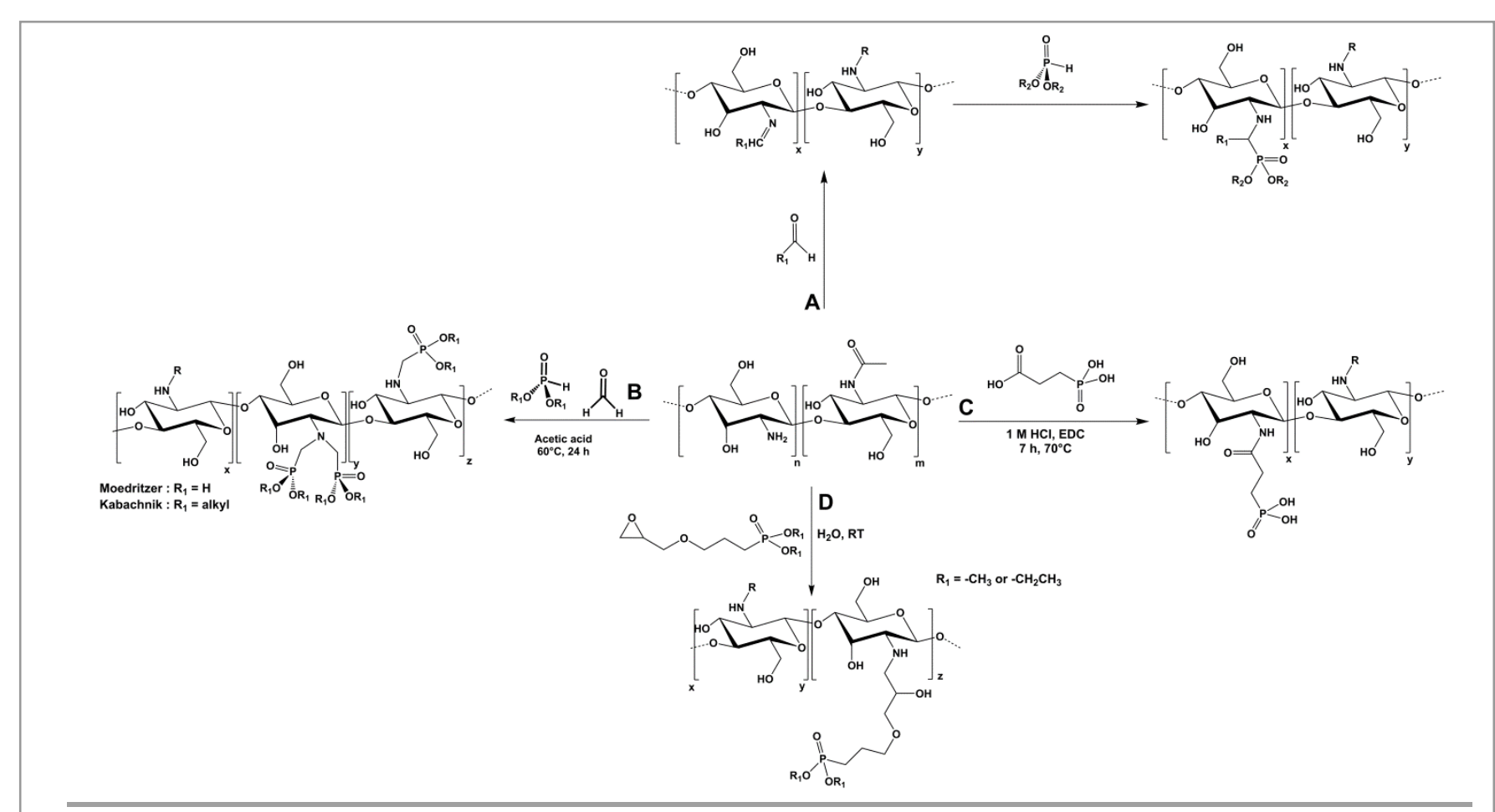

Scheme 14 Preparation methods of phosphorylated chitosan.

Chitosan primary amine groups were also reacted with aldehydes in water to give Schiff bases. Then after purification, the Schiff bases of chitosan were reacted with di-alkyl phosphate to give 2-( $\alpha$-arylamino phosphonate)-chitosan (Scheme 14.A). ${ }^{177} \mathrm{~N}$-methylene phenylphosphonic chitosan can be prepared using chitosan, formaldehyde and phenyl phosphonic acid. ${ }^{178}$

\subsubsection{Acylation: Amine - carboxylic acid reaction}

Condensation reactions between primary amine groups and carboxylic acid containing molecules were used to introduce phosphate groups onto chitosan by formation of amide groups. For instance, 2-carboxyethyl phosphonic acid was covalently grafted onto chitosan by using 1-ethyl-3-(3-dimethylaminopropyl) carbodiimide (EDC) mediated coupling reaction (Scheme 14.C). ${ }^{179}$ This reaction is almost quantitative and proceeds in smooth homogeneous conditions. (5-carboxypentyl) triphenylphosphonium bromide was covalently bonded onto chitosan at $25^{\circ} \mathrm{C}^{180}$ in $\mathrm{H}_{2} \mathrm{O} / \mathrm{DMSO}(\mathrm{v} / \mathrm{v}=2 / 1)$ in presence of 1-hydroxybenzotrizole and 1-ethyl-3-(3-dimethylaminopropyl) 
carbodiimide hydrochloride and the prepared $\mathrm{N}$-phosphonium chitosan derivatives (DS up to 0.21 , Figure 3) were evaluated as antibacterial agent ${ }^{181}$ or as non-viral vector. ${ }^{182}$ The use of water as solvent or co-solvent allows preventing $\mathrm{O}$-acylation side-reaction and also favors a complete chemoselectivity.

\subsubsection{Amine-epoxide reaction}

Numerous papers show that chitosan primary amine groups can react with epoxide compounds ${ }^{183,184}$ but to our knowledge the epoxy-amine reaction has been used only one time to introduce phosphonate groups onto chitosan. ${ }^{176}$ Oligochitosan was reacted with dialkyl (3-(oxiran-2-ylmethoxy)propyl) phosphonates leading to a degree of substitution of 0.6 (Scheme 14.D).

\subsubsection{Derivatization after a protection step}

The hydroxy groups can be protected in a first step followed by the amino groups functionalization and possibly a deprotection step. This strategy shows two main advantages : the second step can be carried out under homogeneous conditions in organic solvent and it affords a high regioselectivity. Lebouc et al. reported the syntheses of alkyl-phosphonate chitosan derivatives in THF starting from 6-O-triphenylmethyl-chitosan (Scheme 15). ${ }^{185}$ The latter was reacted either with tetraethyl vinylidenebisphosphonate according to a Michael addition mechanism or with a halogeno-phosphonate compound. These coupling reactions proceeded with soft conditions in high yields.

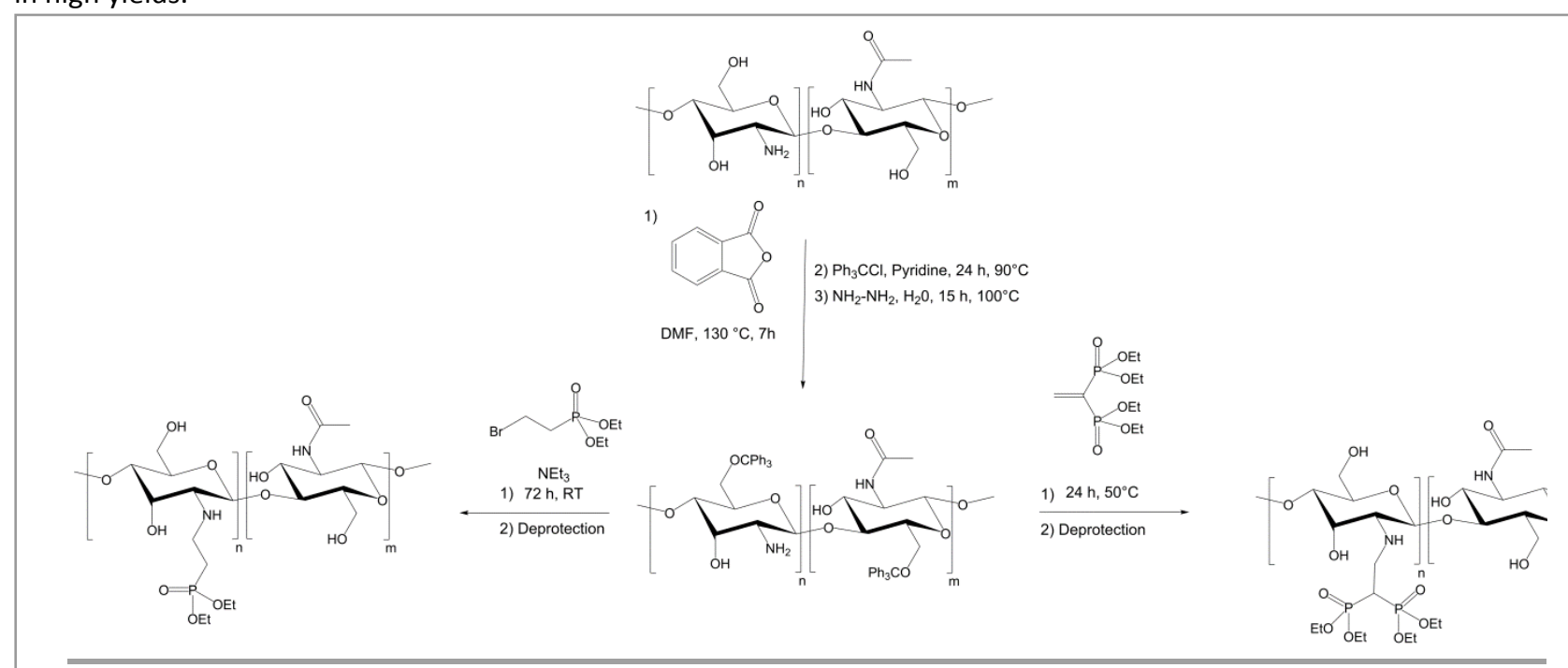

Scheme 15 Preparation methods of phosphonated chitosan.

\subsection{Polysaccharides containing carboxylic acid group}

Barbucci and coll. reacted commercial carboxymethylcellulose with 2-aminoethyl-phosphonic acid in the presence of $\mathrm{N}$-hydroxysuccinimide and 1-ethyl-3-(3-dimethylaminopropyl) carbodiimide hydrochloride as activating

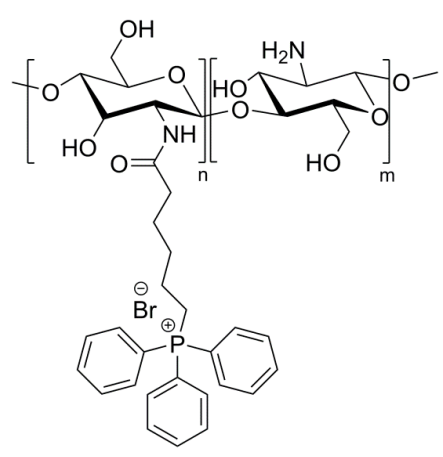

Fig. $3 \mathrm{~N}$-phosphonium chitosan derivative. 
agents. ${ }^{186}$ Amide bonds were created between the amine of the phosphonic acid agent and the carboxylic acids. These derivatives were used to functionalize titanium surfaces and their osteointegration were therefore improved. ${ }^{186}$ Bisphosphonated hyaluronic acid derivatives were synthesized following the same procedure with 2 iminodimethyl-phosphonic acid (Scheme 16) and coated onto titania nanoparticles. ${ }^{187}$

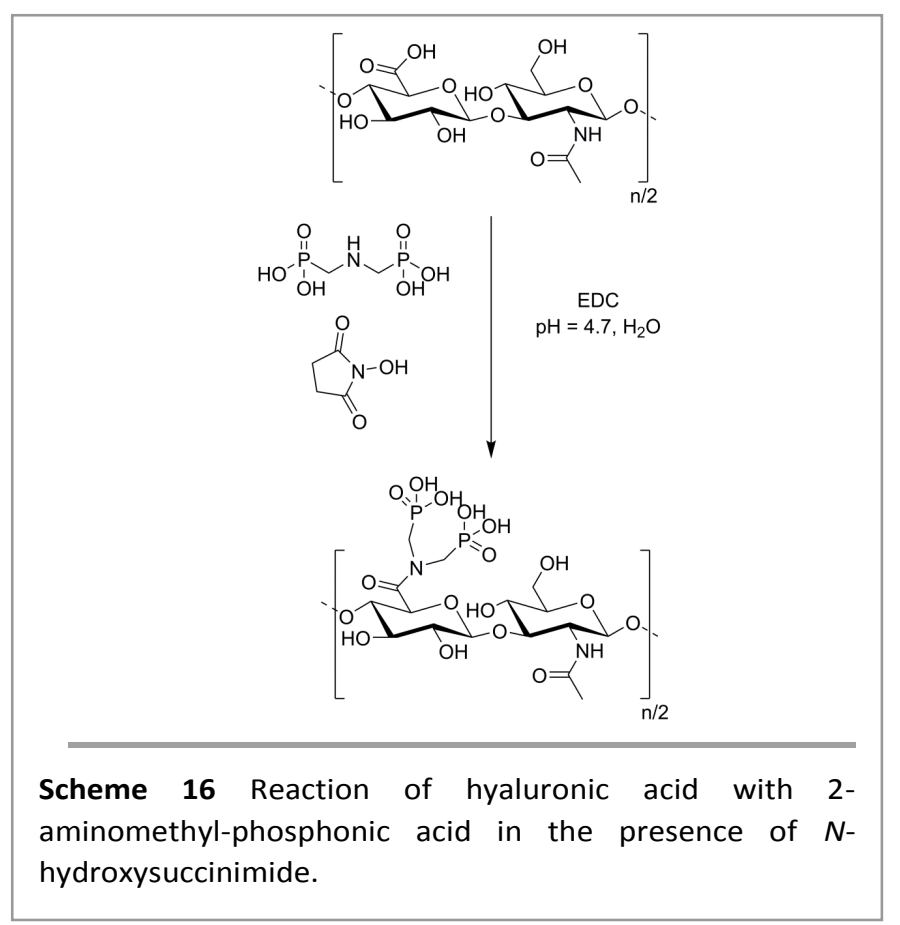

\subsection{Applications of phosphorylated polysaccharides}

For a long time, polysaccharides have been used in a wide range of traditional products from paper to textiles. Therefore, the introduction of phosphorus atoms into polysaccharides backbone has been performed in order to address the technological challenges of these industries. For instance, the use of polyphosphorus or alkyl chlorophosphate compounds as phosphorylating agents has been developed in the field of textile chemistry in order to prepare fireproof fabrics. ${ }^{62}$ Phosphorylated compounds are char-forming materials; they prevent combustion and delay the spread of the fire after ignition. During combustion, phosphorus generates a polymeric form of phosphoric acid. This acid causes a char layer, which acts as a shield protecting the material from oxygen. ${ }^{6}$ The formation of char occurs at the expense of other reactions leading to the formation of combustible volatilized products. Two ways are possible to introduce phosphorus compounds into polysaccharides: either additives are mixed into the polymer or phosphorus moieties are chemically linked to the polysaccharide. Unlike additives, the concentration of chemically linked flame retardants may not decrease during the lifetime of the phosphorylated product and therefore the flame retardancy properties remain stable over time.

Several works deal with the fireproofing of cotton fibers by phosphorylation. Halogenated phosphoruscontaining compounds were commonly used as phosphorylating agent. For example, flame-retardant properties were added to cellulose by reaction of $\mathrm{POCl}_{3}$ in pyridine. ${ }^{188}$ Aoki et al. ${ }^{189}$ reacted cellulose propionate derivatives with alkyl chlorophosphates in pyridine at $40^{\circ} \mathrm{C}$. Phosphated derivatives with degrees of substitution up to 0.96 were synthesized and have demonstrated flame-resistance properties. Cotton fabric was treated with tetramethyl (6-chloro-1,3,5-triazine-2,4-diyl) bis(oxy)bis(methylene) diphosphonate in water-isopropanol solution (50-50), dried and then cured at $140{ }^{\circ} \mathrm{C}$ for $5 \mathrm{~min} .{ }^{190}$ The treated textiles exhibited very good flame-retardant properties (i.e. self-extinguishing material with a LOI of 36 vol\%).

Increasing concerns are emerging concerning the toxicity of halogen-containing compounds, especially due to the close contact of the treated fabrics with the skin. Therefore researchers have to foster halogen-free phosphorus-based compounds. The synthesis of phosphorus-containing graft copolymers from cellulose fibers has been extensively studied. ${ }^{147,}$ 149-151, 153, 155 In particular, nitrogen-and-phosphorus containing monomers allow achieving durable flame retardancy owing to the synergetic effect of P-N. ${ }^{147,149-151,155}$ Nevertheless, if the halogenated compounds are removed from the cotton fiber phosphorylation step, they are still part of the synthesis of the phosphorus containing monomers. Recently, Gashti et al. compatibilized cotton fibers and carbon nanotubes by using vinyl phosphonic acid as cross-linking agent. ${ }^{191}$ Carbon nanotubes are known for their flame- 
retardant properties and since they improve the thermal stability of cotton fabric. Other kind of phosphorylated polysaccharides were also investigated. Chitosan derivatives prepared with $\mathrm{P}_{4} \mathrm{O}_{10}$ were reacted with glycidyl methacrylate and then cross-linked under UV in order to prepare new flame retardant material. ${ }^{192}$

Phosphate groups are known to show excellent chelating properties. Thus, phosphated polysaccharides were used as metal-chelating polymers, as cation exchange materials ${ }^{193}$ and for the treatment of pollution. For example, phosphated chitosan and cellulose were used as adsorbents for uranium ${ }^{64}$ or for various transition metals and lanthanide ions. ${ }^{60}$ Cation exchangers were prepared from cellulose and other natural compounds by reaction in pyridine - dichloromethane. ${ }^{194,195}$

Phosphate bearing chitin derivatives prepared with $\mathrm{P}_{4} \mathrm{O}_{10}$ displayed a very efficient heavy-metal ions adsorption capacity. ${ }^{123,}{ }^{125}$ Water-soluble phosphorylated chitosan derivatives synthesized with $\mathrm{P}_{4} \mathrm{O}_{10}$ were added to phosphate cement systems in order to improve their mechanical properties ${ }^{196}$ or were used as emulsifier. ${ }^{197}$ Phosphorylated starch is water-soluble and a starch-based anionic flocculent has been developed and used in the treatment of drinking water. ${ }^{198}$ Phosphated bacterial cellulose was also used as an adsorbent for proteins. ${ }^{61}$ Mono-starch phosphonates cross-linked with citric acid or succinic anhydride yielded to hydrogels with high water swelling abilities (up to $185 \mathrm{~g} / \mathrm{g}$ ). ${ }^{199}$ The reaction of starch with phosphoric acid and urea under vacuum at 120-150 ${ }^{\circ} \mathrm{C}$ leads to products with phosphate and carbamide moieties. ${ }^{72}$ These cross-linked products show high swelling capacities (up to 50 times its weight) and good metal ion adsorption abilities.

Phosphorus-containing polymers are a great opportunity for the biomedical field as they are often biocompatible, hemocompatible and resistant to protein adsorption. ${ }^{4}$ Thus modified polysaccharides have been considered for numerous applications in the biomedical field. ${ }^{65,200}$ Phosphorylated curdlan product was claimed to be an interesting biological response modifier with possible clinical applications. ${ }^{69,}{ }^{201}$ Phosphorylated xylan, fucoidan and carrageenan displayed good anticoagulant properties. ${ }^{126}$ Water-soluble phosphated curdlan ${ }^{70}$ and (13 )- $\alpha$-D-glucan ${ }^{71}$ exhibited anti-tumor activities whereas native water-insoluble polysaccharides had no bioactivities. Antioxidant properties were introduced on carrageenan by reaction with $\mathrm{POCl}_{3}$ in pyridine formamide. ${ }^{202} 2$-( $\alpha$-arylamino phosphonate)-chitosan (Scheme 14.A) showed significant antifungal activities. ${ }^{177}$ Phosphorylated polysaccharides are good candidate materials for specific use as tissue engineering scaffold material. Indeed, the phosphorylation of the polysaccharides actually tends to improve their biocompatibility $\left(\right.$ bamboo $\left.{ }^{56}\right)$. For instance, phosphorylated cellulose $\left(\mathrm{H}_{3} \mathrm{PO}_{3}\right)$ with a DS close to 1.0 is fully water-soluble and has very good film forming properties. In addition, the film is nontoxic and promote cells proliferation. ${ }^{83}$ Phosphorylated chitin, chitosan or cotton fibres were used as substrates for growing calcium phosphates. ${ }^{59,66,67,84}$ Calcium-phosphate coated films improve the biomineralization processes and therefore the osteointegration. Mucalo et al. have reported that the overall quality of the coating formed on urea- $\mathrm{H}_{3} \mathrm{PO}_{4}$ treated cotton fibres is superior to the one formed on urea- $\mathrm{H}_{3} \mathrm{PO}_{3}$ treated fibres. ${ }^{59}$

Regenerated cellulose surfaces were also phosphorylated by the mixture $\mathrm{H}_{3} \mathrm{PO}_{4}-\mathrm{P}_{2} \mathrm{O}_{5}$ in alcohols - Et $\mathrm{P}_{3} \mathrm{PO}_{4}$. Very high substitution degrees were obtained and cellulose triphosphates have been described for the first time. The phosphorylation enhanced the cellulose surface bioactivity, helped the biomineralization and promoted bone regeneration for future orthopedic applications. ${ }^{203-206}$

Carboxymethyl cellulose with one phosphate group for each disaccharide unit was used to functionalize titanium oxide surfaces and improved their osteointegration. ${ }^{120}$ Similarly, Hydroxypropyl cellulose phosphorylated with polyphosphoric acid (DS = 1.3) demonstrates excellent adhesion onto metallic substrate and efficient corrosion inhibition capabilities, whereas cellulose derivatives without any surface-reactive groups do not build stable layers onto metal surfaces. ${ }^{118}$ Applications in the field of metal implants are considered.

Polysaccharides bearing polar phospholipid-like groups showed excellent hemocompatibility. ${ }^{207}$ Linking $^{2}$ phosphorylcholine groups to polymer usually results in a significant enhancement of their water-solubility. In addition, phosphorylcholine groups have a zwitterionic nature and are of great interest because they exhibit remarkable protein-repelling properties. ${ }^{161}$ For instance, phosphorylcholine substituted chitosan was used in combination with hyaluronan to form robust film by the layer-by-layer process. ${ }^{208}$ Tiera and coll. investigated the interactions between phosphorylcholine-substituted chitosans and DNA and showed that they form polyplexes together. ${ }^{209}$ Phosphorylcholine-substituted chitosans was also used in multi-layer to induce immunocamouflage of red blood cells (protein repelling properties). ${ }^{210}$ The prepared products were non-toxic and have been patented for drug delivery and gene therapy applications.

Anhydrous suspension of phosphorylated polysaccharide particles showed high performance electrorheological effect. ${ }^{63,73,211}$

\subsection{Conclusion}


Numerous papers dealt with the phosphorylation of polysaccharides. The obtained phosphorylated products display very promising properties in various application fields. But the renewable polysaccharide sourcing is very often counterbalanced by the lack of "green-ness" of the phosphorylation processes due to reagent toxicities, non-stoichiometric conditions (excess of phosphorylating reagent), energy-consuming high temperatures and-or volatile organic solvents. Moreover, the final products are often only partially biobased because the phosphorylating agent is not obtained from fully renewable resources. Thus, even if some advances have been achieved toward more environmental friendly processes, improvements are still needed. A future challenge would be to further continue the minimization of the environmental impact of the production.

The structural characterization of the phosphorylated products is also an issue that has to be addressed more carefully. The main chain stability, the functionalization degree and the regioselectivity have to be examined more closely to gain some knowledge on the structure-property relations. For example, living radical polymerization might allow gaining control on the structural design of highly-phosphorylated polysaccharides derivatives. Wellcharacterized phosphorylated polysaccharides may have strong potential for innovative high value and performance products.

\section{Phosphorylation of biophenols}

\subsection{Macromolecular biophenols : Lignins and lignocellulosic materials}

\section{Structure and availability}

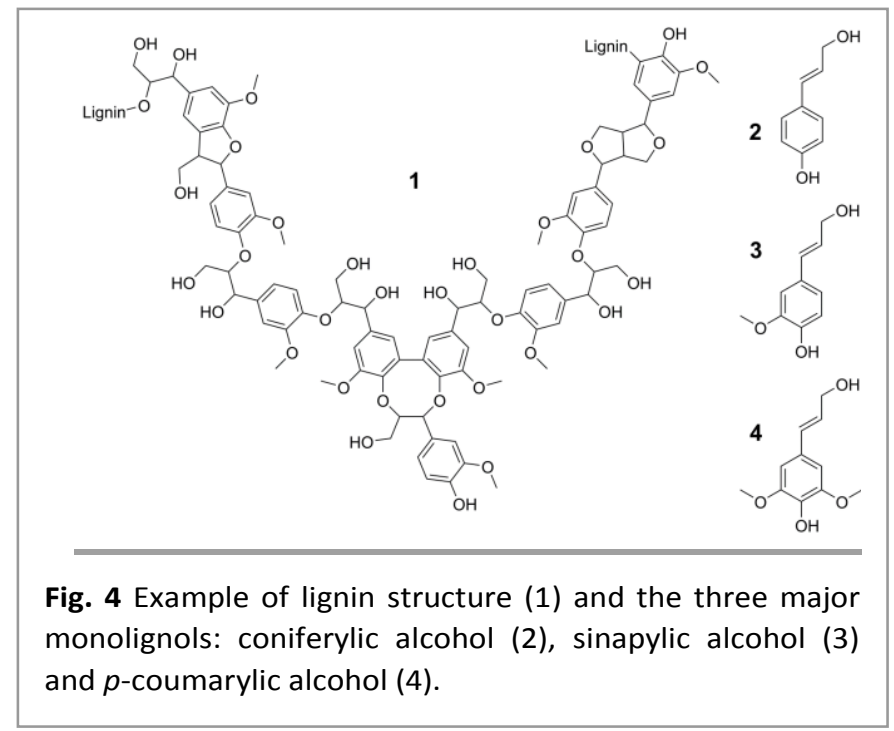

Lignocellulosic biomass such as forest residues or agricultural waste is the most abundant renewable resource for the potential replacement of the fossil raw materials. Lignin is one of its major constituents and represents around $30 \%$ of the organic matter of the biosphere. The lignin is a polyphenolic, highly cross-linked macromolecular polymer (Figure 4). Its structure is not well defined and depends on the resource from which it is extracted. Three different monomers constitute the lignin structures: the coniferylic alcohol, the sinapylic alcohol and the $p$ coumarylic alcohol. Lignin is the only aromatic biobased material and its aromatic structure is essential for many application fields to afford properties such as rigidity or stability.

The chemical treatment of the lignins (by acids, bases or oxidizing agent) aims to reduce the chains size by cleavage of the ether bonds but it also leads to ring hydroxylation by methoxy groups hydrolysis, which increases the number of hydroxy groups on the treated lignin.

\section{Phosphorylation of lignins}

Hydroxy groups are the most present functions on lignins structure and have been widely functionalized since the 1980 's by different chloro-phosphorus containing-compounds through Williamson reaction for different applications.

The reaction of various phospholane chloride 212,213 (Scheme 17.A) with labile proton has been used since the 1980 's. Wroblewski et al. ${ }^{212}$ used this synthesis way in order to define the lignin structure and quantify the hydroxy groups present by quantitative ${ }^{31} \mathrm{P}-\mathrm{NMR}$. 
<smiles>O=P(O)(O)O[Ga]O[Na]</smiles>

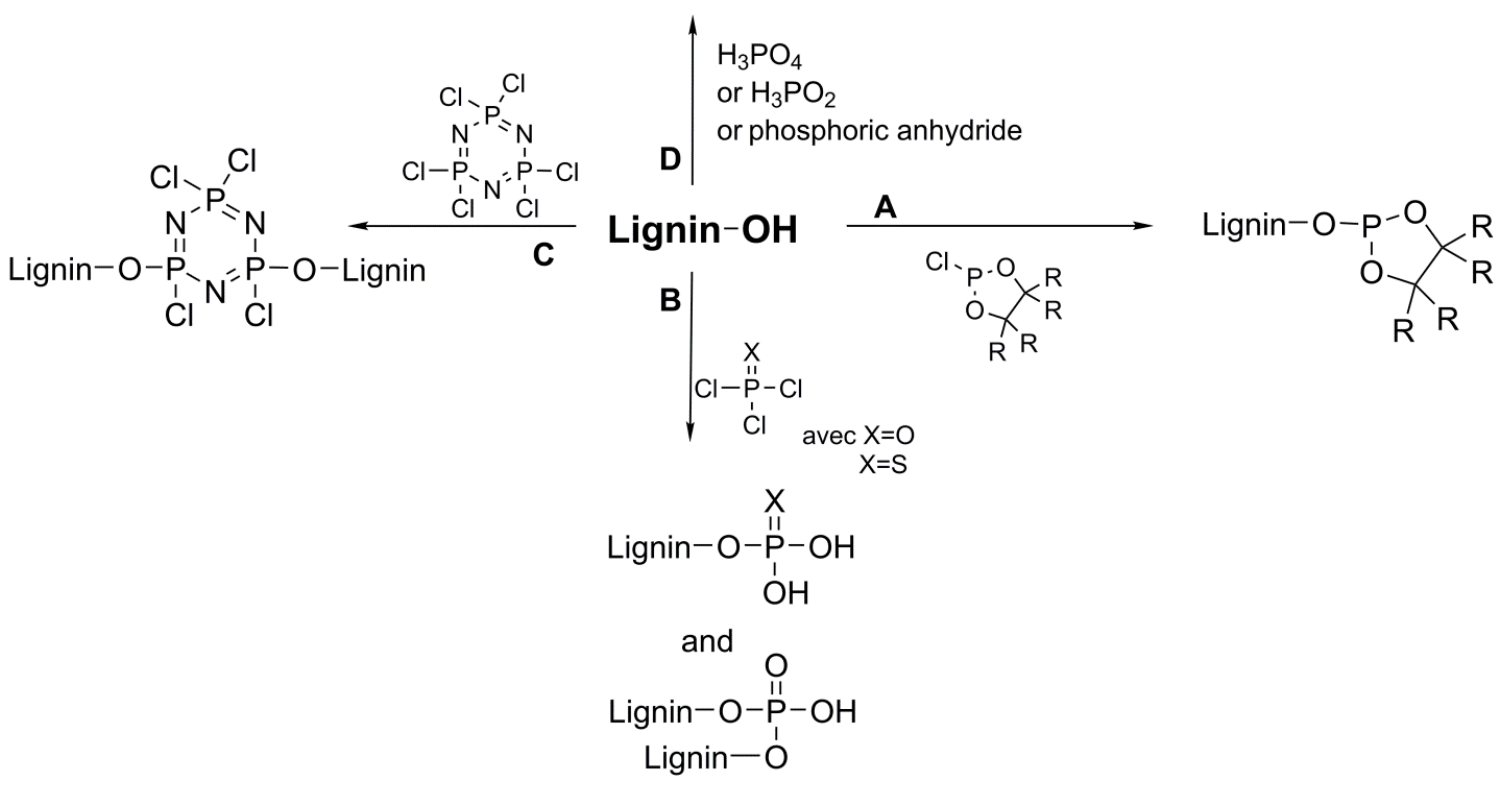

Scheme 17 Phosphorylation of lignins by hydroxy group functionalization.
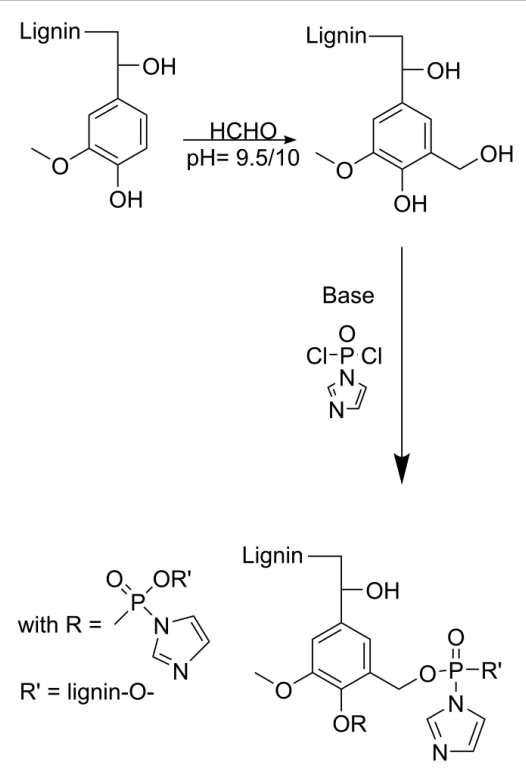

Scheme 18 Increase of the hydroxy group functionality of lignin followed by phosphorylation of modified lignin.

Phosphorylation of lignin's hydroxy groups by Williamson reaction can also be performed with multi halogenatoms containing compounds such as phosphorus oxychloride ${ }^{214}$ or thiophosphorus oxychloride ${ }^{215}$ (Scheme 17.B). The authors reports the formation of $\mathrm{P}$-(O-lignin $)_{2}$ bond, leading to an increased cross-linking rate. Only $(\mathrm{OH})-\mathrm{P}-(\mathrm{O}-$ lignin $)_{2}$ and $(\mathrm{OH})_{2}-\mathbf{P}$-(O-lignin $)_{1}$ bonds formation was reported so far: the formation of $\mathbf{P}$-(O-lignin $)_{3}$ is not favored by steric hindrance. Chlorophosphazene ${ }^{216}$ (Scheme 17.C) has also been used to perform the Williamson grafting leading to nitrogen-phosphorus-containing lignin. Chlorophosphazene played the role of cross-linking agent leading to an increase of the final compound stability but also to a decrease of its solubility. This last synthesis pathway leads to a lignin with equals nitrogen and phosphorus content. However, the syntheses cited used chlorophosphorus containing precursors which are not eco-friendly. Moreover, most of them present some extent of toxicity. 
Nevertheless, hydroxy groups can also be functionalized using phosphoric acid ${ }^{217,218}$, hypophosphoric acid ${ }^{219}$ (Scheme 17.D) or phosphoric anhydride as described in the first part of the review. In these cases the lignin crosslinking was not observed. Furthermore, when the phosphorus reagents are under acid form (i.e. phosphoric acid for instance) high number of polar groups are obtained.

To increase the final phosphorus content of the phosphorylated lignin, $\mathrm{Yu}$ et al. ${ }^{220}$ added a functionalization step prior to phosphorylation. Thus, firstly, formaldehyde was grafted onto the aromatic ring in order to increase the number of hydroxy groups (Scheme 18). Then, the resulting lignin was phosphorylated by grafting phosphorus dichloride compound on hydroxy groups.

Pudovik reaction has also been carried out to graft phosphorus on the lignin structure, allowing to the phosphorus grafting on carbonyl groups of aldehyde functions (Scheme 19). Vasil'eva et al. ${ }^{221}$ carried out the phosphorylation of some model compounds of lignin.

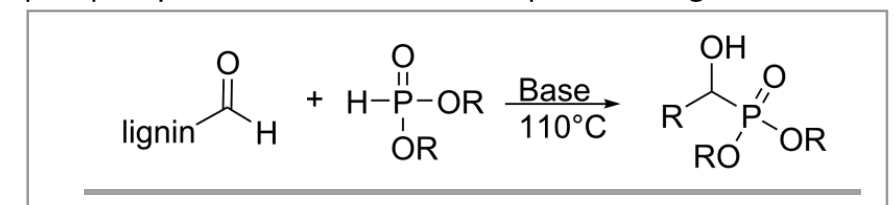

Scheme 19 Phosphorylation of lignin's aldehyde functions by Pudovik reaction.

According to the literature, efficiency of lignins phosphorylation is rather difficult to evaluate because lignin is a natural macromolecule whose chemical structure depends on the resource. The final phosphorus content of the phosphorylated lignins also depends on the type of phosphorylation and the phosphorus-containing precursor used. Among the presented synthesis ways, the phosphorylation using phosphoric acid allows higher final phosphorus content than the synthetic pathways using chloro-phosphorus containing-precursor. The phosphorus content of the modified lignin depends on the hydroxy groups substitution degree. Bykov et al. ${ }^{217}$ used phosphoric acid and obtained a phosphorylated lignin with $16.6{ }_{w} \%$ of phosphorus content, compared to 3.6 w $\%$ of phosphorus using hypophosphorus $\operatorname{acid}^{219}$ and $6-13$ w $\%$ of phosphorus using phosphoric anhydride. ${ }^{174}$

\section{Lignocellulosic phosphorylation}

Thiophosphorylation of lignocellulosic compounds has also been studied. Sanchez et al. ${ }^{222}$ performed the grafting of phosphorus groups in one step by reacting thiophosphoryl chloride on hydroxy groups (Scheme 20). The product was then hydrolyzed to obtain the acid form.

The phosphorylation of lignocellulosic compounds can also proceed in two steps: Davis et al. ${ }^{223}$ firstly realized the halogenation, i.e. brominating or chlorinating the lignocellulosic material, and thereafter reacting the resulting product with triarylphosphite or phosphonate via a Michaelis-Arbuzov reaction (Scheme 21). The extent of phosphorylation was controlled by the amount of alkyl bromide present at the end of the first step.

The phosphorylation is more efficient when using phosphoric acid derivatives instead of halogen-containing ones because (i) toxicity is enhanced by halogen-containing precursor, (ii) phosphoric acid derivatives show higher polarity and (iii) no cross-linking of the modified lignin was observed with phosphoric acid derivatives.

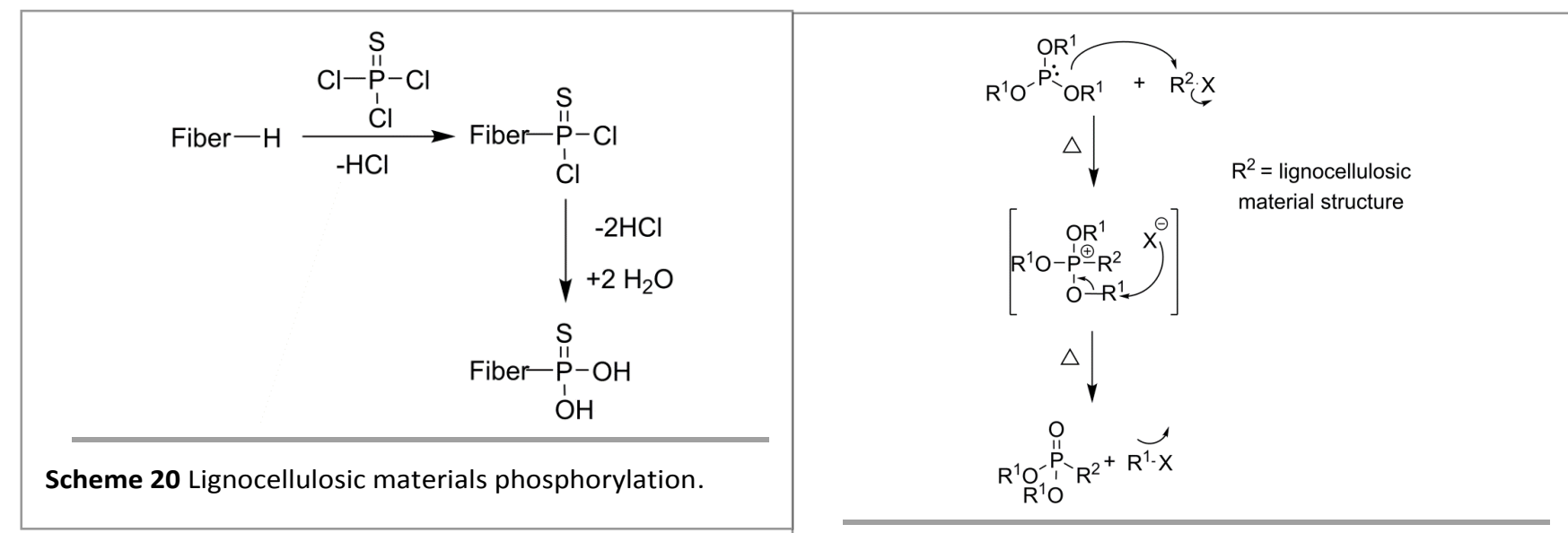

Scheme 21 Phosphorylation of lignocellulosic compound. 
Applications of phosphorylated lignins/lignocellulosic

Except insecticidal activity of the thiophosphorylated lignin prepared by Efanov et al., ${ }^{215}$ the phosphorylated lignins are used in two mains application fields: the polymers flame retardancy and the metals ions complexation. The thermal behavior of lignins modified by chlorophosphazene ${ }^{216}$ was investigated and compared to the raw material. The thermogravimetric and differential thermogravimetric analyses have shown that this type of crosslinked phosphorus-containing polymer was distinctly more thermally resistant than initial lignin raw material. This result can be explained by the flame-retardant action of the modified lignin's phosphorus content. A synergistic effect between phosphorus and nitrogen atoms ${ }^{224}$ can also be considered. The increased cross-linking rate of the modified material may also be responsible of the improved thermal behavior.

The phosphorylated lignin can thus be used as additive polymer flame retardant. Indeed, Yu et al. ${ }^{220}$ realized a lignin phosphorylation and showed that the phosphorus-containing lignin exhibits a much higher char-forming ability. In this case too, the better thermal behavior of the phosphorus-containing lignin can be due to the higher cross-linking brought by the phosphorylation.

Different polypropylene (PP)/phosphorylated-lignin composites were prepared and showed a better thermal stability than PP alone and a higher char rate. This result may be due to the introduction of a cross-linked additive in a linear polymer, which reduces the PP chains mobility, increasing the thermal stability. Moreover, the aromaticity of the lignin favors the charring effect. The Pyrolysis-Combustion Flow Calorimetry (PCFC) analyses show the significant reduction of the maximal heat release rate during thermal decomposition, even for the PPlignin composite. The phosphorus content of the composite seems to only have a slight influence on the fuel gazes production. However, the total heat released during thermal degradation was more reduced for the phosphoruscontaining composites, highlighting the phosphorus flame retardancy.

The other main application field of the phosphorylated lignins is the metal ions complexation. Indeed, the polar phosphorus-containing groups have the ability to form complexes with the metal ions. The sorption capacities of the modified lignins from the different studies are difficult to compare because the ions uptake depends on many parameters such as the concentration of the ions solution and source of the lignin.

Abdel-kader et al. ${ }^{225}$ used phosphorus oxychloride for lignin treatment and determined that the phosphoruscontaining lignin had higher sorption capacity than the raw and carboxylated lignin. This study also shows that sorption ability depends on the radius and electro negativity of the metal ions. ${ }^{214}$ The phosphorylated lignin obtained by Bykov et al. ${ }^{217}$, containing $16,6 \mathrm{w} \%$ of phosphorus, was used as a sorption material for the treatment of wastewaters from atomic industry and of natural waters in contaminated territories to remove toxic metals. The results exhibited high sorption properties. Phosphorylated lignins seem to be good alternative for the preparation of metal ions exchange resins for water treatment.

Other types of raw material have been studied for metals ions exchange: the lignocellulosics including sugarcane bagasse, ${ }^{222,226}$ wood pulp ${ }^{226}$ and sawdust. ${ }^{227}$ Thiophosphorylated lignocellulosic material also presents improved adsorption properties. Sanchez et al. ${ }^{222}$ highlighted these properties toward cadmium ions in aqueous solution and showed that the functionalization of lignocellulosic materials with chelator moieties tailored to heavy metal is an interesting alternative for the use of these residues. 


\subsection{Molecular phenolic compounds}

\section{Structure and availability}

The biophenols studied (Figure 5) are aromatic compounds bearing reactive groups such as hydroxy groups, which can be easily functionalized.

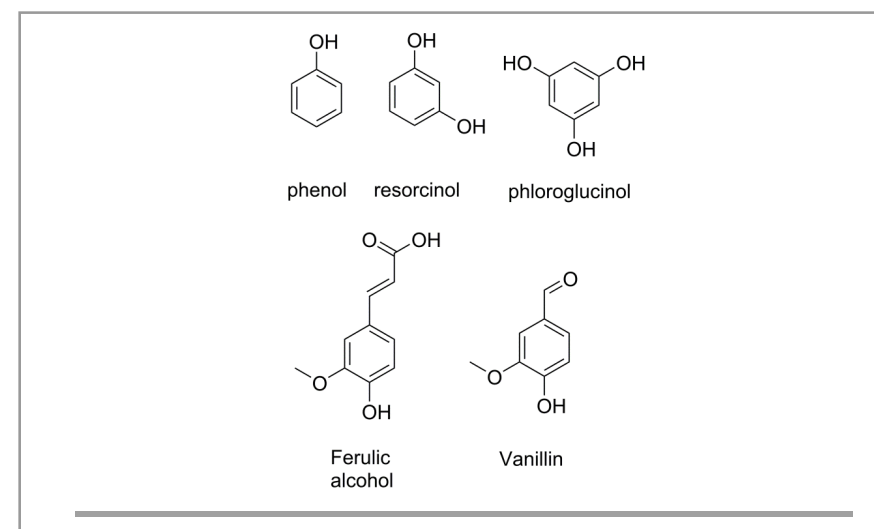

Fig. 5 Some examples of biobased phenolic compounds.

\section{Phosphorylation of molecular phenolic compounds}

Because of their "similar" structure, the synthesis pathways used to graft phosphorus on molecular phenols are similar to that of the lignins. The simplest way to graft phosphorus groups on phenolic compounds is to functionalize the hydroxy groups with chloro-phosphorus compounds from a Williamson reaction in basic medium.

Different oxidation states of phosphorus can be used; indeed this reaction works with chlorophosphate or with dialkyl phosphoryl chloride. Cyclic chloro phosphoryl compounds can be also used: chloro-phosphorus reagent can be prepared via esterification of phosphorus oxychloride by using the adequate alcohol. Vothi et al. ${ }^{228}$ firstly synthesized a cyclic phosphoryl chloride obtained from a diol as shown in Scheme 22.A. The cyclic phosphorus chloride compound was then grafted on hydroxy groups of biobased phenol. Resorcinol and phloroglucinol were functionalized to form bio-based aromatic phosphorus-containing compounds (Scheme 22.B). The biophenol have been partially ${ }^{229}$ (Scheme 22-C) and totally ${ }^{230}$ (Scheme 22-D) functionalized by using diethyl chlorophosphate in the presence of triethylamine in polar solvents and with relatively mild conditions.

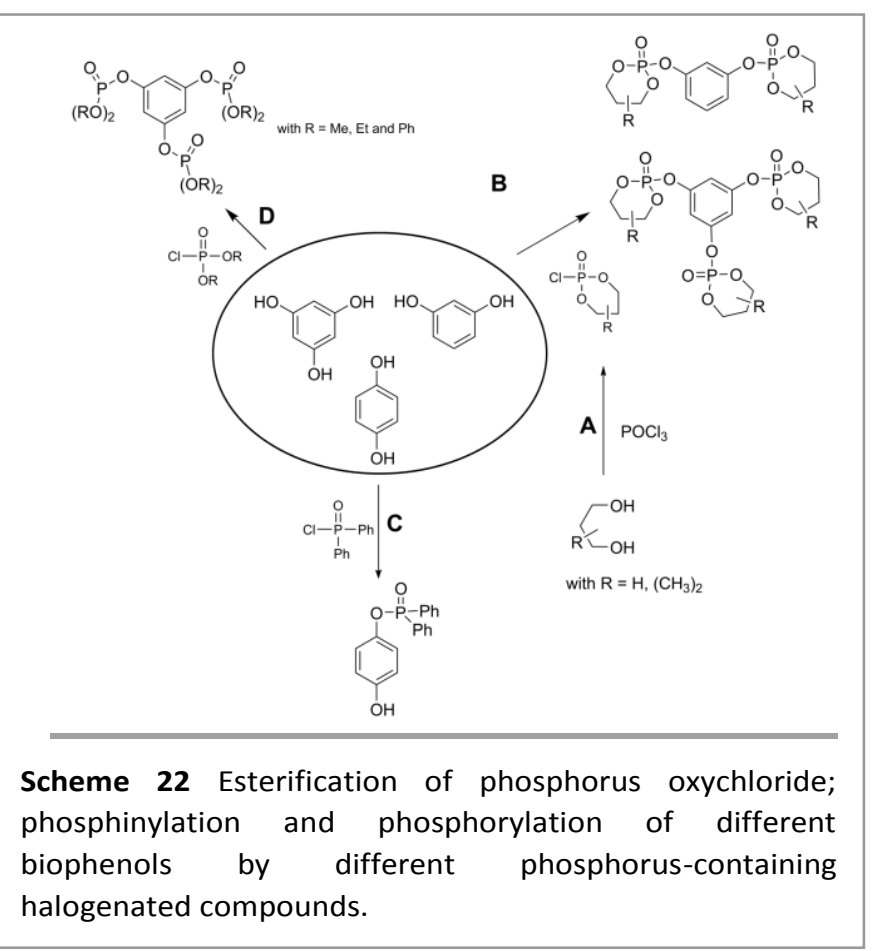




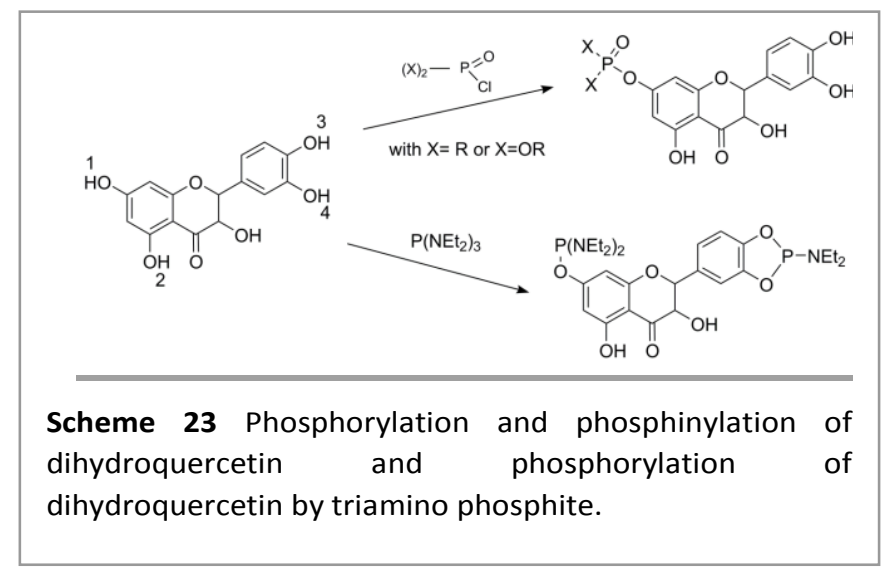

Williamson reaction was also used onto phenolic compounds of higher molecular weight as the flavonoid dihydroquercetin derivatives. Nifant'ev et al. ${ }^{231}$ performed the Williamson reaction of dialkyl chlorophosphate and diphenyl chlorophosphite onto dihydroquercetin as shown in Scheme 23. It was interesting to note that pentavalent phosphorus reagents (chlorophosphate or chlorophosphite) only proceeded onto the most reactive hydroxy groups at the 1-position. Phosphorylation with phosphochloridrates proceeded with low rate. However, the use of microwave radiations allowed higher reaction rate. Another study from the same group ${ }^{232}$ used triamino phosphite to functionalize the hydroxy groups by substitution reaction (Scheme 23).

Delomenède et al. ${ }^{233}$ used a Wittig-Horner reaction between the carbonyl groups of the aldehyde functions of 5,5'-Bisvanillin, obtained from vanillin, and tetraethyl methylene diphosphonate (Scheme 24).

Another method was employed to graft phosphorus groups onto phenolic compounds. The reaction of phosphorus pentoxide on hydroxy groups allowed the formation of a phosphate under the diacid form, which can be functionalized using a primary amine. Toldy et al. ${ }^{234}$ prepared a tris-phosphorylated phloroglucinol by using this method, then the phosphonic product was functionalized with melamine as shown in Scheme 25 .

The amino-phosphate compound obtained by Toldy et al. ${ }^{234}$ is a reactive additive. In fact, its free amino groups

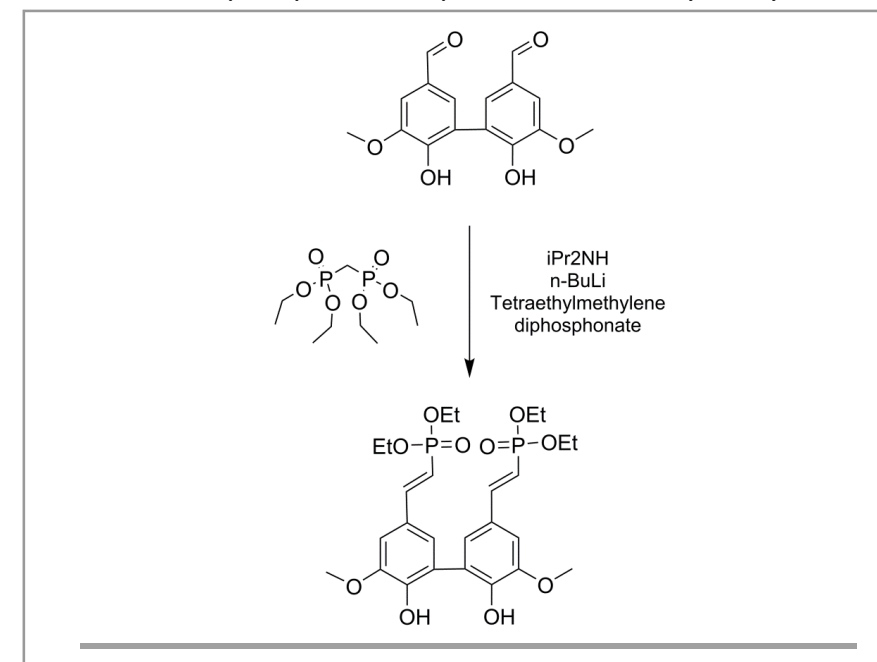

Scheme 24 Wittig-Horner Reaction of 5,5'-Bisvanillin with tetraethyl methylenediphosphonate.

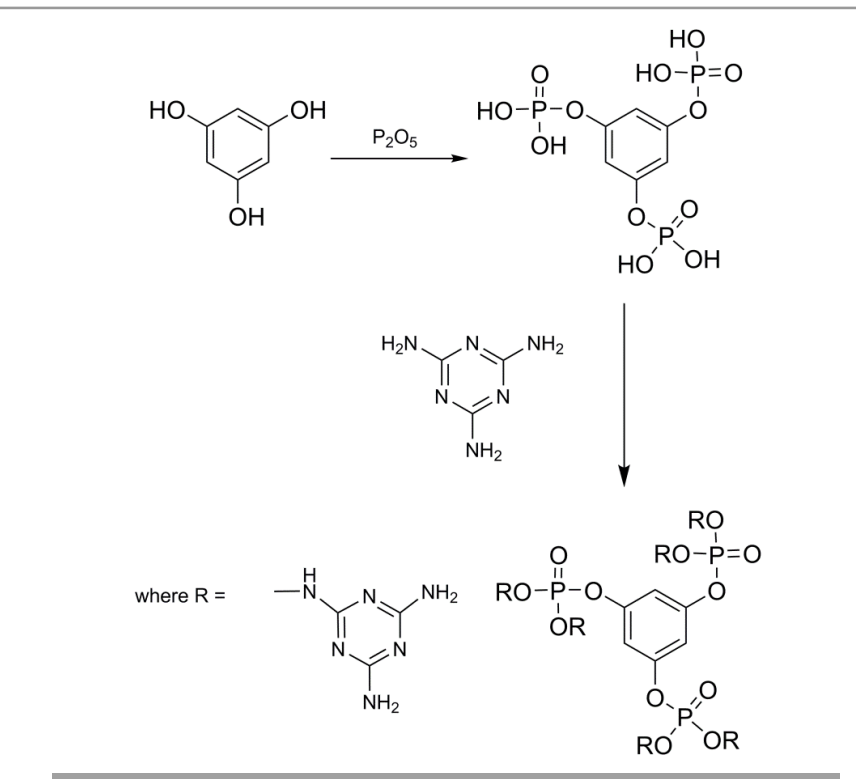

Scheme 25 Phosphorylation of phloroglucinol and grafting by primary amine.

allow reacting with epoxy functions. This product was then used as flame retardant curing agent in epoxy resin formulations in order to improve their thermal behavior. The study showed that the salt form of this comonomer was not suitable for the cross-linking reaction.

Aldehyde groups of biophenols can also be functionalized by a Pudovik reaction. Xie et al. ${ }^{235}$ carried out a twosteps synthesis of novel reactive phosphorus-containing curing agent. The first step consisted in phosphinate grafting, named DOPO (9,10-dihydro-9-oxy-10-phosphaphenanthrene-10-oxide) (thanks to its electrophile $-\mathrm{P}(\mathrm{O})-\mathrm{H}$ group), on the aldehyde function of 4-hydroxy benzaldehyde (4-HBA), followed by nucleophilic substitution with aniline using $p$-TSA (paratoluene sulfonic acid) catalyst (Scheme 26). 

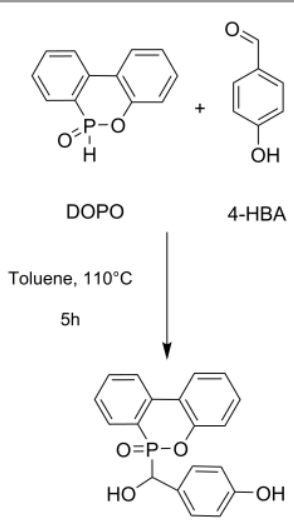

DOPO-HB
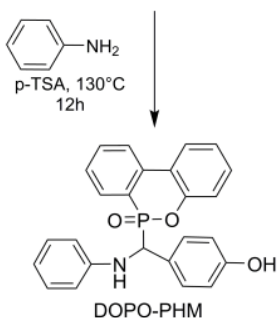

Scheme 26 Phosphorylation of 4-HBA by DOPO.

\section{Applications of phosphorylated molecular phenolic compounds}

The main application of the phosphorus-containing biophenol is the polymer flame retardancy. The aromaticity of these compounds displays an advantage for this type of application as it favors the formation of a high temperature stable char, which is one of the targeted effects for polymers flame retardancy.

Vothi et al. ${ }^{228}$ studied the thermal stability of phloroglucinol containing different phosphate groups and their flame retardant properties in thermoplastic matrices (PC and ABS). The results showed that thermal stability of the flame retardant (FR) is strongly dependent on the type of pendent phosphate group attached to the aromatic ring (Figure 6). It was showed that compounds containing cyclic phosphates started to be degraded at lower temperatures and undergone remarkably great amounts of charred residues at elevated temperature. This effect is probably due to the phosphorus content of the FR. The study also highlighted the effective flame retardancy of some biobased phosphate in thermoplastic matrix.

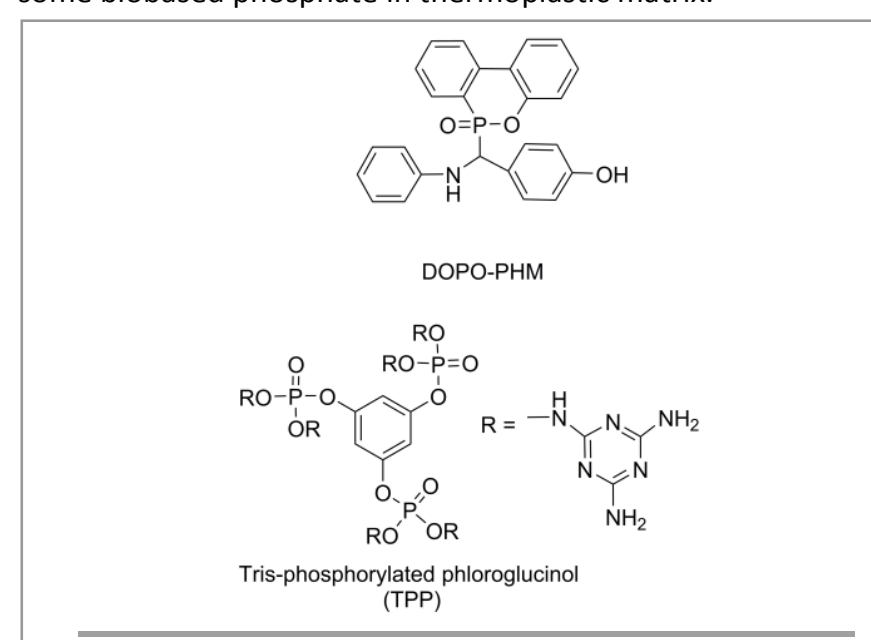

Fig. 6 Structures of the biobased phosphate used as reactive flame retardants.

The flame retardant properties of similar structures have been studied in thermoset matrix. Ménard et al. ${ }^{230}$ prepared different phloroglucinol-based phosphate and characterized their flame retardancy in epoxy thermoset 
matrix. Results highlighted a plasticizing effect of the thermoset matrix by this type of additives. The study confirmed the ability to favor the charring of thermosets during their degradation. Thus, this type of biobased phosphate additive flame retardant could be an alternative to the petro-based ones currently used for the thermosets and the thermoplastics.

The two biobased phosphorus containing compounds (Figure 6) described previously ${ }^{234,236}$ have also been used as reactive flame retardants. Indeed, DOPO-PHM and TPP exhibit reactivity with epoxy groups allowing them to be used as co-curing agent for an epoxy thermoset. The flame retardant properties of the compound DOPOPHM synthesized by Xie et al. ${ }^{236}$ have been evaluated in epoxy matrix. The char yields increased with the increase of the phosphorus content, proving the significant enhancement of materials flame retardancy. A decrease of the cross-linking rate has been observed by measuring the glass transition temperature. Authors attributed these effects to the lower functionality of DOPO-PHM $(f=2)$ compared to the reference curing agent $(f=4)$.

The amino-phosphate TPP compound obtained by Toldy et al. ${ }^{234}$ was also used as reactive flame retardant in epoxy thermoset in combination with montmorillonite nanoparticles. Indeed, its free amino groups enable to react with epoxy functions. This product was then used as flame retardant curing agent in epoxy resin formulations in order to improve their thermal behavior. The thermal analyses results highlighted that an increase of phosphorus content in the material increases the flame retardant properties.

The presented studies showed the ability of biobased phenolic compounds to be efficiently used as flame retardant in different types of polymers, both as additive FR or as reactive FR, which requires another synthesis step to bring reactivity to the compound.

\subsection{Cardanol}

\section{Structure and availability}

The liquid contained within the shell of the cashew nut is called "Cashew Nut Shell Liquid" (CNSL) and is a byproduct of the cashew industry. Cashew nuts themselves grow on trees, Anacardium occidentale, which is native to Brazil and is abundantly available in many parts of the world, such as Brazil, India, and South-East Asia. Natural CNSL contains mainly four components ${ }^{237}$ : anacardic acid, cardanol, cardol, and 2-methyl cardol.

The structures of CNSL components are especially interesting as they all bear an aromatic ring, which is a very stable moiety used in mechanically or thermally demanding applications like fire retardants. They also bear easily functionalizable phenolic hydroxy groups. A long unsaturated hydrocarbon side-chain in the meta position ensures the hydrophobicity of these compounds and their compatibility with oils. Finally, the unsaturations along the chain can also be functionalized.

Commercial-grade CNSL contains hardly any anacardic acid because of its decarboxylation upon heating during the process, leading to cardanol. Cardanol itself is obtained by distillation of CNSL. Additionally, CNSL or cardanol can also be readily hydrogenated to give the corresponding saturated hydrocarbon chains.

The literature reports multiple works dealing with phosphorylation of native or hydrogenated CNSL, cardanol, or cardol. In the vast majority of these works, the reactivity of the phenolic hydroxy groups was used to create a P-O bond and phosphorylation was thus achieved. Applications were centered on thermo-oxidative properties of these phosphorylated compounds, like in fire retardation or radical scavenging applications. The long, pendant hydrocarbon chain makes CNSL derivatives compatible with fuels and oils and thus suitable for applications such as antioxidative additives for lubricants, lubricants themselves or even plasticizers.

\section{Phosphorylation of CNSL and derivatives}


The main reaction to introduce phosphorus-containing moieties onto CNSL or derivatives like cardanol consists in the Williamson reaction $\left(\mathrm{SN}_{2}\right)$ of the phenolate group onto a $\mathrm{P}-\mathrm{Cl}$ bond to yield phenolic (thio)phosphate esters (Scheme 27).

Another synthesis of importance is the preparation of phosphoric acid esters of CNSL and derivatives like cardanol.
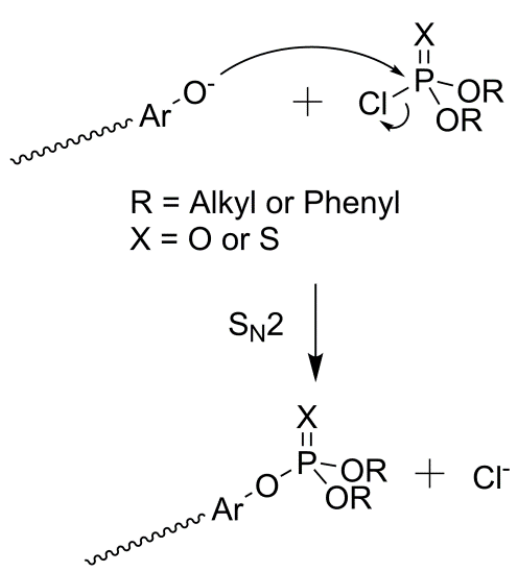

Scheme 27 Williamson reaction between cardanol phenolate and a chloro(thio)phosphate.

The phosphoric acid moiety was introduced onto a hydroxy (either phenolic or introduced in a first step on the unsaturations) by reaction with $\mathrm{P}_{2} \mathrm{O}_{5}$ or $\mathrm{H}_{3} \mathrm{PO}_{4}$ or $\mathrm{POCl}_{3}$ followed by hydrolysis.

It is worthy to note that the reaction with $\mathrm{POCl}_{3}$ led to a dichloride compound that can be further reacted with hydroxy-containing species, including CNSL derivatives themselves.

\section{Applications of phosphorylated CNSL derivatives}

One of the main uses of phosphorylated CNSL derivatives is in fire retardation applications, either as additives or

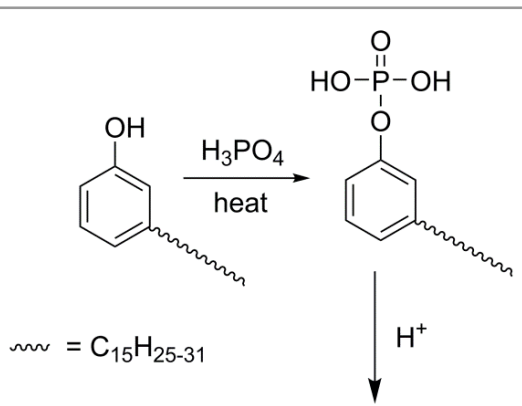<smiles>C[C@H](c1cccc(OP(=O)(O)O)c1)[C@@H](C)c1cccc(OP(=O)(O)O)c1</smiles>

Phosphorylated Cardanol Prepolymer (dimer here)

Scheme 28 Synthesis of phosphorylated cardanol prepolymer.

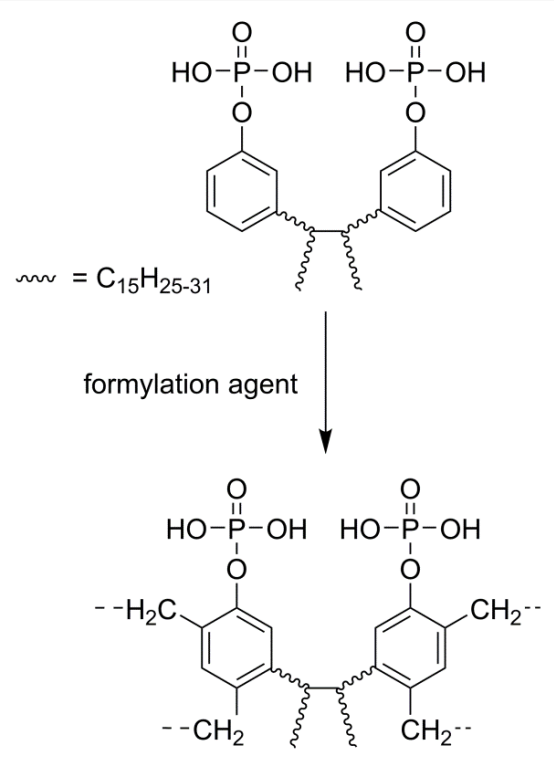

Scheme 29 Cross-linked phosphorylated cardanol prepolymer.

reactive prepolymers. Pillai et al. ${ }^{238}$ reacted cardanol and orthophosphoric acid at $175^{\circ} \mathrm{C}$ to achieve not only the grafting of a phosphoric acid moiety on the phenolic hydroxy groups but also the oligomerization of the cardanol molecules via the unsaturations on the side-chains. The authors obtained Phosphorylated Cardanol Prepolymers (PCP) as shown in (Scheme 28). The same team studied the integration of these PCP to polyethylene ${ }^{239}$ as fire 
retardant additives. The materials prepared displayed improved Limiting Oxygen Index (LOI), validating the fire retardation properties of these PCP additives. This team also employed another strategy by using PCP as a reactive prepolymer to prepare thermosets. ${ }^{238}$ PCP was cross-linked with paraformaldehyde or hexamethylenetetraamine and the authors proposed the structure depicted in Scheme 29 for the materials obtained.

The thermal stability of the materials obtained was studied by TGA. As in all phosphorus-based fire-retardant, the onset of degradation took place at a lower temperature than native cardanol-formaldehyde thermoset, but the residual mass at high temperatures was higher. Materials prepared also displayed a high LOI. The authors concluded that PCP could be used effectively either as a fire retardant additive or as a reactive prepolymer for fire retardant thermosets.

In an interesting but unfortunately poorly detailed patent, Prasad and Pillai ${ }^{240}$ envisaged phosphorylated cardanol derivatives with a higher phosphorus content than the one described above as fire retardant additives. The preparation method mentioned firstly consisted in introducing hydroxy groups on the unsaturations of the chain, followed by the phosphorylation of these hydroxyl groups in a second step, leading to derivatives with potential applications as fire retardants and with LOI > 35 .

Another team adopted the strategy of using phosphorylated cardanol as a co-monomer for the preparation of polyphosphates. ${ }^{241}$ In a first step, cardanol was reacted with $\mathrm{POCl}_{3}$ to obtain the dichlorophosphate ester of cardanol. The second step was about condensing this cardanol derivative with various diphenols (Scheme 30).

The fire retardation properties of the polymers prepared were investigated. Interestingly, thermal stability was found to be independent of molecular weight, indicating a random chain scission mechanism, probably due to the cleavage of $\mathrm{P}-\mathrm{O}$ bonds. The major drawback of this strategy was the use of the $\mathrm{POCl}_{3}$ toxic reactant together with non-renewable co-monomers for the synthesis of these polyphosphates.

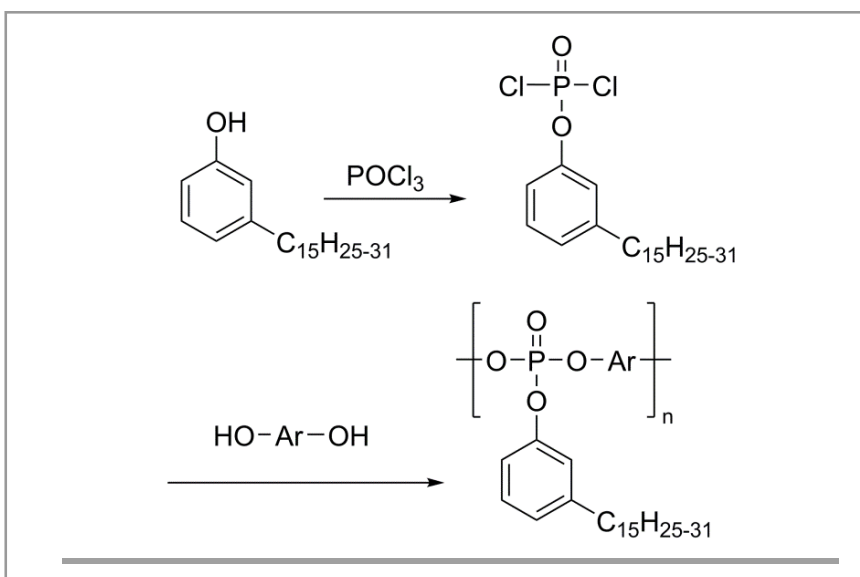

Scheme 30 Synthesis of cardanol-based polyphosphate esters.

The other main application of phosphorylated derivatives of CNSL is as antioxidants. Many authors took advantage of the radical scavenging properties of (thio)phosphate esters. These moieties were introduced by the Williamson reaction already mentioned. Also, the long hydrocarbon chain makes these derivatives highly compatible with oils. These two structural characteristics prompted the use of phosphorylated cardanol derivatives as antioxidants additives for biodiesel, ${ }^{242}$ mineral oils ${ }^{243-247}$ or PMMA films. ${ }^{248}$ The characterizations included TGA and DSC to evidence the initial decomposition temperatures of either pure or formulated additives. Comparison between diphenyl- and diethylphosphate esters of saturated and unsaturated cardanol showed that the phenyl derivatives have a better thermal stability than the ethyl derivatives. ${ }^{242,249}$

An interesting study ${ }^{245}$ also evaluated the potential of a tris(cardanol) phosphate ester (Figure 7) compared to other phenyl- or ethyl- derivatives. This compound did not display significant differences with other phosphate esters. However, thiophosphate esters were found to have an even higher antioxidant effect than phosphate esters. ${ }^{245}$ The authors employed an oxidative stability analysis, in which the mineral oils samples formulated with the phosphorylated cardanol additive were heated at $100{ }^{\circ} \mathrm{C}$ for 164 hours in an $\mathrm{O}_{2}$ flow of $1000 \mathrm{ml} / \mathrm{h}$.

Cardol has the same structure than cardanol but possess a second phenolic hydroxy on the meta position. Thus, a team used cardol to graft two (thio)phosphate ester moieties instead of only one with cardanol. ${ }^{250,251}$ These compounds were also used as additives to mineral oils and the authors concluded that the presence of a second phosphate moiety gave even better results than with only one. 


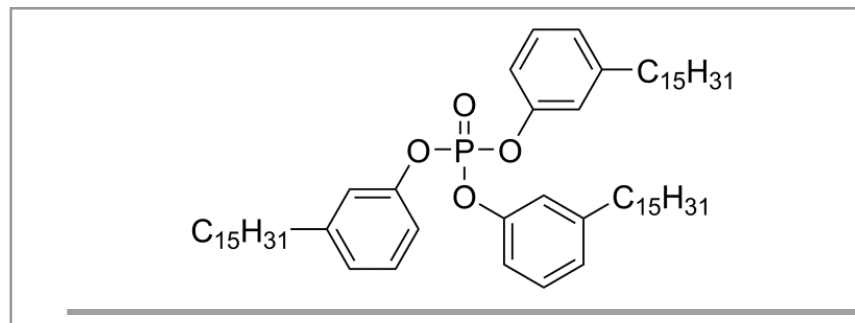

Fig. 7 Tris(cardanol) phosphate ester.

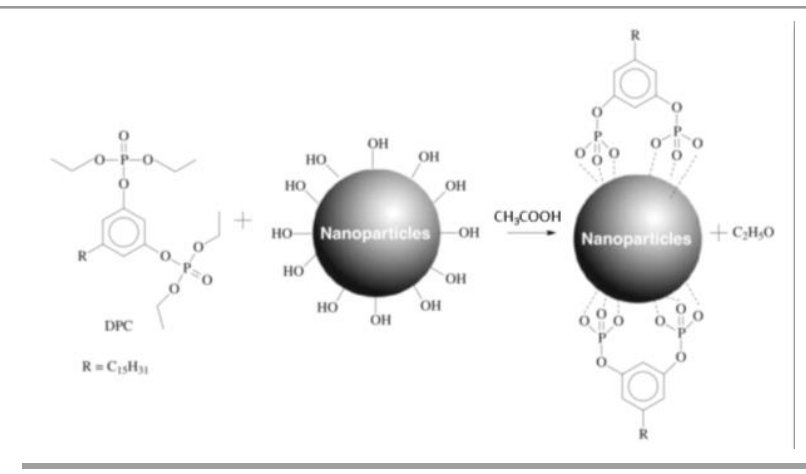

Fig. 8 Grafting of cardanol-based diethylphosphate diester onto magnetic nanoparticles. Reproduced from Ref. 252 with kind permission from Springer Science and Business Media.

Other uses were reported for the phosphorylated derivatives of CNSL, due to the interesting structure of these compounds. For instance, the phosphorus-metal coordination properties can be exploited as illustrated by Barreto et al. ${ }^{252}$ They reported the synthesis of the diethylphosphate diester of cardol and its grafting onto the hydroxy groups found at the surface of magnetic nanoparticles of $\mathrm{Fe}_{3} \mathrm{O}_{4}, \mathrm{CoFe}_{2} \mathrm{O}_{4}$, and $\mathrm{NiFe}_{2} \mathrm{O}_{4}$ (Figure 8). The authors used these coordination properties to synthesize a ferromagnetic fluid. Indeed, due to the coordination of phosphate groups onto the ferromagnetic particles, strong Fe-O-P bonds were formed. Also, stable colloidal particles through steric stabilization were obtained; they consisted in aggregates of the native nanoparticles finely dispersed in the diphosphorylated cardol oil. Among the applications mentioned are magnetic resonance imaging (biological field), or magnetic storage media (industrial field).

A clever use of both the metal coordination properties and high oil compatibility was reported by Mazzatto et al. ${ }^{245}$ The authors used phosphoric acid cardanol derivatives as lubricants (antiwear) for diesel fuels. Authors proposed that the phosphate polar head of these derivatives had strong interactions with the metal parts of the engine and that the pendant hydrocarbon chains created a lubricated layer, reducing the friction. The lubricity capacity of these compounds was evaluated through a High Frequency Reciprocating Rig test, which measures the ability of a fluid to modify friction and wear of surfaces in motion under load. All derivatives tested displayed excellent results.

Another example of an original use of a CNSL phosphorylated derivative was reported by Paul and Pillai. ${ }^{253}$ They prepared phosphoric acid additives for polyanilline (PANI) conducting polymers from different CNSL derivatives. These additives have a plasticization effect due to the pendant alkyl chain of CNSL derivatives and also a doping effect as the protons from phosphoric acid groups are labile and increase the conducting properties of the PANI polymers. CNSL derivatives were reacted on $\mathrm{POCl}_{3}$ and the remaining chlorides were then hydrolyzed to give $\mathrm{P}-\mathrm{OH}$ moieties.

The Phosphorylated Cardanol Prepolymer (Scheme 28) was also blended with natural rubber ${ }^{254}$ in order to improve the processability and vulcanization properties of natural rubber. Significant improvements were observed in mechanical properties and resistance to heat and aging. ${ }^{255}$ The blending of these PCP with natural rubber and subsequent vulcanization was especially interesting for two reasons. The first one is that natural rubber is also biobased. The second reason is that the PCP participated to the cross-linking of the network through the remaining alkyl chain unsaturations during the vulcanization step. PCP acted in this case like a phosphorylated prepolymer rather like an additive. 


\subsection{Conclusion}

Various efforts have been made by the scientific community to prepare phosphorylated derivatives of renewable phenolics. The general functionalization strategies adopted are threefold: 1) direct functionalization of a biopolymer, lignin here. 2) phosphorylation of biophenols (phloroglucinol, cardanol for instance) and their use as additives for polymers. 3) preparation of phosphorylated monomers from biophenols and their polymerization. All three strategies have their advantages and are complementary.

Each considered application has a set of requirements. The underlying idea is always to combine the properties of the natural material and of the phosphorus-containing groups to fulfill them. For example, phosphorylated lignocellulosic materials combine both advantages of containing very stable aromatic groups and being char forming materials. Thus, their use as fire retardant was considered. Some raw materials, for example coming from lignocellulosic biomass, have a complex structure but are very abundant and high volumes are available. Their large-scale utilization is worth considering, for example in waste water treatment when combined with the complexing properties of phosphate groups.

\section{Phosphorylated materials from triglycerides}

\section{Structure and Availability}

A triglyceride is an ester derived from glycerol and three fatty acids found in plants and animals. There are many triglycerides: depending on the oil source, some are highly unsaturated, some less so. The chain lengths of the fatty acids in naturally occurring triglycerides vary, but most contain 16, 18, or 20 carbon atoms. Vegetable oils are one of the cheapest and most abundant, annually renewable natural resources available from various oilseeds, and now are being used in an increasing number of applications. ${ }^{256}$ The carboxylic group and the unsaturations along the chain can be functionalized, for the fatty acids and the hydroxy group can be phosphorylated on the glycerol.

\subsection{From fatty acids or triglycerides}

Providing high values to the resource, phosphorylation of natural oils was a solution. It was possible by different synthetic ways. Depending of the reaction taking place on triglycerides or fatty acids, the available functions were double bonds, hydroxy, carboxylic acids or epoxy functions. These phosphorylated oils obtained by different pathways were used such as monomers for thermosetting resins having long thermal stability properties.

Montero de Espinosa et al. ${ }^{19}$ have reported an original route to obtain phosphorus-containing triglycerides: a photo-oxygenation was realized on high oleic sunflower oil followed by a reduction of the resulting hydroperoxide derivatives to obtain a mixture of secondary allyl alcohols. These allyl alcohols in the presence of chlorodiphenylphosphine led to allyl phosphinites capable by heating to undergo a $[2,3]$-sigmatropic rearrangement, affording tertiary phosphine oxides directly linked to triglyceride in one-pot two-steps reaction (Scheme 31). Acrylation of the obtained phosphorus-containing triglycerides allowed further radical cross-linking in presence of pentaerythritol tetra-acrylate.

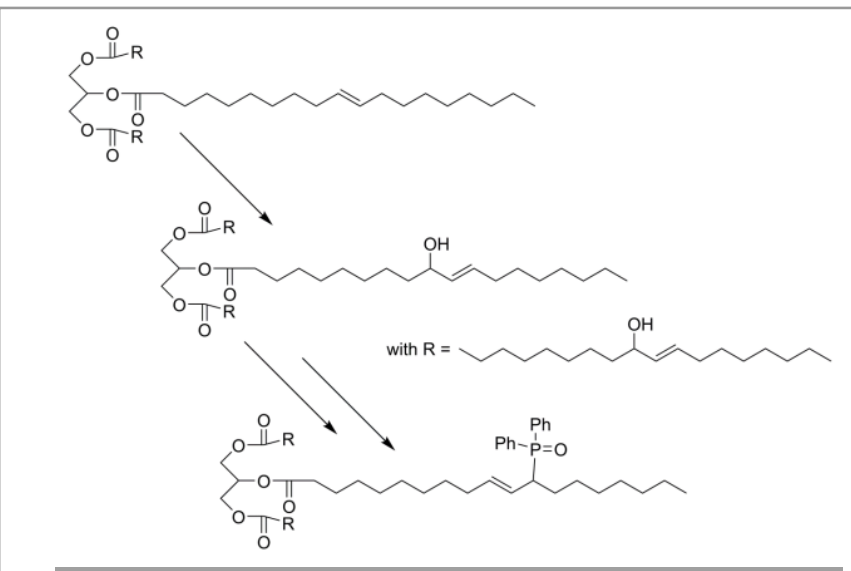

Scheme 31 Synthesis of phosphorylated and acrylated oleic sunflower oil. 
Another solution to directly create a P-C bond onto the fatty acids is the use of Phospha-Michael reaction. Moreno et al. ${ }^{257}$ proposed the addition of a diphenyl phosphine oxide onto the enone derivative of high-oleic sunflower oil (Scheme 32.A). The reaction was investigated under thermal heating with or without catalyst $\left(\mathrm{BF}_{3} \mathrm{OEt}_{2}\right)$ or microwave irradiation allowing the reaction rate increase. The new phosphorus-containing triglyceride was cross-linked to obtain vegetable oil-based thermosets with different phosphorus contents. Moreno et al. ${ }^{258}$ have recently published a similar approach: the preparation through Phospha-Michael addition of a difunctional secondary phosphine oxide, the 1,3-bis(phenylphosphino)propane dioxide on the $\alpha, \beta$-unsaturated ketone derived from high oleic acid. Their aim was first to introduce phosphorus and then cross-link the material in one step with a single product. This reaction took place in presence of boron-catalyst at room temperature or in absence of catalyst at different temperatures $\left(90-140^{\circ} \mathrm{C}\right)($ Scheme $32 . \mathrm{B})$.

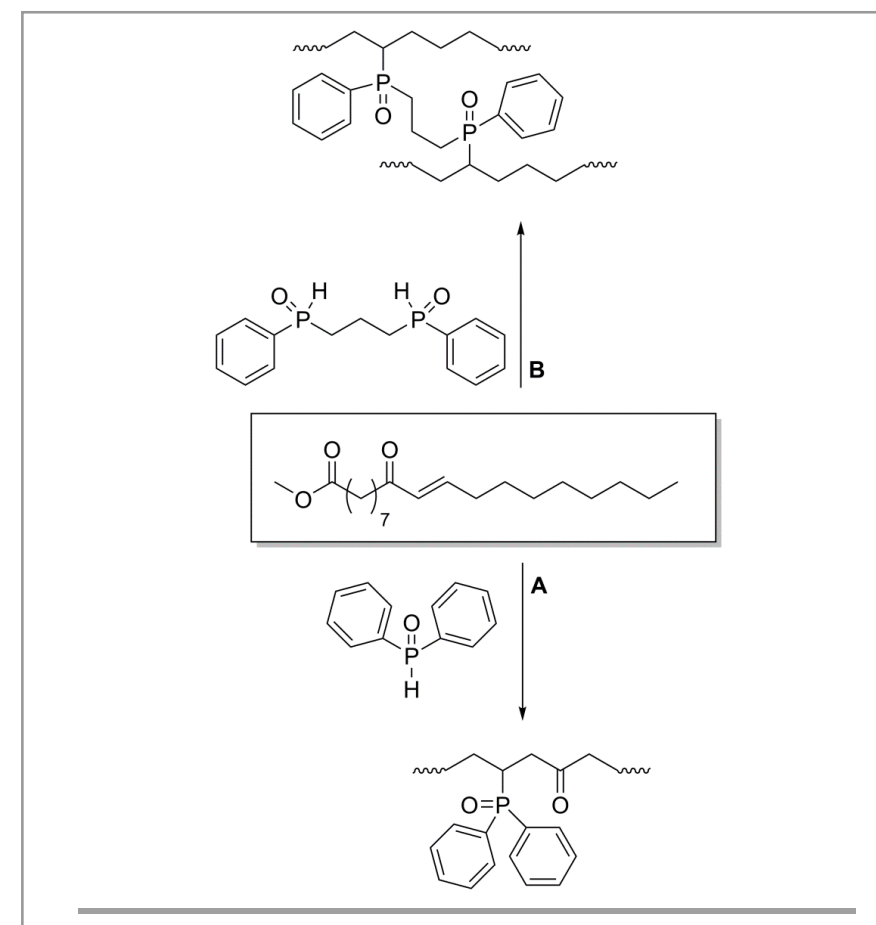

Scheme 32 Phospha-Michael Addition on oleic sunflower oil without $(A)$ or with $(B)$ cross-linking.

Sacristan et al. ${ }^{259}$ have investigated the synthesis of phosphorus-containing soybean-oil copolymers. They have carried out the cross-metathesis reaction of fatty acid (methyl 10-undecenoate) and dimethyl-pvinylbenzylphosphonate or diphenyl styryl phosphine oxide (Scheme 33) to attach the phosphorus moiety to the vegetable-oil derivative. These adducts were incorporated in a styrenic matrix by cationic polymerization with $\mathrm{BF}_{3} \mathrm{OEt}_{2}$ to obtain green thermosets. 
Lligadas et al. $^{260}$ have developed a solution to introduce 9,10-dihydro-9-oxa-10-phosphaphenanthrene-10oxide (DOPO) onto fatty acids structures. As already mentioned above, DOPO is interesting for its flame retardant properties. DOPO was reacted with $p$-benzoquinone to form a phosphonate diol. The hydroxy groups of DOPO derivative were esterified with natural castor oil (Scheme 34.A). With the double bound available from this derivative, Cadiz et al. ${ }^{261}$ explained that acyclic diene metathesis polymerization (ADMET) of a phosphorus-

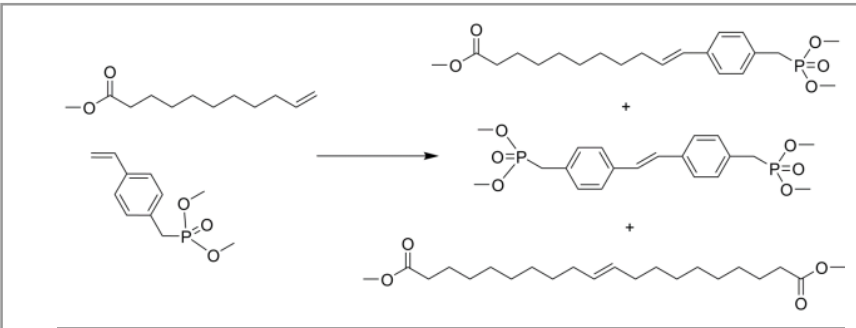

Scheme 33 Synthesis of green reactive phosphonated adduct for styrenic matrix.

containing $\alpha, \omega$-diene afforded a series of phosphorus containing linear polyesters (Scheme 34.B). Or after epoxidation and cross-linking with diamine, a novel phosphorus-containing biobased epoxy resin was realized. ${ }^{260}$

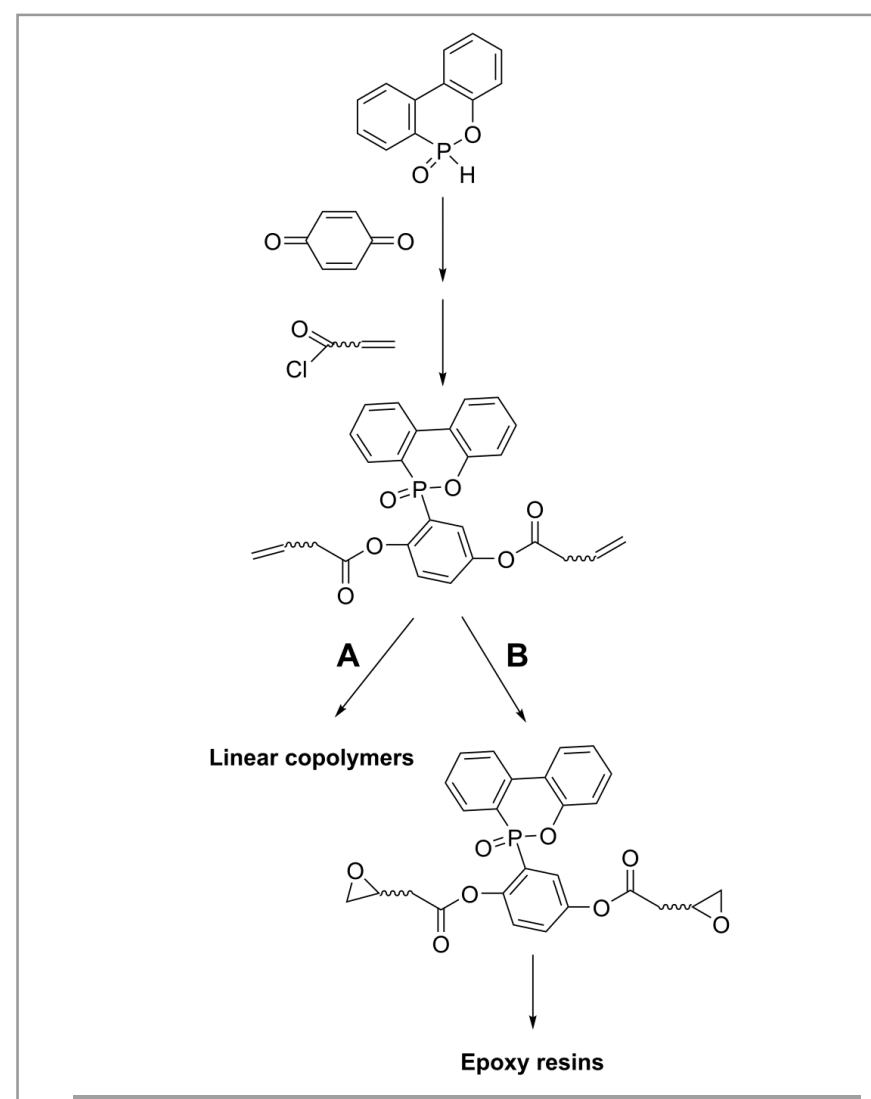

Scheme 34 Synthesis of DOPO-containing reactive FR. Way A: Creation of epoxy networks and Way B: Phosphoruscontaining polyesters via ADMET copolymerization. 
Qiu et al. ${ }^{262}$ have synthesized reactive FR derived from soybean oil by radical addition of DOPO on maleic anhydride followed by esterification of hydroxy groups on acrylated epoxidized soybean. Triglycerides and fatty acids could be chemically modified. Epoxidation is one of the most important functionalization reactions of $\mathrm{C}=\mathrm{C}$ double bonds and opening up the epoxide ring by phosphorus acid was studied. The grafting of phosphorus took place on these epoxy functions. Zhong et al. ${ }^{263}$ have proposed the fully or partially functionalization of epoxidized soybean oils with $\mathrm{H}_{3} \mathrm{PO}_{4}$ at room temperature. The reaction only ran for $30 \mathrm{~min}$ and was exothermic; it stopped when the ratio of phosphate was constant. Basturk et al. ${ }^{264}$ have published phosphorylation of epoxidized soybean oil with vinyl phosphonic acid (VPA). The reaction took place at $80^{\circ} \mathrm{C}$ during 5 hours (Scheme 35).

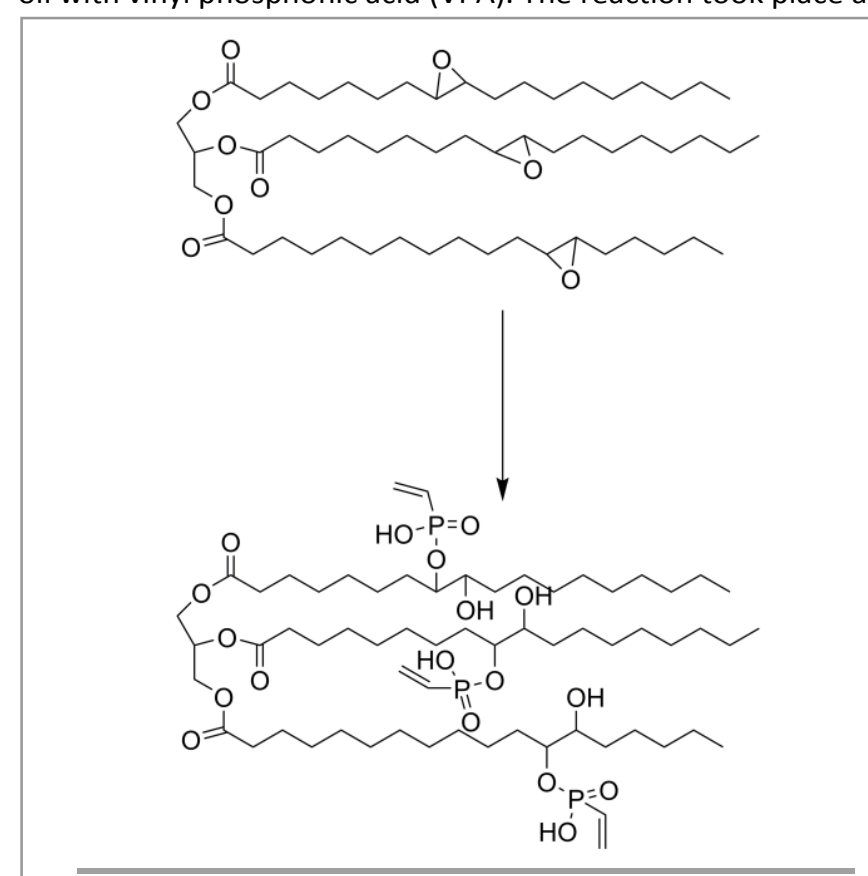

Scheme 35 Synthesis of phosphorylated epoxidized soybean oil.

Some patents described the synthesis by an easy phosphorylation method with $\mathrm{P}_{2} \mathrm{O}_{5}$. Cao and $\mathrm{ZhaO}^{265}$ synthesized phosphorylated ester-exchanged fish oil during 5 hours to obtain a product having monoester/diester molar ratio 4.17/1. Wu et al. obtained phosphorylated lanolin acid by the same method. ${ }^{266,267}$

Bantchev et al. ${ }^{268}$ described the synthesis of three phosphonate derivatives of methyl or ethyl oleates obtained by radical addition (Scheme 36). The phosphonates (different alkoxy groups such as methoxy, ethoxy or n-butoxy) were reacted by elimination of the unsaturation in methyl oleate. A mixture of isomers was obtained with the phosphorus attached at the 9 or 10 -carbon of the stearates. High yields $(>94 \%)$ and high purity products have been obtained in the presence of initiator, while without initiator the reaction proceeded very slowly

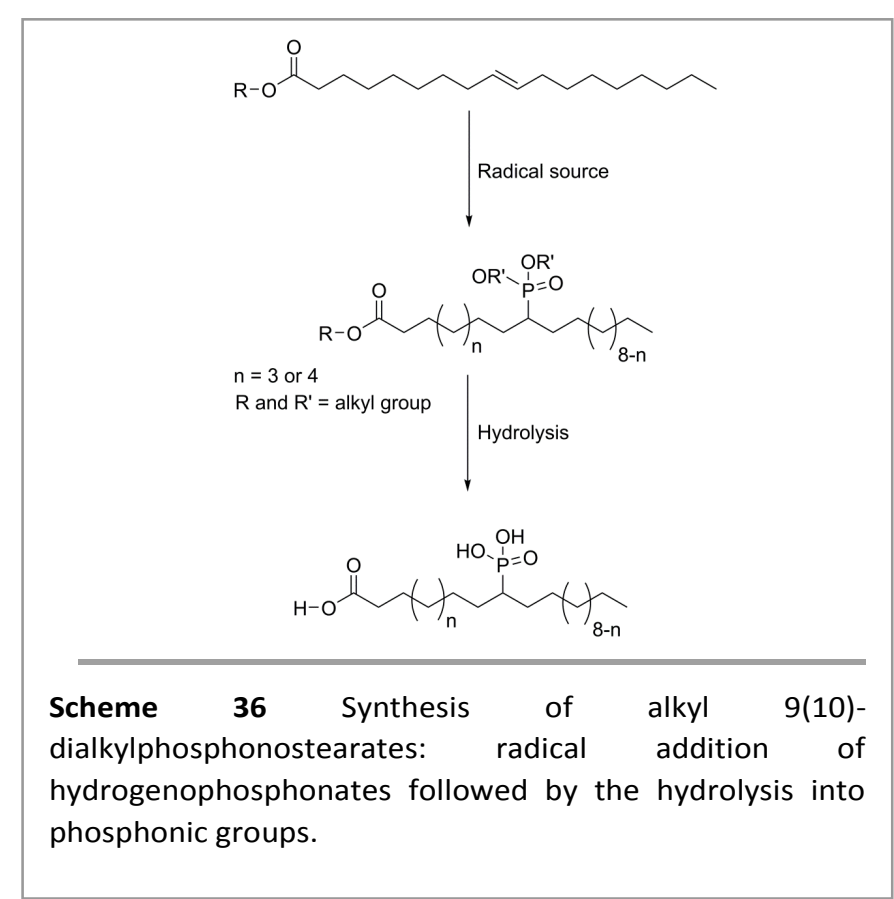


resulting in very low conversions ( $<50 \%$ in 6 days).

Our group ${ }^{269}$ synthesized phosphonic fatty acid just by chemical modification of phosphonate function in phosphonic group. The phosphonation of methyl oleate was carried out in presence of radical initiator (di-tertbutyl peroxide) and two equivalents per double bond of dimethylphosphite at $125^{\circ} \mathrm{C}$ for $12 \mathrm{~h}$ (Scheme 36).

Lastly, Liu et al. ${ }^{270}$ proposed the synthesis of phosphorylated castor oil $\mathrm{POC}$ using $\mathrm{POCl}_{3}$ or chlorophosphates derivative as the phosphorylation reagents on hydroxy function. Herein, a new series of phosphoester cross-linked vegetable oil elastomers with biocompatible vegetable oil (epoxidized linseed oil (ELO) or epoxidized soybean oil (ESO)) as a building block and a biodegradable phosphoester has been prepared. The cross-linking was realized by simply mixing and curing at $37^{\circ} \mathrm{C}$ for $24 \mathrm{~h}$ without any additive.

\section{Applications of phosphorylated oils}

Despite their non-aromatic structure, the main application of these phosphorylated oils was the flame retardancy. Flame retardancy can be reached according to both additive and reactive approaches. After activation by acrylation and fixation of phosphine oxides, the phosphorylated triglycerides obtained by Montero de Espinosa et al. ${ }^{19}$ were polymerized and used in cross-linked polyacrylates for their flame-retardancy properties. The introduction of styrene or divinylbenzene with phosphorylated oils ${ }^{259}$ gives thermosets with only $1 \%$ phosphorus having a limiting oxygen index values about 24, this indicated an improvement in the fire-retardant properties of the soybean-oil-based copolymers. Moreno et al. ${ }^{257} 258$ compared two types of phosphorus-containing sunflower oils as flame retardancy thermoset materials. The LOI values of these thermosets were improved by the incorporation of phosphorus covalently attached to the polymer. LOI values were increased from 21.5 for the phosphorus free material up to 38 for the final material with $4.2 \% \mathrm{P}$ content. With the addition of DOPO, ${ }^{260}$ a phosphorus-containing molecule known for its good flame retardancy properties, good thermal stabilities, important residues and great LOI values were obtained for materials having until $6 \mathrm{w} \%$ of phosphorus.. The SEM study of these materials showed the role of phosphorous for the flame retardant properties: after combustion the phosphorus density increased toward the top burned surface and as a consequence protective phosphorus-rich layer was formed. For all the examples of new flame retardants, the phosphorus function brought with aromatic groups allows balancing the aliphatic chains of triglycerides. These new structures of flame retardant improved the flame resistance both in gas and condensed phases.

Some others applications were also reported in literature where these phosphorylated oils were used as coatings or additives affording specific properties. New soybean oil phosphate ester polyols were used as coatings with excellent impact resistance, good hardness, less severe curing conditions, good thermal properties and lower cost. With a stage of cross-linking under UV, some phosphonated oils were used as flame-retardant curable sol-gel organic-inorganic hybrid coatings. ${ }^{264}$ After hydrolysis of ester functions, the phosphonic acid-bearing oleic acid could also added to a UV-curable methacrylate solution and deposited like a coating on steel substrates for their anti-corrosion properties. ${ }^{269}$

The phosphonate oils were also interesting for their high density and viscosity and improved oxidation stability and cold flow properties. ${ }^{271}$ Lastly, an original application ${ }^{270}$ showing a great potential for phosphoester-oils concerned the preparation of an elastomer with a good elasticity, biodegradability and biocompatibility used as drug delivery systems or implantable materials.

\subsection{From glycerol}

Biobased glycerol is obtained, along with fatty acids (cf. part. II.1), from the hydrolysis of triglycerides. It is a byproduct of the oleochemical and biodiesel industry. About $75 \%$ of the glycerol produced in the US is from natural sources $^{272}$. Biobased glycerol is already industrially available and the technology used for its production is at maturity. Glycerol is also among the twelve top value-added chemicals from biomass identified by US department of Energy ${ }^{272}$ as it is an available and versatile biobased building block (Scheme 37). In particular, it can be used for

$\underset{\text { Scheme } 37 \text { Glycerol and glycidol. }}{\text { glycidol }}$

the synthesis of biobased glycidol.

Glycidol is a compound of interest as it bears an epoxy moiety and could thus be a precursor of biobased epoxy polymers. Liu et al. ${ }^{273}$ prepared an interesting phosphorylated epoxy monomer from glycidol. They used the $\mathrm{SN}_{2}$ 
(Williamson) reaction between the free hydroxy of glycidol and a $\mathrm{P}-\mathrm{Cl}$ bond from phenylphosphonic dichloride (Scheme 38). The product obtained is a diglycidyl phosphonate, i.e. difunctional epoxy monomer, that was cured with various curing agents to give epoxy materials. ${ }^{273,274}$ The phosphonate moiety was then part of the polymer backbone. Phosphonate moieties are widely used in fire retardant materials. The team thoroughly assessed the curing kinetics, thermal and flame retardancy properties of the prepared thermoset. This partially biobased fire retardant epoxy monomer is clearly of great interest.

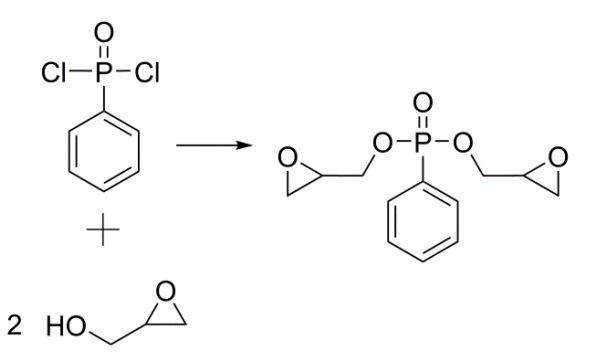

Scheme 38 Synthesis of a phosphorylated diepoxy monomer from glycidol.

\section{Phosphorylation of hydroxy acid compounds}

\subsection{Phosphorylation of Poly(Lactic Acid) (PLA)}

PLA is an aliphatic polyester derived from renewable resources, such as corn starch or sugarcane. It is synthesized either by a direct polycondensation of Lactic Acid (LA), or by a ring-opening reaction of lactide, a cyclic dimer of

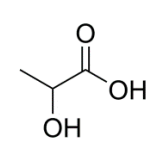

1

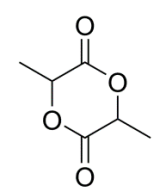

2

Fig. 9 Lactic acid (1) and lactide (2).

lactic acid (Figure 9).

LA is mostly produced by bacterial fermentation of carbohydrates (glucose especially) as it is a natural byproduct of the "glycolysis" pathway. ${ }^{275}$ It is among the top 30 value-added chemicals from biomass. ${ }^{272}$ Two groups, in their attempt to prepare a flame-retarding PLA, included in the backbone a phosphorus-containing compound. On the one hand, Wang et al. ${ }^{276}$ synthesized PLA oligomers in a first step (Scheme 39.1 ) and then used ethyl phosphorodichloridate $\mathrm{O}=\mathrm{PCl}_{2}(\mathrm{OEt}$ ) as a chain extender (Scheme 39.2.A) in a second step.

On the other hand, Yuan et al. ${ }^{277}$ used the same PLA oligomers (Scheme 39.1) but the second step consisted in the copolymerization of these hydroxy-terminated PLA oligomers with a hydroquinone-derivative of DOPO and with a diisocyanate cross-linker (Scheme 39.2B). Authors investigated the thermal properties of the polymers prepared and, in both cases, found that the phosphorylated PLA prepared had better flame retardancy properties than neat PLA.

Once again, however, the main drawback of these works was the use of toxic compounds such as ethyl dichlorophosphate or hexamethylene diisocyanate. PLA is one of the very top candidates when it comes to biobased polymers. However, some improvements still need to be made, especially on the final properties of the material. As shown from these works, the introduction of phosphorus moieties might be a solution to some of these remaining problems. 


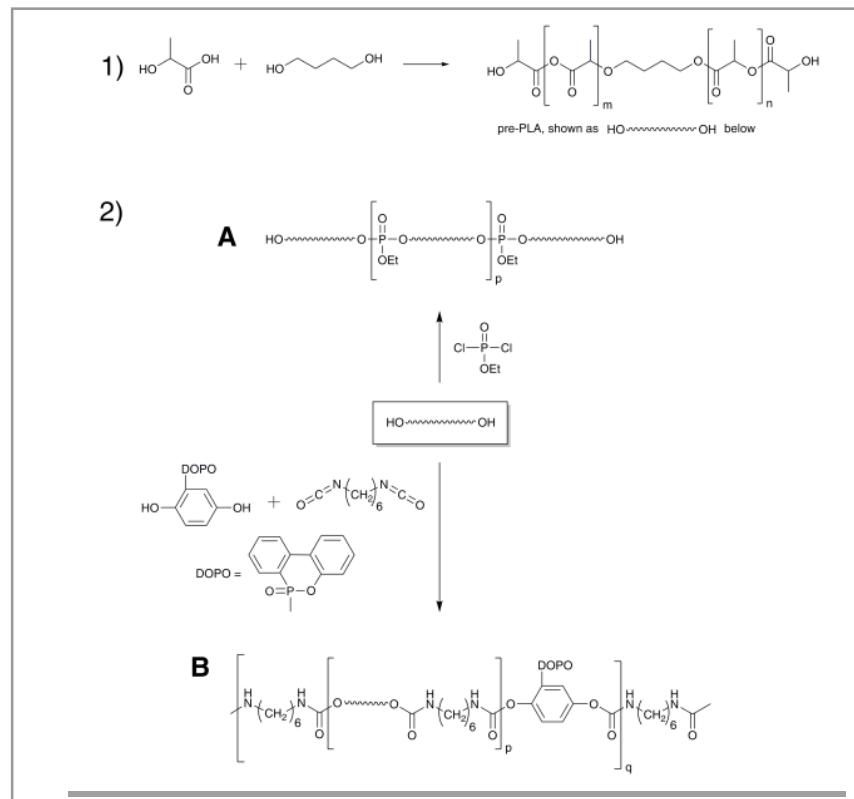

Scheme 39 Preparation of phosphorylated PLA block copolymers.

\subsection{Phosphorylation of tartaric acid}

Tartaric acid (2,3-dihydroxybutanedioic acid) is a degradation product of carbohydrates and occurs naturally in many plants. It is one of the main acids found in wine. It is also the main by-product of grape stock conversion to wine by fermentation. This by-product of the wine industry is a biobased resource with great potential.

Howell et al. prepared phosphorylated tartaric acid. ${ }^{278}$ They reacted the hydroxy groups of diethyltartrate with chlorodiphenylphosphine (Scheme 40) and obtained the diphosphorylated diester. The authors envisaged to use this compound as a plasticizer and fire retardant ${ }^{279,280}$ in polyesters. ${ }^{281}$ This approach seems very interesting in terms of sustainability as tartaric acid is a biomass-derived underused by-product. Its valorization is thus both economically and environmentally profitable.

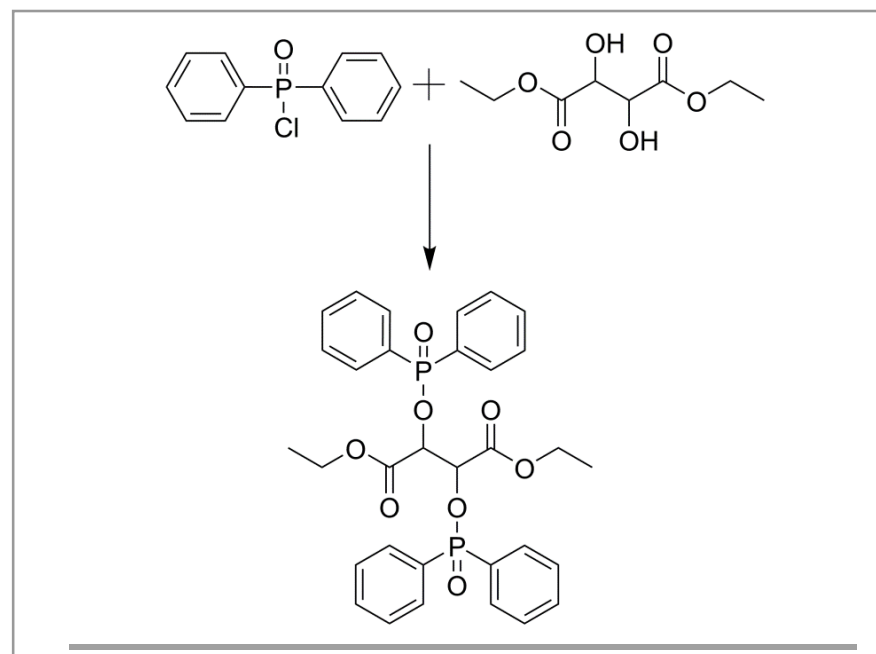

Scheme $\mathbf{4 0}$ Synthesis of phosphorylated tartaric acid. 


\section{Conclusions and perspectives}

During the last decade more than 10000 papers or patents have been devoted to the phosphorus-based polymers. Indeed, the field of phosphorus-based materials is very broad since it concerns a wide variety of polymers, i.e. polyesters, PU, fluoropolymers..., as well as a wide range of applications, i.e. coatings, fireretardants, polyelectrolytes... In the other way, uncertainty in terms of price and availability of petroleum, in addition to global political and institutional tendencies toward the principles of sustainable development, urge chemical industry to a sustainable chemistry. The use of renewable resources has received a great deal of attention, especially in order to synthesize bio-based chemicals and products. Therefore, phosphorylation of biobased compounds becomes of particular interest. This reviewing paper witnesses the large variety of bio-based compounds that have been phosphorylated and focuses particularly on their very promising properties in various application fields.

It is worth noting that these properties are mainly governed both by the structure of the bio-based compounds and by the phosphorus groups chemically bonded to the bio-based compound. Indeed polysaccharides, which are known to be hydrophilic and biocompatible, have been phosphorylated and used for water-treatment (as adsorbents of proteins) as well as for tissue engineering scaffold material. In fact, many researchers already took advantage of the properties combination between polysaccharides and phosphorus groups to afford new biobased materials to be used in the biomedical field or for the treatment of pollution. Phosphorylation of polysaccharides is clearly a key issue due to the specific properties obtained, but also because of their worldwide production. Nevertheless, the structural characterization of phosphorylated polysaccharides still needs to be improved in order to gain knowledge about the structure-properties relationships. Phosphorylation of biophenols and particularly lignin and lignocellulosic materials, due to their strong abundance as reviewable resource, is of particular interest. The main use of phosphorylated lignins is, so far, as flame retardant additive for polymers. Indeed, phosphorylated lignins are high performance flame retardants since the aromatic structure of lignin combined to phosphorus groups afford very efficient char-forming materials. Similarly, some molecular phenolic compounds, most of them obtained from lignin depolymerization, have also been phosphorylated and used as flame retardant additives in different polymers. These compounds have been characterized more precisely than phosphorylated lignins and thus could be an alternative to petro-based flame retardants, currently used for both thermosets and thermoplastics. Phosphorylation of cardanol seems also very attractive. Indeed, the metal coordination properties of phosphorus groups associated to the high oil compatibility of cardanol allowed the synthesis of new bio-based lubricants for diesel fuels. Finally, phosphorylation of fatty acids was also widely developed.

Once again, the combination of the chelating properties of phosphorus with the biocompatibility and the low $\mathrm{T}_{\mathrm{g}}$ of fatty acids afforded new bio-based materials to be used for instance as drug delivery systems. All these examples clearly evidence the positive combination of phosphorus groups with bio-based compounds, thus leading to materials with strongly improved properties compared to those of the neat material. But the renewable compounds sourcing is very often counterbalanced by the lack of "green-ness" of the phosphorylation processes due to reagent toxicities, and thus other synthetic strategies better suiting the green chemistry principles will be also desirable.

Numerous classical organic chemistry reactions have been applied to the phosphorylation of bio-based compounds and have been extensively studied. Therefore, improvements of these reactions or introduction of new methodologies should certainly be rather limited in the near future. Efforts should be focused on a better control and a deep understanding of the final structure of the phosphorylated compounds in order to reach a fine tuning of the properties. This particularly implies improvements of the regioselectivity, of the control of the functionalization density but also of the characterization techniques to precisely know the position of the substituents inside the macromolecules. Researchers might find inspiration in the methods previously developed for the regioselective functionalization of polysaccharides. ${ }^{282}$ "Grafting from" polymerization according to controlled polymerization mechanisms are still an under-explored area in the field of bio-based macromolecules and a promising research axis. Some monomers, such as phospholanes, were scarcely used.

Under the pressure of the public opinion, harsher environmental regulations have been introduced. Chemistry has to find simple, sustainable and efficient production methods to fulfill these new requirements. More and more industries switch partially to the production of fully renewable and biobased compounds. Several bioplastics already are on the market. The development of new industrial processes for the introduction of phosphoruscontaining groups of these preexisting compounds could permit the rapid syntheses of commercially-interesting specialty polymers by combining the intrinsic properties of biobased compounds and of phosphorus atoms. To do 
this, two pathways are conceivable, either the post-functionalization of the preformed macromolecules or the preliminary synthesis of phosphorylated small molecule building blocks. The first solution displays some strong drawbacks such as the difficulty of preparing highly functional materials due to steric or electrostatic hindrances. As shown in this review, the literature displays few examples of the preparation of phosphorus-containing building blocks and of their subsequent covalent assembly. Yet, this pathway allows an easy control on the amount of introduced phosphorus moieties and their homogenous distribution in the material. Therefore, we believe that this pathway should be more intensively studied in the next years.

To address the growing demand for the development of environmentally friendly processes that has recently emerged, the use of a non-toxic biocatalytic approach also offers an alternative to existing and frequently used methods, allowing high atom economy and a work in mild conditions. Phosphorylation of proteins $\left(\mathrm{PO}_{4}{ }^{3-}\right)$ is an important regulatory mechanism, plays a significant role in a wide range of cellular processes and is adaptable to bio-sourced molecules. For example, kinases are enzymes that are able to catalyze the transfer of phosphoryl groups from adenosine triphosphate to organic molecules. Furthermore, biocatalytic processes have proven to be applicable on industrial scale to produce specialty or bulk chemicals. ${ }^{283}$ The combination of chemistry and biochemistry might be the future trend of biobased compounds phosphorylation.

\section{References}

1. Phosphorus-Based Polymers : From Synthesis to Applications, The Royal Society of Chemistry, Cambridge, 2014.

2. H. Frumkin, J. Hess and S. Vindigni, Public Health Reports, 2009, 124, 5-19.

3. A. Gandini and M. N. Belgacem, in Monomers, Polymers and Composites from Renewable Resources, ed. M. N. B. Gandini, Elsevier, Amsterdam, 2008, DOI: http://dx.doi.org/10.1016/B978-0-08-045316-3.00001-6, pp. 1-16.

4. S. Monge, B. Canniccioni, A. Graillot and J.-J. Robin, Biomacromolecules, 2011, 12, 1973-1982.

5. L. Chen, C. Ruan, R. Yang and Y.-Z. Wang, Polymer Chemistry, 2014, 5, 3737-3749.

6. I. van der Veen and J. de Boer, Chemosphere, 2012, 88, 1119-1153.

7. P. Joseph and S. Tretsiakova-Mcnally, Polymers for Advanced Technologies, 2011, 22, 395-406.

8. G. Ilia, Polymers for Advanced Technologies, 2009, 20, 707-722.

9. M. G. Hobbs and T. Baumgartner, European Journal of Inorganic Chemistry, 2007, DOI: 10.1002/ejic.200700236, 3611-3628.

10. A. M. Caminade and J. P. Majoral, Progress in Polymer Science, 2005, 30, 491-505.

11. M. V. Chaubal, A. Sen Gupta, S. T. Lopina and D. F. Bruley, Critical Reviews in Therapeutic Drug Carrier Systems, 2003, 20, 295-315.

12. S. Maiti, S. Banerjee and S. K. Palit, Progress in Polymer Science, 1993, 18, 227-261.

13. A. Michaelis and R. Kaehne, Ber. Dtsch. chem. Ges., 1898, 31, 1048-1055.

14. M. Honjo, Y. Furukawa and K. Kobayashi, Chem Pharm Bull (Tokyo), 1966, 14, 1061-1065.

15. US 3,488,140, 1970.

16. WO9804567A1, 1998.

17. P. L. Granja, L. Pouysegu, M. Petraud, B. De Jeso, C. Baquey and M. A. Barbosa, Journal of Applied Polymer Science, 2001, 82, 3341-3353.

18. T. Sowa and S. Ouchi, Bulletin of the Chemical Society of Japan, 1975, 48, 2084-2090.

19. L. Montero De Espinosa, J. C. Ronda, M. GaliA and V. Cadiz, Journal of Polymer Science, Part A: Polymer Chemistry, 2009, 47, 4051-4063.

20. B. Kaboudin, Journal of Chemical Research, Synopses, 1999, DOI: 10.1039/a900183b, 402-403.

21. S. Pisarek, H. Bednarski and D. Gryko, Synlett, 2012, 23, 2667-2671.

22. A. N. Pudovik and I. V. Konovalova, Synthesis, 1979, DOI: 10.1055/s-1979-28566, 81-96.

23. V. A. Alfonsov, Phosphorus Sulfur Silicon Relat. Elem., 2008, 183, 2637-2644.

24. J. V. Alegre-Requena, E. Marques-Lopez, P. J. Sanz Miguel and R. P. Herrera, Organic \& Biomolecular Chemistry, 2014, 12, 1258-1264.

25. A. N. Pudovik, Zhurnal Obshchei Biologii, 1952, 22, 473-477.

26. K. D. Troev, Chemistry and applications of H-phosphonates, Elsevier Science Ltd, Amsterdam, 2006.

27. L.-B. Han and C.-Q. Zhao, Journal of Organic Chemistry, 2005, 70, 10121-10123.

28. D. Semenzin, G. Etemad-Moghadam, D. Albouy, O. Diallo and M. Koenig, Journal of Organic Chemistry, 1997, 62, 2414-2422. 
29. O. Tayama, A. Nakano, T. Iwahama, S. Sakaguchi and Y. Ishii, Journal of Organic Chemistry, 2004, 69, 54945496.

30. L.-B. Han, F. Mirzaei, C.-Q. Zhao and M. Tanaka, Journal of the American Chemical Society, 2000, 122, 54075408.

31. D. Enders, A. Saint-Dizier, M.-I. Lannou and A. Lenzen, European Journal of Organic Chemistry, 2005, DOI: 10.1002/ejoc.200500593, 29-49.

32. R. Bodalski and K. Pietrusiewicz, Tetrahedron Letters, 1972, DOI: 10.1016/s0040-4039(01)94277-7, 4209-4212.

33. D. Simoni, F. P. Invidiata, M. Manferdini, I. Lampronti, R. Rondanin, M. Roberti and G. P. Pollini, Tetrahedron Letters, 1998, 39, 7615-7618.

34. R. A. Stockland, Jr., R. I. Taylor, L. E. Thompson and P. B. Patel, Organic Letters, 2005, 7, 851-853.

35. E. Maerten, S. Cabrera, A. Kjrsgaard and K. A. Jorgensen, Journal of Organic Chemistry, 2007, 72, 8893-8903.

36. F. R. Atherton, H. T. Openshaw and A. R. Todd, J. Chem. Soc., 1945, DOI: 10.1039/jr9450000660, 660-663.

37. M. I. Kabachnik and T. Y. Medved, Doklady Akademii Nauk, 1952, 83, 689-692.

38. R. A. Cherkasov and V. I. Galkin, Uspekhi Khimii, 1998, 67, 940-968.

39. X.-J. Mu, M.-Y. Lei, J.-P. Zou and W. Zhang, Tetrahedron Letters, 2006, 47, 1125-1127.

40. K. Moedritzer and R. R. Irani, Journal of Organic Chemistry, 1966, 31, 1603-1607.

41. Z. Persin, K. Stana-Kleinschek, T. J. Foster, J. E. G. van Dam, C. G. Boeriu and P. Navard, Carbohydr. Polym., 2011, 84, 22-32.

42. I. Cumpstey, ISRN Organic Chemistry, 2013, 2013, 27.

43. A. Corma, S. Iborra and A. Velty, Chemical Reviews, 2007, 107, 2411-2502.

44. É. Pecoraro, D. Manzani, Y. Messaddeq and S. J. L. Ribeiro, in Monomers, Polymers and Composites from Renewable Resources, ed. M. N. B. Gandini, Elsevier, Amsterdam, 2007, DOI: http://dx.doi.org/10.1016/B978-0-08-045316-3.00017-X, pp. 369-383.

45. A. J. F. Carvalho, in Monomers, Polymers and Composites from Renewable Resources, ed. M. N. B. Gandini, Elsevier, Amsterdam, 2008, DOI: http://dx.doi.org/10.1016/B978-0-08-045316-3.00015-6, pp. 321-342.

46. C. Peniche, W. Argüelles-Monal and F. M. Goycoolea, in Monomers, Polymers and Composites from Renewable Resources, ed. M. N. B. Gandini, Elsevier, Amsterdam, 2008, DOI: http://dx.doi.org/10.1016/B978-0-08045316-3.00025-9, pp. 517-542.

47. G. S. Dhillon, S. Kaur, S. K. Brar and M. Verma, Critical Reviews in Biotechnology, 2013, 33, 379-403.

48. K. Born, V. Langendorff and P. Boulenguer, in Biopolymers Online, Wiley-VCH Verlag GmbH \& Co. KGaA, 2005, DOI: 10.1002/3527600035.bpol5011.

49. L. Liu, Y. Liu, J. Li, G. Du and J. Chen, Microbial Cell Factories, 2011, 10, 99.

50. R. Zhang and K. J. Edgar, Biomacromolecules, 2014, 15, 1079-1096.

51. X.-B. Zhan, C.-C. Lin and H.-T. Zhang, Appl Microbiol Biotechnol, 2012, 93, 525-531.

52. I.-Y. Lee, in Biopolymers Online, Wiley-VCH Verlag GmbH \& Co. KGaA, 2005, DOI: 10.1002/3527600035.bpol5006.

53. T. Liebert, T. Heize and K. J. Edgar, in Cellulose Solvents: For Analysis, Shaping and Chemical Modification, American Chemical Society, 2010, vol. 1033, pp. ix-x.

54. J. D. Reid and L. W. Mazzeno, Industrial and Engineering Chemistry, 1949, 41, 2828-2831.

55. A. Svensson, E. Nicklasson, T. Harrah, B. Panilaitis, D. L. Kaplan, M. Brittberg and P. Gatenholm, Biomaterials, 2005, 26, 419-431.

56. S. H. Li, Q. Liu, J. deWijn, J. Wolke, B. L. Zhou and K. deGroot, J. Mater. Sci.-Mater. Med., 1997, 8, 543-549.

57. O. Petreus, T. Bubulac, I. Petreus and G. Cazacu, Journal of Applied Polymer Science, 2003, 90, 327-333.

58. S. Rungrodnimitchai, The Scientific World Journal, 2014, 2014, 9.

59. M. R. Mucalo, Y. Yokogawa, T. Suzuki, Y. Kawamoto, F. Nagata and K. Nishizawa, J. Mater. Sci.-Mater. Med., 1995, 6, 658-669.

60. T. Oshima, K. Kondo, K. Ohto, K. Inoue and Y. Baba, React. Funct. Polym., 2008, 68, 376-383.

61. T. Oshima, S. Taguchi, K. Ohe and Y. Baba, Carbohydr. Polym., 2011, 83, 953-958.

62. Y. Sekiguchi, C. Sawatari and T. Yagi, Textile Research Journal, 2000, 70, 71-76.

63. B. G. Ahn, U. S. Choi and O. K. Kwon, Polym. Int., 2000, 49, 567-573.

64. T. Sakaguchi, T. Horikoshi and A. Nakajima, Agricultural and Biological Chemistry, 1981, 45, 2191-2195.

65. D. R. Khanal, K. Miyatake, Y. Okamoto, T. Shinobu, M. Morimoto, H. Saimoto, Y. Shigemasa, S. Tokura and S. Minami, Carbohydr. Polym., 2002, 48, 305-311.

66. Y. Yokogawa, J. P. Reyes, M. R. Mucalo, M. Toriyama, Y. Kawamoto, T. Suzuki, K. Nishizawa, F. Nagata and T. Kamayama, J. Mater. Sci.-Mater. Med., 1997, 8, 407-412.

67. H. K. Varma, Y. Yokogawa, F. F. Espinosa, Y. Kawamoto, K. Nishizawa, F. Nagata and T. Kameyama, Biomaterials, 1999, 20, 879-884.

68. K. Wang and Q. Liu, Carbohydr. Res., 2014, 386, 48-56. 
69. D. L. Williams, R. B. McNamee, E. L. Jones, H. A. Pretus, H. E. Ensley, I. W. Browder and N. R. Di Luzio, Carbohydr. Res., 1991, 219, 203-213.

70. X. Chen, X. Xu, L. Zhang and F. Zeng, Carbohydr. Polym., 2009, 78, 581-587.

71. Q. Huang and L. Zhang, Carbohydr. Polym., 2011, 83, 1363-1369.

72. U. Heinze, D. Klemm, E. Unger and F. Pieschel, Starch-Starke, 2003, 55, 55-60.

73. D. P. Park, J. H. Sung, C. A. Kim, H. J. Choi and M. S. Jhon, Journal of Applied Polymer Science, 2004, 91, 17701773.

74. I. Nehls and F. Loth, Acta Polymerica, 1991, 42, 233-235.

75. US2884413, 1959.

76. US2961440, 1960.

77. US2759924, 1956.

78. R. Jayakumar, H. Nagahama, T. Furuike and H. Tamura, International Journal of Biological Macromolecules, 2008, 42, 335-339.

79. R. Jayakumar, T. Egawa, T. Furuike, S. V. Nair and H. Tamura, Polym. Eng. Sci., 2009, 49, 844-849.

80. I. F. Amaral, P. L. Granja and M. A. Barbosa, J. Biomater. Sci.-Polym. Ed., 2005, 16, 1575-1593.

81. N. Inagaki, S. Nakamura, H. Asai and K. Katsuura, Journal of Applied Polymer Science, 1976, 20, 2829-2836.

82. D. M. Suflet, G. C. Chitanu and V. I. Popa, React. Funct. Polym., 2006, 66, 1240-1249.

83. T. Petreus, B. Stoica, O. Petreus, A. Goriuc, C.-E. Cotrutz, I.-V. Antoniac and L. Barbu-Tudoran, J Mater Sci: Mater Med, 2014, 25, 1115-1127.

84. M. R. Mucalo, Y. Yokogawa, M. Toriyama, T. Suzuki, Y. Kawamoto, F. Nagata and K. Nishizawa, J. Mater. Sci.Mater. Med., 1995, 6, 597-605.

85. N. Gospodinova, A. Grelard, M. Jeannin, G. C. Chitanu, A. Carpov, V. Thiery and T. Besson, Green Chem., 2002, 4, 220-222.

86. D. M. Suflet, G. C. Chitanu and J. Desbrières, Carbohydr. Polym., 2010, 82, 1271-1277.

87. D. M. Suflet, A. Nicolescu, I. Popescu and G. C. Chitanu, Carbohydr. Polym., 2011, 84, 1176-1181.

88. J. D. Reid, L. W. Mazzeno and E. M. Buras, Industrial and Engineering Chemistry, 1949, 41, 2831-2834.

89. O. A. Battista and S. Coppick, Text. Res. J., 1947, 17, 419-422.

90. P. J. Baugh, A. G. W. Bradbury and J. B. Lawton, Carbohydr. Res., 1978, 63, 215-222.

91. A. C. Nuessle, F. M. Ford, W. P. Hall and A. L. Lippert, Text. Res. J., 1956, 26, 32-39.

92. E. F. Paschall, Phosphorylation with inorganic phosphate salts. Methods in carbohydrate chemistry., Academic Press Publishers, New York, 1964.

93. Z. F. Zhu, Carbohydr. Polym., 2003, 54, 115-118.

94. M. Z. Sitohy, S. M. Labib, S. S. El-Saadany and M. F. Ramadan, Starch-Starke, 2000, 52, 95-100.

95. M. Z. Sitohy, S. S. El-Saadany, S. M. Labib and M. F. Ramadan, Starch-Starke, 2000, 52, 101-105.

96. J. Zhang and Z.-W. Wang, Industrial Crops and Products, 2009, 30, 105-113.

97. L. Passauer, H. Bender and S. Fischer, Carbohydr. Polym., 2010, 82, 809-814.

98. M. Meiczinger, J. Dencs, G. Marton and B. Dencs, Ind. Eng. Chem. Res., 2005, 44, 9581-9585.

99. N. Moszner, U. Salz and J. Zimmermann, Dental materials : official publication of the Academy of Dental Materials, 2005, 21, 895-910.

100. N. Inagaki and K. Katsuura, Journal of Polymer Science: Polymer Chemistry Edition, 1980, 18, 441-448.

101. N. Inagaki and K. Katsuura, Journal of Polymer Science: Polymer Chemistry Edition, 1978, 16, 2771-2779.

102. E. J. Blanchard and E. E. Graves, Text. Res. J., 2003, 73, 22-26.

103. US3539551, 1970.

104. US2801242, 1957.

105. H. C. Srivastava and M. M. Patel, Starch - Stärke, 1973, 25, 17-21.

106. K. Woo and P. A. Seib, Carbohydr. Polym., 1997, 33, 263-271.

107. S. Lim and P. A. Seib, Cereal Chem., 1993, 70, 137-144.

108. H. Inoue, Y. Baba and M. Tsuhako, Phosphorus Res. Bull., 1993, 3, 61-66.

109. H. Inoue, N. Tone, H. Nakayama and M. Tsuhako, Chemical and Pharmaceutical Bulletin, 2002, 50, 14531459.

110. H. Inoue, Y. Baba and M. Tsuhako, Chem. Phar. Bull., 1995, 43, 677-678.

111. N. A. Landerito and Y.-J. Wang, Cereal Chemistry Journal, 2005, 82, 271-276.

112. Y.-H. Chang and C.-Y. Lii, Journal of Food Science, 1992, 57, 203-205.

113. US4166173, 1979.

114. US4216310, 1980.

115. M. Yalpani, Carbohydr. Polym., 1992, 19, 35-39.

116. N. K. Luneva and A. G. Oputina, Polym. Eng. Sci., 1997, 37, 940-944.

117. D. Klemm, T. Heinze, B. Philipp and W. Wagenknecht, Acta Polymerica, 1997, 48, 277-297. 

830.

120. D. Pasqui, A. Rossi, F. Di Cintio and R. Barbucci, Biomacromolecules, 2007, 8, 3965-3972.

121. US3565886, 1971.

122. S. S. Kim, W. Y. Jeong, B. C. Shin, S. Y. Oh, H. W. Kim and J. M. Rhee, J. Biomed. Mater. Res., 1998, 40, 401406.

123. N. Nishi, Y. Maekita, S.-i. Nishimura, O. Hasegawa and S. Tokura, International Journal of Biological Macromolecules, 1987, 9, 109-114.

124. N. Nishi, A. Ebina, S. Nishimura, A. Tsutsumi, O. Hasegawa and S. Tokura, International Journal of Biological Macromolecules, 1986, 8, 311-317.

125. N. Nishi, S.-i. Nishimura, A. Ebina, A. Tsutsumi and S. Tokura, International Journal of Biological Macromolecules, 1984, 6, 53-54.

126. R. Dace, E. McBride, K. Brooks, J. Gander, M. Buszko and V. M. Doctor, Thrombosis Research, 1997, 87, 113-121.

127. US2328537, 1943.

128. R. Lohmar, J. W. Sloan and C. E. Rist, Journal of the American Chemical Society, 1950, 72, 5717-5720.

129. T. L. Vigo and C. M. Welch, Carbohydr. Res., 1974, 32, 331-338.

130. A. V. Singh and L. K. Nath, International Journal of Biological Macromolecules, 2012, 50, 14-18.

131. G. Cardenas, G. Cabrera, E. Taboada and M. Rinaudo, Journal of the Chilean Chemical Society, 2006, 51, 815-820.

132. S. Meng, Z. G. Liu, W. Zhong, Q. H. Wang and Q. G. Du, Carbohydr. Polym., 2007, 70, 82-88.

133. C. S. Marvel and B. R. Bluestein, Journal of Polymer Science, 1951, 6, 351-358.

134. G. L. Drake, W. A. Reeves and J. D. Guthrie, Text. Res. J., 1959, 270-275.

135. G. Palma, P. Casals and G. Cardenas, Journal of the Chilean Chemical Society, 2005, 50, 719-724.

136. T. Heinze, V. Sarbova and M. Nagel, Cellulose, 2012, 19, 523-531.

137. M. Gericke, P. Fardim and T. Heinze, Molecules, 2012, 17, 7458-7502.

138. W. Xie and L. Shao, Starch - Stärke, 2009, 61, 702-708.

139. H. T. Vo, Y. J. Kim, E. H. Jeon, C. S. Kim, H. S. Kim and H. Lee, Chem.-Eur. J., 2012, 18, 9019-9023.

140. M. Yalpani, Polymer, 1993, 34, 1102-1105.

141. K. Manoi and S. S. H. Rizvi, Carbohydr. Polym., 2010, 81, 687-694.

142. US2610953, 1952.

143. G. C. Daul, J. D. Reid and R. M. Reinhardt, Industrial \& Engineering Chemistry, 1954, 46, 1042-1045.

144. F. Masuko, C. Mitani and M. Sakamoto, Sen-I Gakkaishi, 1998, 54, 185-197.

145. F. Masuko, C. Mitani and M. Sakamoto, Fire Mater., 2002, 26, 225-234.

146. K. Ishihara, N. Nakabayashi, K. Fukumoto and J. Aoki, Biomaterials, 1992, 13, 145-149.

147. H. A. Cheema, A. El-Shafei and P. J. Hauser, Carbohydr. Polym., 2013, 92, 885-893.

148. H. Chen, Y. C. Nho and A. S. Hoffman, J. Biomater. Sci.-Polym. Ed., 2004, 15, 841-849.

149. S. K. Verma and I. Kaur, Journal of Applied Polymer Science, 2012, 125, 1506-1512.

150. M. J. Tsafack and J. Levalois-Grutzmacher, Surf. Coat. Technol., 2006, 201, 2599-2610.

151. B. Edwards, A. El-Shafei, P. Hauser and P. Malshe, Surface and Coatings Technology, 2012, 209, 73-79.

152. W. Xing, G. Jie, L. Song, S. Hu, X. Lv, X. Wang and Y. Hu, Thermochimica Acta, 2011, 513, 75-82.

153. K. Opwis, A. Wego, T. Bahners and E. Schollmeyer, Polym. Degrad. Stabil., 2011, 96, 393-395.

154. L. F. Yan and K. Ishihara, J. Polym. Sci. Pol. Chem., 2008, 46, 3306-3313.

155. I. Kaur and S. K. Verma, Surf. Coat. Technol., 2010, 205, 2082-2090.

156. L. Ma, G. H. Li, L. M. Li and P. Liu, International Journal of Biological Macromolecules, 2010, 47, 578-581.

157. L. Ma, K. Li, L. Li and P. Liu, Chinese Journal of Chemistry, 2012, 30, 413-417.

158. R. Zeng, H. Fu and Y. Zhao, Macromolecular Rapid Communications, 2006, 27, 548-552.

159. B. O. Jung, C. H. Kim, K. S. Choi, Y. M. Lee and J. J. Kim, Journal of Applied Polymer Science, 1999, 72, 1713-1719.

160. H. Kang, Y. Cai, J. Deng, H. Zhang, Y. Tang and P. Liu, European Polymer Journal, 2006, 42, 2678-2685.

161. A. Zhu, S. Wang, Y. Yuan and J. Shen, Journal of Biomaterials Science, Polymer Edition, 2002, 13, 501-510.

162. M. J. Tiera, X.-P. Qiu, S. Bechaouch, Q. Shi, J. C. Fernandes and F. M. Winnik, Biomacromolecules, 2006, 7, 3151-3156.

163. A. Heras, N. M. Rodriguez, V. M. Ramos and E. Agullo, Carbohydr. Polym., 2001, 44, 1-8.

164. G. L. Matevosyan, Y. S. Yukha and P. M. Zavlin, Russian Journal of General Chemistry (Translation of Zhurnal Obshchei Khimii), 2003, 73, 1725-1728. 
165. V. M. Ramos, N. M. Rodriguez, M. F. Diaz, M. S. Rodriguez, A. Heras and E. Agullo, Carbohydr. Polym., 2003, 52, 39-46.

166. V. M. Ramos, N. M. Rodriguez, M. S. Rodriguez, A. Heras and E. Agullo, Carbohydr. Polym., 2003, 51, 425429.

167. V. M. Ramos, N. M. Rodriguez, I. Henning, M. F. Diaz, M. P. Monachesi, M. S. Rodriguez, A. Abarrategi, V. Correas-Magana, J. L. Lopez-Lacomba and E. Agullo, Carbohydr. Polym., 2006, 64, 328-336.

168. Y. J. Yin, X. Y. Luo, J. F. Cui, C. Y. Wang, X. M. Guo and K. D. Yao, Macromolecular Bioscience, 2004, 4, $971-$ 977.

169. F. Lebouc, I. Dez and P. J. Madec, Polymer, 2005, 46, 319-325.

170. D. W. Zhu, J. G. Bo, H. L. Zhang, W. G. Liu, X. G. Leng, C. X. Song, Y. J. Yin, L. P. Song, L. X. Liu, L. Mei, X. L. Li, Y. Zhang and K. De Yao, Chinese Chemical Letters, 2007, 18, 1407-1410.

171. K. D. Demadis, A. Ketsetzi, K. Pachis and V. M. Ramos, Biomacromolecules, 2008, 9, 3288-3293.

172. K. D. Demadis, K. Pachis, A. Ketsetzi and A. Stathoulopoulou, Advances in Colloid and Interface Science, 2009, 151, 33-48.

173. A. Zuniga, A. Debbaudt, L. Albertengo and M. S. Rodriguez, Carbohydr. Polym., 2010, 79, 475-480.

174. P. Datta, S. Dhara and J. Chatterjee, Carbohydr. Polym., 2012, 87, 1354-1362.

175. M. S. Rodrìguez, L. Albertengo, M. Etcheverry and P. C. Schulz, Colloid Polym Sci, 2005, 283, $1298-1304$.

176. N. Illy, G. Couture, R. Auvergne, S. Caillol, G. David and B. Boutevin, RSC Adv., 2014, 4, 24042-24052.

177. Z. Zhong, P. Li, R. Xing, X. Chen and S. Liu, International Journal of Biological Macromolecules, 2009, 45, 255-259.

178. R. Jayakumar, R. L. Reis and J. F. Mano, Journal of Macromolecular Science Part a-Pure and Applied Chemistry, 2007, 44, 271-275.

179. R. Jayakumar, R. L. Reis and J. F. Mano, Journal of Bioactive and Compatible Polymers, 2006, 21, 327-340.

180. L. Wang, X. Xu, S. Guo, Z. Peng and T. Tang, International Journal of Biological Macromolecules, 2011, 48, 375-380.

181. A. Guo, F. Wang, W. Lin, X. Xu, T. Tang, Y. Shen and S. Guo, International Journal of Biological Macromolecules, 2014, 67, 163-171.

182. C. Qian, X. Xu, Y. Shen, Y. Li and S. Guo, Carbohydr. Polym., 2013, 97, 676-683.

183. N. Illy, S. Benyahya, N. Durand, R. Auvergne, S. Caillol, G. David and B. Boutevin, Polym. Int., 2014, 63, 420-426.

184. N. Illy, M. Robitzer, R. Auvergne, S. Caillol, G. David and B. Boutevin, J. Polym. Sci. Pol. Chem., 2014, 52, 39-48.

185. F. Lebouc, I. Dez, M. Gulea, P. J. Madec and P. A. Jaffres, Phosphorus Sulfur Silicon Relat. Elem., 2009, 184, 872-889.

186. R. Barbucci, E. Arturoni, G. Panariello and C. Di Canio, Journal of Biomedical Materials Research Part A, 2010, 95A, 58-67.

187. D. Pasqui, L. Golini, C. D. Giovampaola, A. Atrei and R. Barbucci, Biomacromolecules, 2011, 12, $1243-1249$.

188. C. F. Cullis, M. M. Hirschler and R. G. Madden, European Polymer Journal, 1992, 28, 493-497.

189. D. Aoki and Y. Nishio, Cellulose, 2010, 17, 963-976.

190. T.-M. D. Nguyen, S. Chang, B. Condon, M. Uchimiya, E. Graves, J. Smith, M. Easson and P. Wakelyn, Polymers for Advanced Technologies, 2012, 23, 1036-1044.

191. M. P. Gashti and A. Almasian, Compos. Pt. B-Eng., 2013, 45, 282-289.

192. S. Hu, L. Song, H. Pan, Y. Hu and X. Gong, Journal of Analytical and Applied Pyrolysis, 2012, 97, $109-115$.

193. J. F. Jurgens, J. D. Reid and J. D. Guthrie, Text. Res. J., 1948, 18, 42-44.

194. J. Lehrfeld, Journal of Applied Polymer Science, 1996, 61, 2099-2105.

195. A.-A. M. A. Nada and M. L. Hassan, Journal of Applied Polymer Science, 2003, 89, 2950-2956.

196. X. H. Wang, J. B. Ma, Y. N. Wang and B. L. He, Biomaterials, 2001, 22, 2247-2255.

197. S. Chongprakobkit, R. Maniratanachote and W. Tachaboonyakiat, Carbohydr. Polym., 2013, 96, 82-90.

198. J. Dencs, G. Nos, B. Dencs and G. Marton, Chemical Engineering Research and Design, 2004, 82, $215-219$.

199. L. Passauer, F. Liebner and K. Fischer, Starch-Starke, 2009, 61, 621-627.

200. N. M. Boroujeni, H. Zhou, T. J. F. Luchini and S. B. Bhaduri, Journal of Biomedical Materials Research Part B: Applied Biomaterials, 2014, 102, 260-266.

201. D. L. Williams, C. Li, T. Ha, T. Ozment-Skelton, J. H. Kalbfleisch, J. Preiszner, L. Brooks, K. Breuel and J. B. Schweitzer, Journal of Immunology, 2004, 172, 449-456.

202. H. Yuan, W. Zhang, X. Li, X. Lü, N. Li, X. Gao and J. Song, Carbohydr. Res., 2005, 340, 685-692.

203. P. L. Granja, L. Pouysegu, D. Deffieux, G. Daude, B. De Jeso, C. Labrugere, C. Baquey and M. A. Barbosa, Journal of Applied Polymer Science, 2001, 82, 3354-3365. 
204. P. L. Granja, M. A. Barbosa, L. Pouysegu, B. De Jeso, F. Rouais and C. Baquey, J. Mater. Sci., 2001, 36, 2163-2172.

205. J. C. Fricain, P. L. Granja, M. A. Barbosa, B. de Jeso, N. Barthe and C. Baquey, Biomaterials, 2002, 23, 971980.

206. P. L. Granja, B. De Jeso, R. Bareille, F. Rouais, C. Baquey and M. A. Barbosa, React. Funct. Polym., 2006, 66, 728-739.

207. K. Ishihara, R. Takayama, N. Nakabayashi, K. Fukumoto and J. Aoki, Biomaterials, 1992, 13, $235-239$.

208. P. Kujawa, G. Schmauch, T. Viitala, A. Badia and F. M. Winnik, Biomacromolecules, 2007, 8, 3169-3176.

209. A. H. Casé, I. P. D. Picola, M. E. D. Zaniquelli, J. C. Fernandes, S. R. Taboga, F. M. Winnik and M. J. Tiera, Journal of Colloid and Interface Science, 2009, 336, 125-133.

210. S. Mansouri, Y. Merhi, F. o. M. Winnik and M. Tabrizian, Biomacromolecules, 2011, 12, 585-592.

211. J. H. Sung, D. P. Park, B. J. Park, H. J. Choi and M. S. Jhon, Biomacromolecules, 2005, 6, 2182-2188.

212. A. E. Wroblewski, C. Lensink, R. Markuszewski and J. G. Verkade, Energy \& Fuels, 1988, 2, 765-774.

213. H. J. Lucas, F. W. Mitchell and C. N. Scully, Journal of the American Chemical Society, 1950, 72, 5491-5497.

214. A.-A. M. A. Nada, N. F. Kassem and M. S. H., BioResources, 2008, 3, 538-548.

215. M. V. Efanov and A. I. Galochkin, Chem Nat Compd, 2012, 48, 457-459.

216. H. Struszczyk, Fire Mater., 1982, 6, 7-9.

217. G. L. Bykov and B. G. Ershov, Russ J Appl Chem, 2010, 83, 316-319.

218. A. I. U. losilevich, Kh. U.; loannides, O. , Uzbekskii Khimicheskii Zhurnal, 1963, 7, 61-63.

219. E. V. L. Vasil'eva, A. A., Koksnes Kimija, 1988, 113-115.

220. Y. Yu, S. Fu, P. a. Song, X. Luo, Y. Jin, F. Lu, Q. Wu and J. Ye, Polym. Degrad. Stabil., 2012, 97, 541-546.

221. V. P. P. Vasil'eva, L. A., Khimiya Drevesiny, 1973, 13, 62-65.

222. R. A. Sanchez and B. P. Esposito, BioResources, 2011, 6, 2448-2459.

223. US3459588 A, 1969.

224. Z. Zheng, B. W. T. Y. S. Liu, X. Cui and H. Wang, Polymer Composites, 2014, DOI: 10.1002/pc.23069, n/an/a.

225. A. H. Abdel-kader, Der Chemica Sinica, 2012, 3(3):689-697.

226. A. M. A. Nada, M. A. Eid, A. I. Sabry and M. N. Khalifa, Journal of Applied Polymer Science, 2003, 90, 97104.

227. C. Jeon and J. H. Kim, Journal of Industrial and Engineering Chemistry, 2009, 15, 910-913.

228. H. Vothi, C. Nguyen, K. Lee and J. Kim, Polym. Degrad. Stabil., 2010, 95, 1092-1098.

229. G. Marosi, A. Toldy, G. Parlagh, Z. Nagy, K. Ludanyi, P. Anna and G. Keglevich, Heteroatom Chemistry, 2002, 13, 126-130.

230. R. Ménard, C. Negrell-Guirao, L. Ferry, R. Sonnier and G. David, Journal, 2014, 86, 1637.

231. E. E. Nifant'ev, M. S. Krymchak, T. S. Kukhareva and L. K. Vasyanina, Dokl Chem, 2011, 441, 330-333.

232. E. E. Nifant'ev, M. S. Krymchak, T. S. Kukhareva, L. K. Vasyanina and M. V. Turbina, Russian Journal of General Chemistry (Translation of Zhurnal Obshchei Khimii), 2010, 80, 423-427.

233. M. Delomenède, F. Bedos-Belval, H. Duran, C. Vindis, M. Baltas and A. Nègre-Salvayre, Journal of Medicinal Chemistry, 2008, 51, 3171-3181.

234. A. Toldy, N. Tóth, P. Anna and G. Marosi, Polym. Degrad. Stabil., 2006, 91, 585-592.

235. C. Xie, B. Zeng, H. Gao, Y. Xu, W. Luo, X. Liu and L. Dai, Polym. Eng. Sci., 2013, DOI: 10.1002/pen.23642, 1192-1200.

236. C. Xie, B. Zeng, H. Gao, Y. Xu, W. Luo, X. Liu and L. Dai, Polymer Engineering \& Science, 2013, DOI: 10.1002/pen.23642, n/a-n/a.

237. C. Voirin, S. Caillol, N. V. Sadavarte, B. V. Tawade, B. Boutevin and P. P. Wadgaonkar, Polymer Chemistry, 2014, 5, 3142-3162.

238. C. K. S. Pillai, V. S. Prasad, J. D. Sudha, S. C. Bera and A. R. R. Menon, Journal of Applied Polymer Science, 1990, 41, 2487-2501.

239. V. S. Prasad and C. K. S. Pillai, Journal of Applied Polymer Science, 2000, 77, 2631-2640.

240. WO2007077567A1, 2007.

241. R. Antony, Journal of Polymer Science Part A: Polymer Chemistry, 1993, 31, 3187-3191.

242. D. Lomonaco, F. J. N. Maia, C. S. Clemente, J. P. F. Mota, A. E. Costa and S. E. Mazzetto, Fuel, 2012, 97, 552-559.

243. A. A. S. Lopes, E. A. Carneiro, M. A. S. Rios, J. J. Hiluy Filho, J. O. B. Carioca, G. G. Barros and S. E. Mazzetto, Brazilian Journal of Chemical Engineering, 2008, 25, 119-127.

244. M. A. Rios Facanha, S. E. Mazzetto, J. Beserracarioca and G. Debarros, Fuel, 2007, 86, 2416-2421.

245. S. E. Mazzetto, L. D. M. Oliveira, D. Lomonaco and P. A. Veloso, Braz. J. Chem. Eng., 2012, 29, 519-524.

246. M. A. de Sousa Rios and S. E. Mazzetto, J Therm Anal Calorim, 2013, 111, 553-559. 
247. M. A. de Sousa Rios and S. E. Mazzetto, Fuel Processing Technology, 2012, 96, 1-8.

248. D. Lomonaco, F. Y. Cangane and S. E. Mazzetto, J Therm Anal Calorim, 2011, 104, 1177-1183.

249. M. A. de Sousa Rios, T. L. Nascimento, S. N. Santiago and S. E. Mazzetto, Energy \& Fuels, 2009, 23, 54325437.

250. F. J. N. Maia, V. G. Ribeiro, C. S. Clemente, D. Lomonaco, P. H. M. Vasconcelos and S. E. Mazzetto, J Therm Anal Calorim, 2011, 109, 1013-1018.

251. F. J. N. Maia, V. G. P. Ribeiro, D. Lomonaco, F. M. T. Luna and S. E. Mazzetto, Industrial Crops and Products, 2012, 36, 271-275.

252. A. C. H. Barreto, F. J. N. Maia, V. R. Santiago, V. G. P. Ribeiro, J. C. Denardin, G. Mele, L. Carbone, D. Lomonaco, S. E. Mazzetto and P. B. A. Fechine, Microfluidics and Nanofluidics, 2011, 12, 677-686.

253. R. K. Paul and C. K. S. Pillai, Journal of Applied Polymer Science, 2001, 80, 1354-1367.

254. A. R. R. Menon, C. K. S. Pillai and G. B. Nando, Journal of Applied Polymer Science, 1994, 51, $2157-2164$.

255. A. R. R. Menon, T. A. Sonia and J. D. Sudha, Journal of Applied Polymer Science, 2006, 102, 5123-5130.

256. F. Seniha Güner, Y. Yağcı and A. Tuncer Erciyes, Progress in Polymer Science, 2006, 31, 633-670.

257. M. Moreno, G. Lligadas, J. C. Ronda, M. Galia and V. Caldiz, Journal of Polymer Science, Part A: Polymer Chemistry, 2012, 50, 3206-3213.

258. M. Moreno, G. Lligadas, J. C. Ronda, M. Galia and V. Cadiz, Journal of Polymer Science, Part A: Polymer Chemistry, 2013, 51, 1808-1815.

259. M. Sacristan, J. C. Ronda, M. Galia and V. Cadiz, Journal of Applied Polymer Science, 2011, 122, 16491658.

260. G. Lligadas, J. C. Ronda, M. Galia and V. Cadiz, Journal of Polymer Science, Part A: Polymer Chemistry, 2006, 44, 5630-5644.

261. L. M. de Espinosa, M. A. R. Meier, J. C. Ronda, M. Galià and V. Cádiz, Journal of Polymer Science Part A: Polymer Chemistry, 2010, 48, 1649-1660.

262. J. F. Qiu, M. Q. Zhang, M. Z. Rong, S. P. Wu and J. Karger-Kocsis, Journal of Materials Chemistry A, 2013, 1, 2533-2542.

263. B. Zhong, C. Shaw, M. Rahim and J. Massingill, J. Coat. Technol., 2001, 73, 53-57.

264. E. Baştürk, T. İnan and A. Güngör, Progress in Organic Coatings, 2013, 76, 985-992.

265. X.-y. Cao and X. Zhao, Yingyong Huagong, 2004, 33, 15-18.

266. China Pat., CN103012547, 2013.

267. CN103012547A, 2013.

268. G. B. Bantchev, G. Biresaw, K. E. Vermillion and M. Appell, Spectrochimica Acta, Part A: Molecular Spectroscopy, 2013, 110, 81-91.

269. F. Millet, R. Auvergne, S. Caillol, G. David, A. Manseri and N. Pebere, Progress in Organic Coatings, 2014, 77, 285-291.

270. Z. Liu, Y. Xu, L. Cao, C. Bao, H. Sun, L. Wang, K. Dai and L. Zhu, Soft Matter, 2012, 8, 5888-5895.

271. G. Biresaw and G. B. Bantchev, Journal of the American Oil Chemists' Society, 2013, 90, 891-902.

272. T. Werpy, G. Petersen, U. S. D. o. E. O. o. t. B. Program, P. N. N. Laboratory and N. R. E. Laboratory, Top Value Added Chemicals from Biomass: Results of screening for potential candidates from sugars and synthesis gas, [U.S. Department of Energy [Office of] Energy Efficiency and Renewable Energy, 2004.

273. Y.-L. Liu, G.-H. Hsiue, Y.-S. Chiu, R.-J. Jeng and L.-H. Perng, Journal of Applied Polymer Science, 1996, 61, 613-621.

274. Y.-L. Liu, G.-H. Hsiue, Y.-S. Chiu and R.-J. Jeng, Journal of Applied Polymer Science, 1996, 61, 1789-1796.

275. G.-Q. Chen and M. K. Patel, Chemical Reviews (Washington, DC, United States), 2011, 112, 2082-2099.

276. D.-Y. Wang, Y.-P. Song, L. Lin, X.-L. Wang and Y.-Z. Wang, Polymer, 2011, 52, 233-238.

277. X.-Y. Yuan, D.-Y. Wang, L. Chen, X.-L. Wang and Y.-Z. Wang, Polym. Degrad. Stabil., 2011, 96, 1669-1675.

278. B. A. Howell, K. E. Carter and H. Dangalle, ACS Symposium Series, 2011, 1063, 133-152.

279. B. A. Howell and K. E. Carter, Polymer Preprints (American Chemical Society, Division of Polymer Chemistry), 2010, 51, 755-756.

280. B. A. Howell and K. E. Carter, J Therm Anal Calorim, 2010, 102, 493-498.

281. B. A. Howell and H. Dangale, PMSE Preprints, 2012, 105-107.

282. S. C. Fox, B. Li, D. Xu and K. J. Edgar, Biomacromolecules, 2011, 12, 1956-1972.

283. S. Wenda, S. Illner, A. Mell and U. Kragl, Green Chem., 2011, 13, 3007-3047. 